DAYANE APARECIDA NASCIMENTO BARBOSA

\title{
Potenciais evocados auditivos em doenças desmielinizantes na infância
}

\author{
Dissertação apresentada à Faculdade de \\ Medicina da Universidade de São Paulo para \\ obtenção do título de Mestre em Ciências. \\ Programa de Ciências da Reabilitação \\ Orientadora: Profa. Dra. Carla Gentile Matas
}

São Paulo

2019 
DAYANE APARECIDA NASCIMENTO BARBOSA

Potenciais evocados auditivos em doenças desmielinizantes na infância

Dissertação apresentada à Faculdade de Medicina da Universidade de São Paulo para obtenção do título de Mestre em Ciências.

Programa de Ciências da Reabilitação

Orientadora: Profa. Dra. Carla Gentile Matas

São Paulo

2019 


\section{Dados Internacionais de Catalogaçăo na Publicaçăo (CIP)}

Preparada pela Biblioteca da

Faculdade de Medicina da Universidade de São Paulo

(Creprodução autorizada pelo autor

Barbosa, Dayane Aparecida Nascimento

Potenciais evocados auditivos em doenças

desmielinizantes na infancia / Dayane Aparecida

Nascimento Barbosa. -- São Paulo, 2019.

Dissertação (mestrado)--Faculdade de Medicina da

Universidade de São Paulo.

Programa de Ciências da Reabilitação.

Orientadora: Carla Gentile Matas.

Descritores: 1.Esclerose múltipla 2.Testes auditivos 3.Eletrofisiologia 4. Substancia branca

5.Transtornos da audição 6. Neuromielite óptica

$\mathrm{USP} / \mathrm{FM} / \mathrm{DBD}-307 / 19$

Responsável: Erinalva da Conceição Batista, CRB-8 6755 


\section{Dedicatória}

Aos meus tios Edivaldo e Hilda que me assumiram como uma filha e batalharam com muito amor para que eu chegasse até aqui. Sempre acreditaram e confiaram em meus objetivos. Ensinaram-me o caminho da verdade e do respeito. Nunca poderei retribuir tanto zelo e amor.

Ao meu esposo Paulo por todo o companheirismo e paciência durante toda minha pesquisa. Gratidão por toda a ajuda e todo carinho em todos os momentos. Obrigada por cada incentivo, cada vibração com minhas conquistas e cada idéia encorajadora. Obrigada por ser esse maravilhoso esposo e tão amoroso pai para o nosso filho Raul.

Ao meu amado e tão esperado filho Raul por se tornar mais um motivo para a conclusão deste estudo. Você se tornou a razão para ter forças e continuar a luta.

Obrigada por existir e me escolher para ser sua mamãe.

Ao meu querido pai de coração Romeu que sempre incentivou meus estudos, porém não pode estar aqui para acompanhar minha trajetória acadêmica. Aquele que também contribuiu de forma significativa para o meu desenvolvimento pessoal e profissional. Serei eternamente grata! Saudades!

À minha mãe Hina que infelizmente não pode estar aqui para acompanhar meu desenvolvimento pessoal e profissional, mas sei que estaria orgulhosa. Saudades!

Ao meu pai Geraldo por estar presente em minha vida como eu sempre quis e por torcer tanto pelas minhas conquistas! 


\section{Agradecimentos}

Primeiramente a Deus por cada oportunidade e cada vitória concedida. Sei que nada disso seria possível sem a sua benção.

À minha querida orientadora Prof ${ }^{a}$ Dra Carla Gentile Matas por me aceitar como orientanda, contribuindo imensamente para o meu desenvolvimento profissional. Pela paciência e disponibilidade, por compartilhar tamanho conhecimento... Por todo o carinho durante a pesquisa, na vida profissional e também com meu filho Raul.

À minha sogra Sandra por toda a ajuda em conseguir voluntários para participar da pesquisa. Pela ajuda para transportar os voluntários e ainda cuidar do neto enquanto a coleta era realizada. Por todo o incentivo e admiração. Minha eterna gratidão!

À minha cunhada Ana Carolina por toda a ajuda na formatação deste trabalho e por se disponibilizar a ajudar também na coleta de dados.

À querida Fga. Ms. Liliane Fagundes por toda a paciência, ajuda e por compartilhar todo o conhecimento e prática na realização dos exames. Por sempre se disponibilizar e estar pronta a ajudar.

À querida Fga. Dra. Renata Leite pela paciência e por compartilhar todo o conhecimento na escrita, estruturação e elaboração da pesquisa.

À querida Fga Natália Rosa por todo o auxílio durante a realização da coleta de dados e também pelo companheirismo.

Ao Dr José Albino da Paz e a Dra Danielle Patriota de Oliveira por aceitarem participar do estudo, possibilitando livre acesso aos participantes da pesquisa. Por compartilharem todo o conhecimento em neurologia e pela prontidão em auxiliar em todos os aspectos.

À querida Prof $^{a}$ Dra Alessandra Giannella Samelli por toda a contribuição por meio do seu conhecimento em nosso estudo.

Ao ITACI/ Instituto da Criança - HCFMUSP pelos recursos disponibilizados e por me acolher como funcionária e pesquisadora da melhor maneira possível.

Em especial a todos os participantes da pesquisa e seus familiares, pela disponibilidade e paciência para se deslocarem até o local de coleta e realizarem todos os exames.

O presente trabalho foi realizado com apoio da Coordenação de Aperfeiçoamento de Pessoal de Nível Superior - Brasil (CAPES) - Código de Financiamento 001. 


\section{Normatização adotada}

Esta dissertação está de acordo com as seguintes normas, em vigor no momento desta publicação:

Referências: adaptado de International Committee of Medical Journals Editors (Vancouver). Universidade de São Paulo. Faculdade de Medicina. Divisão de Biblioteca e Documentação. Guia de apresentação de dissertações, teses e monografias. Elaborado por Anneliese Carneiro da Cunha, Maria Julia de A. L. Freddi, Maria F. Crestana, Marinalva de Souza Aragão, Suely Campos Cardoso, Valéria Vilhena. 3a ed. São Paulo: Divisão de Biblioteca e Documentação; 2011.

Abreviaturas dos títulos dos periódicos de acordo com List of Journals Indexed in Index Medicus. 


\section{SUMÁRIO}

Lista de Tabelas

Lista de Quadros

Lista de Abreviaturas

Lista de símbolos

Lista de Siglas

Resumo

Summary

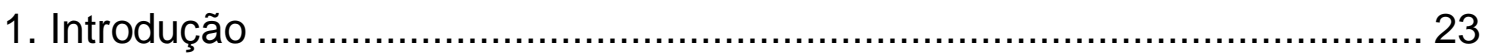

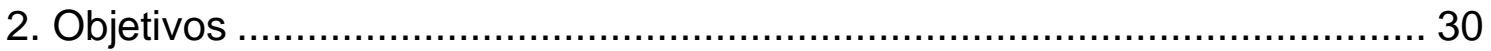

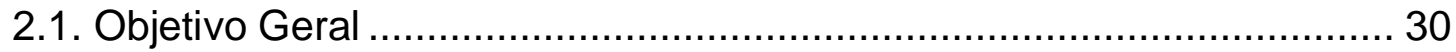

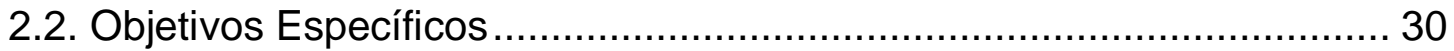

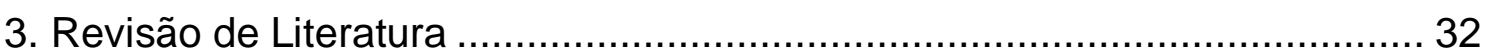

3.1. Esclerose Múltipla ................................................................. 32

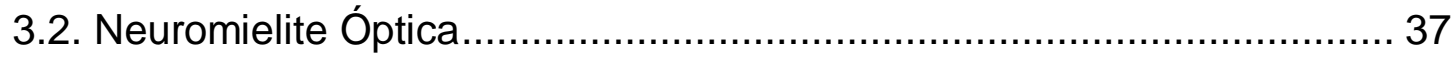

3.3. Potenciais Evocados Auditivos em indivíduos com Esclerose Múltipla E Neuromielite Óptica. ............................................................. 41

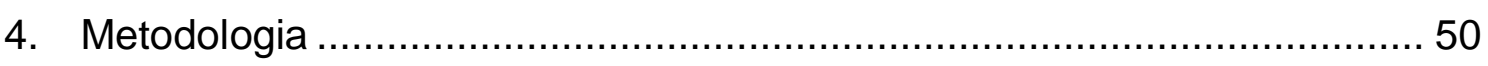

4.1. Tipo de estudo e aspectos éticos .............................................. 50

4.2. Casuística ............................................................................ 50

4.2.1.Grupo Estudo .................................................................. 51

4.2.2.Grupo Comparação............................................................... 51

4.3. Materiais e Equipamentos ............................................................... 52

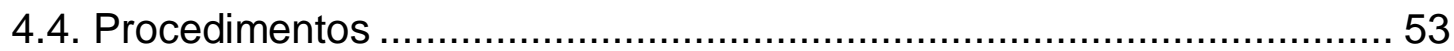

4.4.1.Informações sobre a pesquisa para os pais ou responsáveis:....... 54

4.4.2. Coleta da história clínica dos indivíduos ................................... 54

4.4.3.Avaliação Audiológica ............................................................. 55

4.4.4.Avaliação eletrofisiológica da audição....................................... 56

4.5. Critérios de classificação dos resultados ........................................ 57

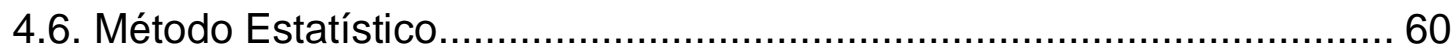

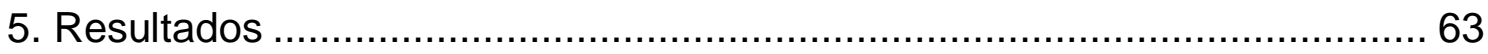




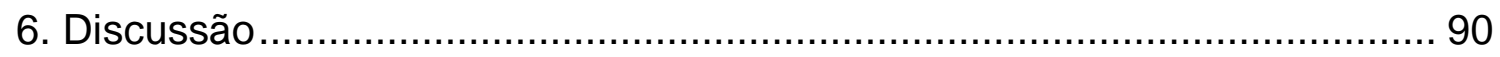

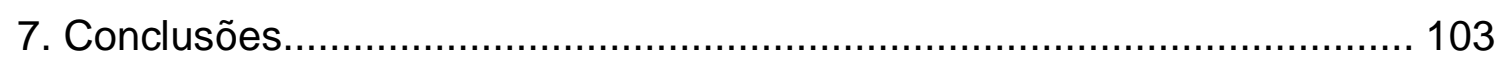

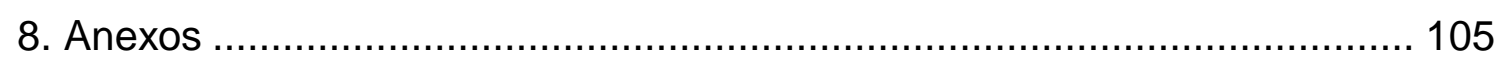

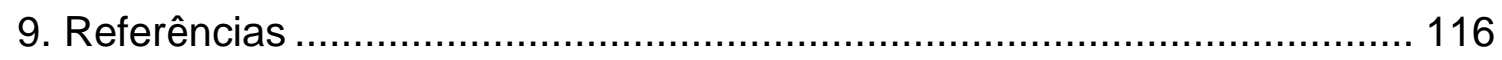




\section{LISTA DE TABELAS}

Tabela 01: Comparação das latências das ondas I, III, e V e dos interpicos I-III, III-V e I-V entre as orelhas direita e esquerda no PEATE, para o GE1 65

Tabela 02: Comparação das latências das ondas I, III, e V e dos interpicos I-III, III-V e I-V entre as orelhas direita e esquerda no PEATE, para o GC1. 66

Tabela 03: Comparação das latências das ondas I, III, e V e dos interpicos I-III, III-V e I-V entre as orelhas direita e esquerda no PEATE, para o GE2

Tabela 04: Comparação das latências das ondas I, III, e $V$ e dos interpicos I-III, III-V e I-V entre as orelhas direita e esquerda no PEATE, para o GC2

Tabela 05: Comparação das latências absolutas das ondas I, III, e V e dos interpicos I-III, III-V e I-V do PEATE, nos GE1 e GC1. 69

Tabela 06: Comparação das latências absolutas das ondas I, III, e V e dos interpicos I-III, III-V e I-V do PEATE, nos GE2 e GC2.

Tabela 07: Comparação das latências absolutas das ondas I, III, e V e dos interpicos I-III, III-V e I-V do PEATE, nos GE1 e GE2.

Tabela 08: Distribuição da ocorrência de resultados normais e alterados no PEATE, nos GE1 e GC1

Tabela 09: Distribuição dos tipos de alterações encontrados no PEATE, nos GE1 e GC1

Tabela 10: Distribuição da ocorrência de resultados normais e alterados no PEATE, nos GE2 e GC2

Tabela 11: Distribuição dos tipos de alterações encontrados no PEATE, nos GE2 e GC2. 
Tabela 12: Distribuição da ocorrência de resultados normais e alterados no PEATE, nos GE1 e GE2

Tabela 13: Distribuição dos tipos de alterações encontrados no PEATE, nos GE1 e GE2

Tabela 14: Comparação das latências de P1, N1, P2, N2 e P300 e amplitudes P1-N1, P2-N2 e P3 entre as orelhas direita e esquerda no PEALL, para o GE1 76

Tabela 15: Comparação das latências de P1, N1, P2, N2 e P300 e amplitudes P1-N1, P2-N2 e P3 entre as orelhas direita e esquerda no PEALL, para o GC1

Tabela 16: Comparação das latências de P1, N1, P2, N2 e P300 e amplitudes P1-N1, P2-N2 e P3 entre as orelhas direita e esquerda no PEALL, para o GE2.

Tabela 17: Comparação das latências de P1, N1, P2, N2 e P300 e amplitudes P1-N1, P2-N2 e P3 entre as orelhas direita e esquerda no PEALL, para o GC2

Tabela 18: Comparação das latências de P1, N1, P2, N2 e P300 e das amplitudes P1-N1, P2-N2 e P3 do PEALL, entre GE1 e GC1.

Tabela 19: Comparação das latências de P1, N1, P2, N2 e P300 e das amplitudes P1-N1, P2-N2 e P3 do PEALL, entre GE2 e GC2.

Tabela 20: Comparação das latências de P1, N1, P2, N2 e P300 e das amplitudes P1-N1, P2-N2 e P3 do PEALL, entre GE1 e GE2

Tabela 21: Distribuição da ocorrência de resultados normais e alterados no PEALL, nos GE1 e GC1

Tabela 22: Distribuição dos tipos de alterações encontrados no PEALL, nos GE1 e GC1

Tabela 23: Distribuição da ocorrência de resultados normais e alterados no PEALL, nos GE2 e GC2 85

Tabela 24: Distribuição dos tipos de alterações encontrados no PEALL, nos GE2 e GC2. 
Tabela 25: Distribuição da ocorrência de resultados normais e alterados no PEALL, nos GE1 e GE2

Tabela 26: Distribuição dos tipos de alterações encontrados no PEALL, nos GE1 e GE2

Tabela 27: Distribuição da ocorrência de resultados normais e alterados na associação PEATE e PEALL, nos GE1 e GC1

Tabela 28: Distribuição da ocorrência de resultados normais e alterados na associação PEATE e PEALL, nos GE2 e GC2 88

Tabela 29: Distribuição da ocorrência de resultados normais e alterados na associação PEATE e PEALL, nos GE1 e GE2 88 


\section{LISTA DE QUADROS}

Quadro 01: Padrão de normalidade das latências e interpicos do PEATE, para indivíduos acima de 24 meses, proposto pelo "Evoked Potential User Manual". 58

Quadro 02: Padrão de normalidade das latências dos componentes P1, N1, P2, N2 e P300 (em milissegundos -ms) do PEALL proposto por McPherson (1996), para as faixas etárias de 5 a 12 anos e acima de 12 anos. 


\section{LISTA DE ABREVIATURAS}

$\mathrm{dB} \quad$ decibel

dB NA decibel nivel de audição

dBnNA decibel nível de audição normalizado

et al. e outros

kohms Kilo ohms

ms milissegundo

N tamanho da amostra 
LISTA DE SÍMBOLOS

$\begin{array}{ll}\mu \mathrm{V} & \text { micro Volt } \\ \mathrm{Hz} & \text { Hertz } \\ \mathrm{kHz} & \text { kilo Hertz } \\ \mathrm{ms} & \text { milissegundos }\end{array}$




\section{LISTA DE SIGLAS}

CAPPesq Comissão de Ética para Análise de Projetos de Pesquisa

EMRR Esclerose Múltipla Remitente Recorrente

EMSP Esclerose Múltipla Secundária Progressiva

EMPR Esclerose Múltipla Progressiva Recidivante

EM Esclerose Múltipla

GC Grupo Comparação

GE $\quad$ Grupo Estudo

HCFMUSP Hospital das Clínicas da Faculdade de Medicina da Universidade de São Paulo

NMO Neuromielite Óptica

PEALL Potencial Evocado Auditivo de Longa Latência

PEATE Potencial Evocado Auditivo de Tronco Encefálico

SNC Sistema Nervoso Central

SNAC Sistema Nervoso Auditivo Central

PEs Potenciais Evocados 


\section{Resumo}




\section{RESUMO}

Barbosa DAN. Potenciais evocados auditivos em doenças desmielinizantes na infância [dissertação]. São Paulo: Faculdade de Medicina, Universidade de São Paulo; 2019.

INTRODUÇÃO:Em crianças, uma doença desmielinizante aguda pode evoluir como uma doença multifásica com várias recidivas, tais como a esclerose múltipla (EM) e neuromielite óptica (NMO). O Potencial Evocado Auditivo de Tronco Encefálico (PEATE) é um potencial de curta latência que permite a análise neurofisiológica da via auditiva, desde a orelha interna até o tronco encefálico alto. Os Potenciais Evocados Auditivos de Longa Latência (PEALL) refletem a atividade neuroelétrica da via auditiva nas regiões do tálamo e córtex auditivo, estruturas responsáveis pelas funções de discriminação, integração e atenção, fornecendo informações sobre o funcionamento do Sistema Nervoso Auditivo Central (SNAC). Portanto, os PEATE e PEALL contribuem para a identificação das alterações retrococleares ou outras alterações do SNAC. OBJETIVO: caracterizar os potenciais evocados auditivos de tronco encefálico e de longa latência em crianças e adolescentes com EM e NMO, e verificar os valores diagnósticos destes potenciais em cada uma das doenças desmielinizantes. MÉTODOS: A casuística foi composta por dois grupos estudo (GE1 - esclerose múltipla, GE2 - neuromielite óptica) e dois grupos comparação (GC1 e GC2), pareados por idade e gênero (faixa etária de 9 a 18 anos 11 meses). Foram realizadas avaliação audiológica básica e avaliação eletrofisiológica da audição por meio dos PEATE e PEALL. Os resultados obtidos nos indivíduos do GE1 e do GE2 foram comparados entre si e com os dados obtidos nos indivíduos com desenvolvimento típico (GC1 e GC2). RESULTADOS: Em relação ao PEATE, na análise dos dados qualitativos não houve diferença estatisticamente significante entre GE1 e GE2, porém o GE1 apresentou maior ocorrência de alterações (alteração mais frequente foi de tronco encefálico alto no GE1 e de tronco encefálico baixo no GE2); na análise dos dados quantitativos houve diferença estatisticamente significante para 0 interpico III-V, sendo que o GE1 apresentou maior valor quando comparado 
com o GE2. No que diz respeito aos PEALL, na análise dos dados qualitativos não houve diferença estatisticamente significante entre GE1 e GE2, porém observou-se maior número de alterações no GE2; na análise quantitativa, ao compararmos os grupos GE1 e GE2, verificou-se diferença estatisticamente significante para a latência de N2 (maior valor para GE2), para a amplitude P2N2 (menor valor para GE1); e para a amplitude P300 (menor valor para o GE2). Quanto aos valores de sensibilidade, especificidade e acurácia para o PEATE, observou-se $63,64 \%, 100 \%$ e $81,82 \%$ respectivamente para o GE1; 33,34\%, $100 \%$ e $66,67 \%$ respectivamente para o GE2. Para o PEALL, observou-se $36,36 \%, 90,91 \%$ e $63,64 \%$ respectivamente para o GE1; $66,67 \%, 88,89 \%$ e $77,78 \%$ respectivamente para O GE2. Conclusão: Indivíduos com EM apresentaram maior ocorrência de alterações no PEATE e indivíduos com NMO maior ocorrência de alterações no PEALL. Evidencia-se a necessidade de mais estudos nesta população, bem como mais estudos sobre a contribuição e a eficácia do PEATE e do PEALL no diagnóstico diferencial da EM e da NMO.

Descritores: Esclerose múltipla; Testes auditivos; Eletrofisiologia; Substância branca; Transtornos da audição; Neuromielite óptica. 
Summary 


\section{SUMMARY}

Barbosa DAN. Auditory evoked potentials in childhood demyelinating diseases [dissertation]. São Paulo: "Faculdade de Medicina, Universidade de São Paulo"; 2019.

INTRODUCTION: In children, an acute demyelinating disease may evolve as a multiphasic disease with multiple relapses, such as multiple sclerosis (MS) and optic neuromyelitis (ONM). Brainstem Auditory Evoked Potential (BAEP) is a short latency potential that allows the neurophysiological analysis of the auditory pathway, from the inner ear to the upper brainstem. Long Latency Auditory Evoked Potentials (LLAEP) reflect the neuroelectric activity of the auditory pathway in the thalamus and auditory cortex regions, structures responsible for discrimination, integration and attention functions, providing information about the Central Auditory Nervous System (CANS). Therefore, BAEP and LLAEP contribute to the identification of retrocochlear alterations or other changes in the CANS. OBJECTIVE: to characterize BAEP and LLAEP in children and adolescents with MS and ONM, and to verify the diagnostic values of these potentials in each of the demyelinating diseases. METHODS: The study group consisted of two study groups (GE1 - multiple sclerosis, GE2 - optic neuromyelitis) and two comparison groups (GC1 and GC2), matched by age and gender (age range 9 to 18 years 11 months). Basic audiological evaluation and electrophysiological assessment of hearing were performed through the BAEP and LLAEP. The results obtained in the individuals of GE1 and GE2 were compared among themselves and with the data obtained in the individuals with 
typical development (GC1 and GC2). RESULTS: Regarding the BAEP, in the analysis of the qualitative data there was no statistically significant difference between GE1 and GE2, but the GE1 presented a higher occurrence of alterations (more frequent alteration was of a upper brainstem in GE1 and of a low brainstem in GE2); in the analysis of the quantitative data there was a statistically significant difference for the interpeak III-V, being that the GE1 presented higher value when compared to the GE2. Regarding LLAEP, in the analysis of the qualitative data there was no statistically significant difference between GE1 and GE2, but a greater number of GE2 alterations were observed; in the quantitative analysis, when comparing the groups GE1 and GE2, there was a statistically significant difference for the N2 latency (higher value for GE2), for the P2-N2 amplitude (lower value for GE1); and for the P300 amplitude (lower value for GE2). Regarding the values of sensitivity, specificity and accuracy for BAEP, were observed $63,64 \%, 100 \%$ and $81,82 \%$ respectively for GE1; 33,34\%, 100\% and 66,67\% respectively for the GE2. For the LLAEP, $36,36 \%, 90,91 \%$ and $63,64 \%$, respectively, were observed for GE1; 66,67\%, $88,89 \%$ and $77,78 \%$ respectively for the GE2. CONCLUSION: Individuals with MS had higher occurrences of alterations in BAEP and individuals with ONM had a higher occurrence of alterations in LLAEP. There is evidence of the need for further studies in this population, as well as more studies on the contribution and efficacy of BAEP and LLAEP in the differential diagnosis of MS and ONM.

DESCRIPTORS: Multiple sclerosis; Hearing tests; Electrophysiology; White matter; Hearing disorders; Neuromyelitis optica. 
lntrodução 


\section{INTRODUÇÃO}

Doenças desmielinizantes adquiridas são doenças raras em crianças com uma incidência estimada entre 0,6-0,7 / 100.000 (Banwell et al., 2009; Absoud et al., 2014; Reinhardt et al., 2014). São caracterizadas por neuroinflamação associada com sintomas neurológicos graves e sua etiologia e mecanismos não são totalmente compreendidos (Brilot et al., 2009).

Em crianças, uma doença desmielinizante aguda pode evoluir como uma doença monofásica com recuperação e nenhum novo surto, como é o caso da encefalomielite disseminada aguda (ADEM), da mielite transversa isolada ou da neurite óptica isolada, ou evoluir como uma doença multifásica com várias recidivas, tais como a esclerose múltipla $(\mathrm{EM})$ ou neuromielite óptica (NMO) (Mader et al., 2011; Probstel et al., 2011).

Descrita como uma doença inflamatória, crônica, desmielinizante e multicêntrica, a EM é responsável pela destruição de estruturas importantes para o funcionamento do Sistema Nervoso Central (SNC), sobretudo da substância branca, por processo autoimune (Ferreira et al., 2004). É caracterizada pela reação das células de defesa do sistema imunológico (linfócitos T), que desconhecendo os lipídeos e as proteínas da bainha de mielina como próprias do indivíduo, a atacam e destroem, com ajuda dos macrófagos. A impossibilidade da passagem do impulso elétrico ocorre devido à degeneração dos axônios impedindo a comunicação entre os neurônios, estabelecendo-se as incapacidades motoras e cognitivas do indivíduo (Goldacre et al., 2004). De etiologia ainda desconhecida, a doença evolui por 
meio de surtos, nos quais os sintomas ocorrem de acordo com a localização da lesão (Papais-Alvarenga e Alvarenga, 1995; Maudonnet e Maudonnet, 2002).

Considerada o tipo mais comum de doença desmielinizante, a EM é predominantemente encontrada em adultos jovens, tendo curso lento e progressivo, com períodos de surto e remissão dos sintomas específicos. Alterações no nervo óptico, medula espinhal, tronco encefálico e substância branca periventricular são frequentemente encontradas na EM (Kurtzke et al., 1972).

Enquanto a maioria dos pacientes apresenta o início dos sintomas de EM no início da idade adulta, os mecanismos biológicos envolvidos no início da doença manifestam-se provavelmente muitos anos antes. Este fato tem limitado a capacidade de estudar precocemente a patogênese da doença (Banwell et al., 2007; Yeh et al., 2009). Alguns pacientes, porém, apresentam o início clínico antes dos 18 anos de idade (Banwell et al., 2007).

Estudos relatam que $50 \%$ dos pacientes com EM apresentam neurite óptica isolada, sendo $75 \%$ dos pacientes do sexo feminino e $34 \%$ do sexo masculino ou podem apresentar outras alterações neurológicas concomitantes (Miller e Newman, 1998; Dantas e Zangalli, 1999).

De acordo com pesquisadores, o quadro clínico clássico da neurite óptica consiste na perda visual unilateral de início agudo, desconforto periocular que piora com a movimentação dos olhos e disco óptico com aspecto normal em aproximadamente $67 \%$ dos casos (Beck, 1988; Miller e Newman, 1998; Dantas e Zangalli, 1999; Brusa et al., 2001; Fuhr et al., 2001). Dentre os exames complementares preconizados para o diagnóstico de EM 
estão a ressonância nuclear magnética, o exame do líquido cefalorraquidiano por punção lombar com pesquisa de bandas oligoclonais e o potencial evocado visual (PEV) (Halliday et al., 1972; Asselman et al., 1975; Duwaer e Spekreijse, 1978; Cuypers et al., 1995; Tumas e Sakamoto, 1995; Miller e Newman, 1998; Dantas et al., 1999; Dantas e Zangalli, 1999).

Também considerada uma doença desmielinizante, a neuromielite óptica (NMO) acomete predominantemente o nervo óptico e a medula espinhal. Porém, o conceito da doença tem sido alterado ao longo da última década (Pires et al., 2012).

No aspecto neurológico, a NMO deixou de ser considerada um subtipo de EM para ser diagnosticada como uma doença própria e de curso clínico diferenciado, assim como tratamento e prognóstico diferentes em relação à EM. No aspecto imunológico, foi crucial a descoberta do acometimento dos canais de água do sistema nervoso central (aquaporina) por um autoanticorpo, chamado anti-AQP4, para que a doença fosse vista de forma diferenciada. $O$ ataque propiciado pelos complexos autoimunes às regiões com canal de água, notadamente próximos às regiões periventriculares, nos nervos ópticos e ao redor do canal central da medula, causa necrose desta região, o que leva ao desenvolvimento de lesões mais graves e de difícil recuperação quando comparadas com as lesões da EM (Pires et al., 2012).

Atualmente, os critérios diagnósticos para a NMO incluem a presença de lesões na ressonância magnética de crânio que não preenchem os critérios de imagem para EM. As lesões intracranianas de ressonância magnética são pouco específicas, entretanto comuns, acometendo até $90 \%$ dos casos. Porém, 
cerca de 8 a $10 \%$ dos pacientes apresentam lesões cerebrais mais graves, com imagens típicas que acometem as regiões ricas em canais de APQ4, como ao redor do terceiro ventrículo, substância cinzenta periaquedutal, hipotálamo e região periventricular (Pires et al., 2012).

Um dos métodos objetivos que avaliam a audição, mais utilizado na prática clínica, é a pesquisa dos Potenciais Evocados Auditivos (PEA). Os PEA avaliam a atividade neuroelétrica na via auditiva desde o nervo auditivo até o córtex cerebral, em resposta a um estímulo acústico e são classificados de acordo com a sua latência (intervalo de tempo decorrido entre a apresentação do estímulo sonoro e o surgimento das ondas) (Junqueira e Frizzo, 2011).

O PEATE é um método objetivo e não invasivo que permite a análise neurofisiológica da via auditiva, desde a orelha interna até o tronco encefálico alto (Anias et al., 2004). É considerado um exame de grande importância na prática clínica, pois permite auxiliar no diagnóstico de alterações no limiar auditivo e do tipo de perda auditiva, na avaliação da maturação do Sistema Nervoso Auditivo Central (SNAC) em neonatos e na identificação de alterações retrococleares ou outras alterações relacionadas ao SNC, dentre elas as doenças desmielinizantes (Esteves et al., 2009).

A incidência de alterações no PEATE em indivíduos portadores de EM é bastante variável na literatura. Estima-se que cerca de $65 \%$ dos pacientes com EM apresentam uma ou mais manifestações em tronco encefálico ou cerebelo no curso da doença (Nakashima et al., 1999). 
Alguns autores acreditam que, durante as crises da doença, ocorra um processo inflamatório com lesões desmielinizantes no nervo coclear, podendo esta ser uma das causas do comprometimento auditivo (Galligo e Orue, 1999).

Os Potenciais Evocados Auditivos de Longa Latência (PEALL) refletem a atividade neuroelétrica da via auditiva nas regiões do tálamo e córtex auditivo, estruturas responsáveis pelas funções de discriminação, integração e atenção, e que fornecem informações referentes ao funcionamento do SNAC (Kraus e McGee, 1999; Soares et al., 2011). Desta forma, a realização destes potenciais pode contribuir também para a detecção de mudanças nas vias auditivas centrais em indivíduos com doenças desmielinizantes (Soares et al., 2011).

Sabe-se que desmielinização induz a desaceleração da propagação do impulso nervoso, o que reflete em um aumento das latências dos potenciais evocados. Estudos demonstram que além do comprometimento da via auditiva no tronco encefálico, sugerindo que as regiões do núcleo coclear ao lemnisco lateral podem estar comprometidas, pacientes com EM também podem apresentar anormalidades nos potenciais evocados auditivos mais tardios, sugerindo comprometimento em regiões subcorticais e corticais do SNAC (Matas et al., 2010).

A utilidade clínica das pesquisas com potenciais evocados já foi estabelecida para EM, em que estes potenciais podem detectar lesões clinicamente silenciosas nas vias visuais, auditivas, sensoriais e motoras (Leocani et al., 2006).

Por outro lado, existem poucos relatos sobre potenciais evocados auditivos em pacientes com NMO (Watanabe, 2009; Neto et al., 2013). 
Um estudo realizado por Ohnari et al. (2016) identificou os recursos característicos destes potenciais em pacientes com NMO, e os comparou com os de EM para elucidar se a análise do potencial evocado auditivo adiciona valor de diagnóstico para diferenciar entre NMO e EM.

A literatura especializada ressalta que os potenciais evocados auditivos, podem ser um ponto crítico para a diferenciação de NMO e EM, visto que pacientes com EM provavelmente apresentam PEATE anormal mesmo no estágio inicial da doença, enquanto em pacientes com NMO não evidencia-se esta característica (Ohnari et al., 2016).

Portanto, mostra-se de suma importância a combinação de diferentes métodos objetivos de avaliação eletrofisiológica da audição (PEATE e PEALL), para a investigação do envolvimento das vias auditivas centrais em indivíduos com desmielinizantes, bem como para verificar se existe um tipo de alteração predominante nos PEA de acordo com a doença desmielinizante apresentada que possa contribuir para o diagnóstico diferencial. 
Objetivos 


\section{OBJETIVOS}

\subsection{Objetivo Geral}

O presente estudo tem por objetivo caracterizar os potenciais evocados auditivos de tronco encefálico e de longa latência (PEATE e PEALL) em crianças e adolescentes com doenças desmielinizantes (Esclerose Múltipla EM e Neuromielite Óptica - NMO), e verificar os valores diagnósticos destes potenciais para cada uma das doenças.

\subsection{Objetivos específicos}

- Comparar os resultados do PEATE e do PEALL entre os indivíduos com EM e os do grupo comparação;

- Comparar os resultados do PEATE e do PEALL entre os indivíduos com NMO e os do grupo comparação;

- Comparar os resultados do PEATE e do PEALL entre os indivíduos com EM e NMO;

- Estabelecer os valores diagnósticos do PEATE e do PEALL para cada uma das doenças desmielinizantes (EM e NMO), identificando a sensibilidade, especificidade e acurácia de cada procedimento. 
Revisão de Literatura 


\section{REVISÃO DE LITERATURA}

Diversos estudos encontrados na literatura descrevem os resultados comportamentais e eletrofisiológicos da audição obtidos em adultos com doenças desmielinizantes, sendo raros os relatos em crianças e adolescentes.

Considerando o objetivo do presente estudo, uma revisão da literatura foi realizada dando-se maior enfoque às publicações dos últimos 20 anos e as pesquisas que fundamentaram teoricamente este trabalho estão descritas a seguir, divididas em três tópicos:

- Esclerose Múltipla;

- Neuromielite Óptica;

- Potenciais evocados auditivos de curta e longa latências em indivíduos com esclerose múltipla e neuromielite óptica.

\subsection{Esclerose Múltipla}

O caso mais antigo descrito na literatura da EM, ocorreu no século XIV, em uma freira alemã, cuja doença iniciou aos 16 anos de idade (Medaer, 1979).

Devido à sua cronicidade e por acometer adultos jovens, entre 20-40 anos de idade, a EM está entre as mais vulneráveis das doenças neurológicas e como uma das mais importantes. Afeta a substância branca do sistema nervoso central, podendo ocorrer múltiplas lesões espalhadas ou acometer grande região do encéfalo e medula espinhal. As lesões ocorrem por conta da destruição da bainha de mielina dos neurônios, levando, assim, a uma deficiência na condução nervosa (Cardoso, 2010).

Adams e Victor (1989) definiram a EM como uma doença que afeta o sistema nervoso, causando destruição da mielina (desmielinização), proteína fundamental na transmissão do impulso nervoso. Consideraram a EM uma enfermidade inflamatória, provavelmente auto-imune.

Oliveira e Souza (1998) descreveram que, embora as características clínicas sejam bem conhecidas, os aspectos etiológicos constituem o alvo 
principal de exaustivos estudos, ou seja, os fatores imunológicos e genéticos, a influência ambiental, são fatores que podem contribuir direta ou indiretamente para a determinação da evolução clínica.

Segundo Oliveira e Souza (1998), coube a Charcot, em 1868, a primeira correlação de achados clínicos com a topografia das lesões desmielinizantes. As primeiras propostas em relação à etiopatogenia datam do século XIX. Em 1884, Pierre Marie sugeriu a presença de um agente infeccioso no início dos sintomas. Eichhorst, em 1896, chamou a EM de "doença hereditária e transmissível".

No que se refere à epidemiologia, o Brasil é considerado um país de baixa prevalência. Segundo Poser et al., em 1994, a estimativa da cidade de São Paulo era de aproximadamente 5/100.000 habitantes. Entretanto, os estudos na América Latina apontavam para taxas de prevalência entre 4 a 12/100.000. Segundo o Datasus (2014), no Brasil, há aproximadamente 35 mil portadores e 13 mil estavam em tratamento; dados da Associação Brasileira de Esclerose Múltipla (ABEM, 2011) registraram mais de 30.000 indivíduos com EM.

Em relação à distribuição por raça, a EM é mais comum em brancos, sendo considerada rara entre os orientais, negros e índios. Entretanto, alguns trabalhos brasileiros demonstraram a presença de $30 \%$ de negros entre os doentes (Hartung, 1993).

Quanto à distribuição por sexo, estudo realizado por Oliveira e Souza (1998) verificou que a EM é mais comum nas mulheres e, levando-se em consideração a faixa etária, é mais comum nos adultos jovens, sendo rara antes da puberdade e após 60 anos.

Segundo Fazekas et al (1988), a EM afeta o sistema nervoso central, predominantemente o nervo óptico, a medula cervical, o tronco cerebral e a substância branca periventricular. Não é conhecida a razão para tal predileção; porém, pode haver relação com a distribuição vascular, o que permitiria maior concentração de citoquinas e células inflamatórias nessas regiões.

Existe perda axonal e redução dos oligodendrócitos nas lesões crônicas que, de modo geral, se apresentam com poucas células e perda 
abrupta de mielina, mais intensa no meio da placa. Em casos de longa duração, nota-se atrofia cerebral com alargamento dos ventrículos laterais. A histopatologia da EM compreende a presença de processo inflamatório e áreas confluentes de desmielinização (Kurtzke, 1980).

Nos estágios iniciais, a lesão de EM começa com uma reação imune celular mediada por células $\mathrm{T}$, determinando inflamação e desmielinização. Com a cronicidade do processo, existem reações imunes específicas que determinam lesão do complexo mielinaoligodendrócito (Medaer, 1979).

A evolução clínica da doença foi subdividida em surto-remissiva, progressiva primária, progressiva secundária e surto-progressiva (Shibasaki et al, 1981).

A forma surto-remissiva caracteriza-se por apresentar episódios agudos de comprometimento neurológico, com duração de 24 horas ou mais e com intervalo de, no mínimo, trinta dias entre cada surto (Schumacher et al., 1965).

A forma progressiva apresenta piora contínua e gradual de sinais neurológicos, presentes por seis meses ou mais. Ocasionalmente, pode ocorrer estabilização do quadro. Quando a fase progressiva ocorre após um início em surtos, denomina-se progressiva secundária. A forma surto-progressiva apresenta uma combinação de exacerbações e progressão e é a forma mais difícil de ser definida (Shibasaki et al, 1981).

Os sintomas iniciais mais comuns compreendem alterações piramidais, sensitivas e cerebelares, que são identificadas como sinais maiores, e manifestações visuais e esfincterianas, identificadas como menores (Poser, 1983).

Vários esquemas foram propostos para facilitar o diagnóstico e a classificação da doença. Os mais utilizados são os de Schumacher et al. (1965) e Poser et al. (1983). Ambos possuem como propósito a demonstração da disseminação no tempo e no espaço, característicos dessa doença.

Schumacher et al. (1965) postularam como essencial para o diagnóstico de EM clinicamente definida: a) duas lesões separadas no sistema nervoso central; b) dois ataques ou surtos com duração mínima de 24 horas, 
separados por um período de, no mínimo, um mês; c) exame neurológico alterado; d) sintomas e sinais de comprometimento da substância branca; e) intervalo de idade entre 10 e 50 anos; f) ausência de qualquer outra doença que possa justificar o quadro.

Os critérios de Poser et al. (1983) admitem quatro tipos de situações clínicas: A: Clinicamente definida: A1) dois surtos e evidência clínica de duas lesões separadas; A2) dois surtos; evidência clínica de uma lesão e paraclínica (compreendendo os achados na ressonância nuclear magnética e nos estudos eletrofisiológicos) de outra. B: Laboratorialmente definida: B1) dois surtos; evidência clínica ou paraclínica de uma lesão e presença de lgG à eletroforese de proteínas liquóricas; B2) um surto; evidência clínica de duas lesões e presença de IgG; B3) um surto; evidência clínica de uma lesão e paraclínica de outra, e presença de IgG. C: Clinicamente provável: $\mathrm{C} 1$ ) dois surtos e evidência clínica de uma lesão; C2) um surto e evidência clínica de duas lesões; C3) um surto; evidência clínica de uma lesão e paraclínica de outra. D: Laboratorialmente provável: D1) dois surtos e presença de lgG.

Devido à existência de doenças que podem determinar o mesmo padrão de lesão à RNM, tais como vasculites, sífilis, doenças desmielinizantes agudas, HTLV-1, neoplasias, Paty et al. (1988) e Fazekas et al. (1988) criaram critérios para o diagnóstico de EM do ponto de vista de imagens à ressonância nuclear magnética (RNM).

Fazekas et al. (1988) consideraram sugestivo para o diagnóstico de EM, RNM com três ou mais áreas de sinal hiperintenso em T2 e densidade de próton, acompanhadas de dois dos seguintes critérios: a) tamanho maior ou igual a $5 \mathrm{~mm}$; b) lesão infratentorial; c) lesões adjacentes aos ventrículos laterais. A avaliação do líquor permite diferenciar a EM de outras doenças neurológicas. De rotina, encontra-se um processo inflamatório linfomonocitário. O aumento da taxa de imunoglobulinas, com distribuição oligoclonal, é considerado um aspecto importante, por refletir síntese de imunoglobulinas intratecal.

A partir de 1993, obedecendo aos critérios de Witebsky-Rose (Rose e Bona, 1993), pôde-se afirmar que a EM cumpre os critérios indiretos de doença 
autoimune, quais sejam: a indução de um modelo experimental por antígenos da mielina, a transferência adotiva da doença por linfócitos $T$, a existência de modelos genéticos de doença e identificação de anticorpos, e linfócitos $T$ autorreativos nas lesões desmielinizantes e em circulação nos doentes.

Com base em um consenso de especialistas da Sociedade de Esclerose Múltipla Norte-Americana (US National Multiple Sclerosis Society NMSS) em 1996, a doença pode ser classificada em várias formas, de acordo com critérios clínicos caracterizados pela ocorrência de surtos e progressão: EM Remitente-Recorrente (EMRR), EM primária progressiva (EMPP), EM secundária progressiva (EMSP) e EM progressiva recidivante (EMPR), e ainda as designadas como benigna e maligna. As designações benigna e maligna devem ser usadas com cautela, pois não são formas clínicas da EM, e sim demonstram o grau de gravidade e a atividade da doença, que pode se alterar significativamente e de forma imprevisível (Lublin e Reingold, 1996).

Os resultados promissores com o uso do $\beta$-interferon (Poser, 1992; Lublin e Reingold 1996) e do copolímero-1 (IFNB, 1995), nas formas surtoremissão da esclerose múltipla, e mais recentemente o $\beta$-interferon também nas formas progressivas, abriram novas possibilidades no tratamento.

$\mathrm{Na}$ fase aguda, os pacientes têm sido tratados com corticóides endovenosos sob a forma de pulsoterapia (Johnson et al., 1998), o que pode aumentar o intervalo entre os surtos. Outras tentativas de tratamento com anticorpos monoclonais, sobrecarga de antígeno endovenoso, plasmaferese, imunoglobulina endovenosa não apresentaram resultados satisfatórios e conclusivos nos estudos clínicos e experimentais realizados.

A evidência de atividade da doença e progressão clínica reflete processos inflamatórios e neurodegenerativos respectivamente. Assim, podem ter impacto no prognóstico e definir as decisões terapêuticas (Sellner et al., 2010; Lublin et al., 2014). 


\subsection{Neuromielite Óptica}

Segundo Jarius e Wildermann (2013), a doença foi relatada pela primeira vez por Eugène Devic (1858-1930), neurologista francês, em 1894, no Congresso Francês de Medicina em Lyon, como uma síndrome caracterizada pela associação, simultânea ou sequencial, de mielite aguda e neurite ótica, à qual denominou "neuro-myélite optique aiguë". Ainda no mesmo ano, Fernand Gault, aluno de Devic, publicou a sua tese de doutoramento "De la neuromyélite optique aiguë", onde reviu a literatura e analisou o caso de Devic. No entanto, em 1907, Peppo Acchioté propôs a designação "maladie de Devic" em honra a Eugène Devic -, a qual acaba por prevalecer na literatura nãofrancesa.

Desde então, a comunidade científica tem debatido a relação entre a NMO e outras doenças neuroinflamatórias, nomeadamente a EM. Em 1939, Russell Brain defendeu que as diferenças clínicas e patológicas entre ambas apenas refletiam diferenças de intensidade e duração de uma só mesma doença (Jarius e Wildermann, 2013). Apesar de estudos posteriores apresentarem dados clínicos, laboratoriais e de imagem que sugeriam uma clara distinção, foi sobretudo a imunopatologia que mais contribuiu para o reconhecimento da NMO enquanto doença distinta (Matà e Lolli, 2011).

Em 2004, Lennon et al., identificaram um autoanticorpo imunoglobulina G ( $\mathrm{lgG}$ ) com elevada especificidade para a NMO, NMO-lgG, não detectado na EM - e portanto bastante útil como biomarcador serológico no seu diagnóstico diferencial -, que mais tarde se comprovou ter como alvo o canal de água aquaporina 4 (AQP4) expresso nos astrócitos, desencadeando múltiplos processos patogênicos.

Lennon et al. (2005) então, propõem que a NMO seja uma canalopatia autoimune.

O NMO-IgG veio também ampliar o espectro da NMO. Foram relatadas formas de apresentação clínica e radiológica não clássicas, incluindo eventos limitados espacialmente e lesões cerebrais, na presença de seropositividade 
para NMO-lgG, introduzindo o conceito de doenças do espectro da NMO (Wingerchuk, 2007).

Neste sentido, Jarius e Wildermann (2013) defendem que a NMO e seu espectro constituem uma síndrome, mais do que uma doença isolada, e que o termo "doença de Devic" deve ser abandonado.

Segundo Wingerchuk et al. (2007), a NMO é relativamente comum nas raças não-brancas, constituindo entre $15 \%$ a $48 \%$ do total de doenças desmielinizantes.

Em relação à raça caucasiana, segundo um estudo italiano, a NMO representa cerca de $1,5 \%$ do total de doenças desmielinizantes (Bizzoco et al., 2009). Em oposição, um estudo dinamarquês aponta para um peso significativamente superior, $26 \%$ do total de doenças desmielinizantes (Asgari et al., 2011).

Atinge, sobretudo, mulheres, principalmente na forma recorrente, enquanto que na forma monofásica não se verificam discrepâncias tão acentuadas entre os gêneros (Wingerchuk et al., 1999; O'Riordan et al., 1996).

Em 2002, Lucchinetti et al. examinaram 82 lesões de 9 casos de NMO confirmados clinicamente e encontraram características transversais a todos os casos: extensa desmielinização atingindo múltiplos segmentos da medula espinhal, associada a cavitação, necrose e extensa lesão axonal, em ambas as substâncias branca e cinzenta. Verificaram, também, perda pronunciada de oligodendrócitos. Nas lesões ativas, foram observados infiltrados inflamatórios constituídos por células polimorfonucleares (eosinófilos e neutrófilos) e mononucleares (macrófagos), assim como depósitos perivasculares de componentes de imunoglobulina e complemento em padrão coincidentes com a distribuição normal de AQP4 nos processos podais dos astrócitos. Identificouse hialinização e fibrose vascular, o que, juntamente com a extensa ativação do complemento e com a infiltração eosinofílica, apoia o papel da autoimunidade humoral na patogênese da doença.

Em suma, os principais achados histopatológicos observados nas lesões de NMO são edema, inflamação, desmielinização e necrose. A NMO é, 
por isso, classificada como uma síndrome inflamatória e desmielinizante do SNC (Hinson et al., 2012).

O NMO-IgG é um autoanticorpo imunoglobulina-G seletivo para a AQP4, o canal de água mais predominante no SNC (Lennon et al., 2005).

Em 2008, Hinson et al. verificaram infrarregulação dos canais de água AQP4 acoplada à infrarregulação do transportador 2 de aminoácido excitatório denominado EAAT2 (do inglês excitatory amino acid transporter 2). O EAAT2 é expresso seletivamente nos astrócitos e tem um papel fundamental na captura de glutamato nas sinapses excitatórias, sendo responsável por mais de $90 \%$ da sua absorção no SNC. Assim, foi sugerido que a AQP4 e o EAAT2 coexistam na forma de um complexo macromolecular e que a exposição da AQP4 ao NMO-IgG desencadeia a sua internalização - com eventual desregulação da homeostasia da água e edema - associada à internalização do EAAT2 - com consequente diminuição da captura de glutamato do espaço extracelular, desregulação da sua homeostasia e efeitos excitotóxicos potenciais que the advém. A desregulação da homeostasia de água e edema seriam consequência não só da internalização de AQP4 (Hinson et al., 2008), como também de um bloqueio direto do fluxo de água (Hinson et al., 2012).

Marignier et al. (2010) apresentaram resultados concordantes com os achados de Hinson et al. (2008) e verificaram ainda diminuição da atividade da glutamina sintase, enzima presente nos astrócitos responsável pela conversão de glutamato em glutamina. Deste modo, sugeriram que a exposição da AQP4 ao NMO-lgG resultaria em disfunção astrocítica, com consequente excitotoxicidade e dano oligodendrocítico.

Ratelade e Verkman (2012) defendem que a citotoxicidade dependente do complemento (isto é, morte celular como consequência da ativação do complemento) é o principal mecanismo envolvido na patogenia da NMO. A citoxicidade celular dependente do anticorpo (isto é, morte celular por ativação de células efetoras, incluindo as células Natural Killer) pode ter alguma contribuição. Consideram, no entanto, irrelevantes na patogenia da doença a alteração da função do alvo ou a internalização do alvo com redução da sua expressão na superfície da célula. 
Por fim, Chanson et al. (2013) verificaram reatividade contra outros autoantigénios que não a AQP4 no soro de pacientes com NMO, como por exemplo, a proteína básica de mielina, razão pela qual sugerem a existência de outros alvos imunológicos envolvidos na patogenia da doença.

O quadro clínico da NMO consiste na associação de episódios agudos e severos de mielite transversa e neurite ótica, num curso recorrente (2/3 dos casos de NMO) (Wingerchuk et al., 1999) ou monofásico (Jacob et al., 2013; O'Riordan et al., 1996).

A mielite transversa cursa com paraplegia simétrica severa, perda sensitiva abaixo da lesão e disfunção vesical ou intestinal. Pode ser também acompanhada de sinal de Lhermitte, espasmos tónicos paroxísticos ou dor radicular, principalmente na doença recorrente. As lesões surgem preferencialmente entre os segmentos cervical e torácico médio, poupando geralmente as regiões torácica inferior e sacral (Matá e Lolli, 2011; Wingerchuk et al., 1999).

A neurite ótica, unilateral (mais frequente, principalmente na forma recorrente) (Wingerchuk et al., 1999) ou bilateral, manifesta-se frequentemente por dor ocular, acompanhada de perda de visão central e, ocasionalmente, de discromatopsia (Matá e Lolli, 2011).

Embora exista uma seletividade pelos nervos óticos e medula espinhal, outros territórios podem ser igualmente afetados. Deste modo, além do quadro clínico supracitado, outros sintomas neurológicos podem preceder ou acompanhar a NMO. O relato de casos que não se enquadram integralmente na definição clássica de NMO na presença de seropositividade para NMO-IgG veio ampliar o seu espectro de apresentação clínica e radiológica e introduzir o conceito de doenças do espectro da NMO. Nestas incluem-se formas limitadas de NMO (neurite ótica recorrente, mielite transversa recorrente) e lesões que afetam o cérebro, como por exemplo, o tronco cerebral (podendo manifestar-se por soluços e náusea intratável, insuficiência respiratória aguda neurogênica) ou o hipotálamo, cujo compromisso cursa com um quadro de secreção inapropriada de hormona antidiurética (Wingerchuk et al., 2007; Matá e Lolli, 2011; Jacob et al., 2013). 
$\mathrm{Na}$ maioria dos pacientes com diagnóstico de NMO, mais da metade dos casos são positivos para o anticorpo AQP-4. Em 2006, Wingerchuk et al. propuseram os critérios diagnósticos revisados de NMO que incorporou o nível de anticorpos AQP-4. Para o diagnóstico de NMO, há necessidade de pelo menos dois dos três critérios de suporte: (1) lesão contígua da medula espinal na imagem por ressonância magnética que se estende ao longo de três segmentos vertebrais; (2) imagens de ressonância magnética do cérebro que não cumprem os critérios de diagnóstico para a EM; (3) a soropositividade para anticorpos AQP-4.

\subsection{Potenciais evocados auditivos em indivíduos com esclerose} múltipla e neuromielite óptica.

Os PEA avaliam a atividade neuroelétrica na via auditiva desde o nervo auditivo até o córtex cerebral, em resposta a um estímulo acústico (Junqueira e Frizzo, 2011).

Dentre os PEA mais utilizados na prática clínica tem-se o Potencial Evocado Auditivo de Tronco Encefálico (PEATE), potencial de curta latência que ocorre entre 0 e 10 milissegundos (ms) após a apresentação do estímulo acústico e que representa a atividade elétrica sincronizada dos elementos neurais do tronco encefálico (Junqueira e Frizzo, 2011).

O PEATE é composto por sete ondas, sendo as cinco primeiras mais fáceis de serem visualizadas, apresentando os seguintes sítios geradores segundo Möller et al. (1981): I - porção distal do nervo auditivo, II - porção proximal do nervo auditivo, III - núcleo coclear, IV - complexo olivar superior e $\mathrm{V}$ - lemnisco lateral.

A análise do PEATE é realizada por meio do estudo das latências das ondas I, III e V e dos interpicos I-III, III-V, I-V (Junqueira e Frizzo, 2011).

Dentre as aplicações clínicas do PEATE tem-se o auxílio no diagnóstico de alterações no limiar auditivo e do tipo de perda auditiva, na avaliação da maturação do Sistema Nervoso Auditivo Central (SNAC) em neonatos e na identificação de alterações retrococleares ou outras alterações 
relacionadas ao SNC, dentre elas as doenças desmielinizantes (Esteves et al., 2009).

A pesquisa do PEATE em indivíduos com doenças desmielinizantes é útil para averiguar o envolvimento do SNC, sendo que a identificação de alterações no PEATE sugere a presença de lesão nesta região, muitas vezes não suspeitada clinicamente (Chiappa, 1997).

As anormalidades encontradas no PEATE em pacientes com EM incluem prolongamento das latências das ondas e dos intervalos interpicos, diminuição da amplitude da onda $\mathrm{V}$, diminuição da razão das medidas da amplitude das ondas V/I, e desaparecimento da onda V (Nuwer, 1997). Segundo Hood (1998), os tipos de alterações mais comumente encontrados em casos de EM são o prolongamento dos intervalos interpicos, ausência de ondas ou pouca reprodutibilidade das mesmas.

Os Potenciais Evocados Auditivos de Longa Latência (PEALL) têm sido utilizados na clínica audiológica pelo fato de avaliarem a atividade elétrica no sistema nervoso auditivo central. Apresentam como componentes P1, N1, P2, N2 e P300 e podem ser observados entre 80 e 700 milissegundos (ms) após a apresentação de um estímulo acústico. Subdividem-se em potenciais exógenos (P1, N1, P2, N2), fortemente influenciados pelas características físicas do estímulo (intensidade e freqüência, entre outras), e potenciais endógenos (P300), influenciados predominantemente por eventos internos relacionados às habilidades cognitivas (McPherson, 1996).

Alguns autores (Musiek e Lee, 2001) relatam que as ondas N1 e P2 podem ser utilizadas para examinar o processamento cortical auditivo, como a habilidade para discriminar sons com base em suas propriedades acústicas ou fonéticas, podendo ser úteis na avaliação da integridade auditiva central.

O componente P300 do PEALL é considerado um potencial cognitivo, endógeno, pois reflete o uso funcional que o indivíduo faz do estímulo, não dependendo diretamente de suas características físicas. Para que o mesmo seja gerado é necessário que ocorra a discriminação de um estímulo auditivo raro, dentre outro frequente de mesma modalidade e características físicas diferentes (Duarte et al., 2004). 
A análise dos PEALL é realizada por meio do estudo das latências dos componentes positivos e negativos P1, N1, P2, N2 e P3 (em milissegundos ms), e das amplitudes P1 - N1, P2 - N2 e N2 - P3 (em microvolts - $\mu \mathrm{v}$ ). Segundo McPherson (1996), para crianças de cinco a 12 anos espera-se valores de latência dos componentes aproximadamente entre: P1 - 54 a $75 \mathrm{~ms}$, N1 - 83 a 135ms, P2 - 137 a 194ms, N2 - 200 a 280ms e P300 - 241 a 396 ms. Por sua vez, para indivíduos acima de 12 anos de idade até a fase adulta espera-se os seguintes valores de latência: P1 - 54 a 73ms, N1 - 83 a 135ms, P2 - 137 a 194ms, N2 - 188 a 231 ms e P300 - 225 a 365ms.

Os sítios geradores dos PEALL não foram completamente estabelecidos, sendo que o componente P1 e N1 parecem ser originados na região do córtex auditivo primário e córtex auditivo de associação, o $\mathrm{P} 2$ parece apresentar-se na região do lobo temporal e do sistema límbico, o N2 no córtex auditivo supratemporal e o P300 tem sua possível geração na região do hipocampo, córtex auditivo, córtex auditivo centro-parietal e córtex auditivo frontal (McPherson, 1996).

É aceito que uma proporção significativa dos pacientes com esclerose múltipla (EM) apresentem distúrbios de função cognitiva (Gil et al., 1993).

Como a EM é clinicamente heterogênea, torna-se difícil correlacionar o déficit cognitivo com a evolução da doença; além disso, poucos grupos de pacientes foram estudados e os testes psicométricos não são padronizados (Peyser et al. 1980; Herndon, 1990).

$\mathrm{Na}$ literatura científica compilada encontramos vários estudos que abordam os PEA na EM, principalmente em adultos, e raros estudos que abordam estes potenciais na NMO, estando os mesmos descritos a seguir.

Robinson e Rudge (1975), verificaram anormalidade nos resultados do PEATE em 22 dos 30 indivíduos adultos com diagnóstico de EM que participaram do estudo. Destes, 10 apresentaram aumento da latência da onda V e 16 apresentaram diminuição da amplitude da onda V.

Rudge e Robinson, em 1977, realizaram um estudo dos potenciais evocados auditivos de tronco encefálico em 88 pacientes com EM (36 do sexo masculino e 52 do sexo feminino), com idade média de 39 anos, e encontrou 
que $79 \%$ deles apresentou anormalidade no exame (aumento da onda V), sugerindo então lesões em tronco encefálico. Ao analisarem os PEALL, encontram alteração (atraso na latência do componente N1) em apenas 3 pacientes $(3,4 \%$ dos casos).

Jerger (1986) realizou um estudo com 62 pacientes adultos com diagnóstico de EM, no qual verificou que $52 \%$ dos sujeitos apresentou alteração no PEATE.

Musiek et al. (1989) estudaram os resultados da avaliação eletrofisiológica da audição por meio do PEATE em 33 indivíduos com diagnóstico de EM. Mais de $40 \%$ dos indivíduos com audição periférica normal apresentaram queixas subjetivas de dificuldades auditivas. Verificaram que 0 PEATE foi o teste mais sensível na detecção da disfunção auditiva central.

Rao et al. (1991) evidenciaram que as alterações cognitivas podem acometer pacientes com EM, por meio de estudo que aplicou uma bateria de testes neuropsicológicos em 100 pacientes adultos com EM. Dos 31 testes cognitivos aplicados, 48 pacientes com EM foram prejudicados em quatro ou mais testes, gerando uma taxa de $43 \%$ de alteração. Os pacientes com EM foram mais freqüentemente prejudicados em medidas de memória recente, atenção sustentada, fluência verbal, raciocínio conceitual e percepção visoespacial, e menos freqüentemente prejudicados em medidas de linguagem e memória imediata e remota. O comprometimento cognitivo não se associou significativamente à duração da doença, à depressão, ao curso da doença ou ao uso de medicamentos, mas foi significativamente (embora fracamente) correlacionado com a incapacidade física.

Gil et al. (1993) estudaram101 pacientes com EM (29 do sexo masculino e 72 do sexo feminino), na faixa etária entre 18 e 83 anos de idade, por meio de testes psicométricos e avaliação eletrofisiológica por meio do PEALL, e também classificaram os pacientes como deprimidos e não deprimidos. Observaram que o aumento da latência do componente P300 apresentou maior ocorrência em pacientes que apresentaram maior incapacidade, estando este componente correlacionado à duração da doença. 
Evidenciaram, também, que as latências dos componentes N2 e P300 apresentaram-se aumentadas em indivíduos deprimidos.

Celebisoy et al. (1996) realizaram estudo em 30 pacientes adultos com diagnóstico de EM ( 7 do sexo masculino e 23 do sexo feminino), na faixa etária de 19 a 51 anos, no qual avaliaram a audição por meio do PEATE e do PEAML. Encontraram que $60 \%$ dos pacientes apresentaram anormalidades no PEATE, $73 \%$ apresentaram anormalidades no PEAML e 50\% apresentaram anormalidade nos dois potenciais evocados auditivos aplicados. No PEATE, dos 30 pacientes, 3 apresentaram ausência da onda $V$ bilateralmente e 5 unilateralmente; 4 apresentaram aumento do interpico I-V bilateralmente; 4 apresentaram aumento do interpico I-V com ausência da onda V contralateral; 2 apresentaram aumento do interpico I-III unilateralmente. Portanto, concluíram que a combinação do PEATE e do PEAML pode contribuir melhorar a sensibilidade ao examinar todo o sistema auditivo.

Estudo realizado por Japaridze et al., em 2002, realizou a avaliação eletrofisiológica da audição por meio do PEATE e do PEALL em 40 pacientes com EM (31 do sexo feminino e 9 do sexo masculino), na faixa etária entre 18 e 57 anos de idade. Verificaram que $30 \%$ dos indivíduos com EM apresentaram anormalidades nos PEALL e $65 \%$ apresentaram anormalidade no PEATE. A sensibilidade combinada do PEATE e do PEALL foi de $75 \%$. Referente às alterações, encontraram ausência da onda III em 1 caso; ausência da onda V em 2 casos e ausência das ondas III e $V$ em 3 pacientes.

Kurokawa et al. (2003) realizaram o estudo dos potenciais evocados somatossensitivos, visuais, motores e auditivos - PEATE) em 73 japoneses. Além das alterações encontradas nos demais PEs estudados, encontraram anormalidades no PEATE em $34,3 \%$ dos casos.

Santos et al. (2003), com objetivo avaliar a incidência de alterações auditivas e no PEATE em indivíduos portadores de EM, avaliaram 20 indivíduos do sexo feminino (com idade entre 20 e 60 anos) e 9 do masculino (com idade de 26 a 50 anos), sem sinais clínicos ou de alterações de ressonância nuclear magnética de acometimento do tronco encefálico. Foram realizados testes audiométricos e a pesquisa dos PEATE. Dos PEATE 
realizados encontrou-se $60 \%$ de alterações no sexo feminino e $56 \%$ no masculino, totalizando $58,62 \%$. Dentre as alterações, encontraram aumento do intervalo interpico I-V, ausência da onda $\mathrm{V}$ e presença somente da onda I. Concluíram que estes achados enfatizam a relevância da avaliação por meio do PEATE em casos de suspeita clínica de doenças desmielinizantes e naqueles com diagnóstico definido de EM.

Schochat et al. (2006), realizou o estudo de caso de um homem de 27 anos de idade, o qual recebeu o diagnóstico de EM aos 16 anos e em seu último surto havia apresentado também queixa auditiva (dificuldade em ambientes ruidosos e intolerância a sons intensos). O indivíduo compareceu ao local da pesquisa para avaliação audiológica uma semana após o início dos sintomas. Após a primeira avaliação o neurologista prescreveu terapia com corticosteróides e, após sete semanas, o paciente realizou nova avaliação envolvendo os mesmos procedimentos (audiometria tonal, audiometria vocal, testes comportamentais do processamento auditivo central, PEATE, PEAML e P300). Após a corticoterapia, os limiares tonais, reflexos acústicos e o desempenho de fala no ruído na orelha direita melhoraram. Observou-se melhora das latências das ondas do PEATE num geral para ambas as orelhas após o tratamento. Houve aumento das amplitudes de Pa para todos os locais de eletrodos após o tratamento. Observou-se que não houve diferença significativa entre os valores pré e pós-tratamento para a latência do P300 em ambas as orelhas. Concluíram que os testes auditivos centrais (comportamentais e eletrofisiológicos) foram capazes de identificar o local exato do comprometimento (tronco cerebral), que estava de acordo com a queixa do paciente. Ressaltaram que o PEATE é definitivamente apropriado para confirmar lesões do tronco encefálico.

Lima et al. (2009) realizaram um estudo com o objetivo de avaliar a incidência de alterações auditivas e no PEATE em indivíduos com EM. Sua casuística foi composta por 16 pacientes do sexo feminino (33 a 53 anos de idade) e 9 do sexo masculino (24 a 56 anos de idade). Foram realizados testes audiométricos e pesquisa dos PEATE. Dos PEATE avaliados, encontraram $31,25 \%$ de alterações no sexo feminino e $44,44 \%$ no masculino, totalizando 
$36 \%$. Encontram aumento do intervalo interpico I-V em $6,25 \%$ do sexo feminino e em $11,11 \%$ do masculino; degradação da forma das ondas, com morfologia pobre em 5,55\% dos pacientes do sexo masculino; e a presença somente da onda I, que representa maior anormalidade nos traçados, ocorreu em $18,75 \%$ do sexo feminino e em $22,22 \%$ do masculino Os autores enfatizaram a importância da pesquisa dos PEATE em casos de suspeita clínica de doenças desmielinizantes.

Matas et al. (2010) realizaram um estudo com objetivo de caracterizar os resultados dos potenciais evocados auditivos de curta, média e longa latência em adultos com EM do tipo remitente-recorrente. Foram avaliados 25 indivíduos (19 do sexo feminino e 6 do sexo masculino), submetidos às avaliações audiológica e eletrofisiológica da audição, pareados com 25 indivíduos do grupo controle. As idades variaram entre 25 e 55 anos. Como resultado observaram que os indivíduos com EM apresentaram maior ocorrência de resultados anormais quando comparado ao grupo controle, e o tipo de alteração de maior ocorrência foi de tronco encefálico baixo (41\%), sendo observada alteração do tipo tronco encefálico alto e ambos os tipos em $29,5 \%$ dos indivíduos. Chegaram à conclusão que indivíduos com EM apresentam alterações nos potenciais evocados auditivos, indicando comprometimento de diferentes regiões do sistema nervoso auditivo central.

Takanashi et al. (2014) estudaram o caso de uma mulher de 40 anos de idade com diagnóstico de NMO com queixas visuais e auditivas. Foi realizada uma avaliação audiológica por meio da audiometria tonal e vocal e avaliação eletrofisiológica por meio do PEATE antes e após tratamento medicamentoso. Antes do tratamento, a paciente apresentou emissões otoacústicas presentes bilateralmente, ausência dos reflexos acústicos ipsi e contralaterais e diminuição da amplitude das ondas no PEATE, com pior resultado em orelha direita. Após o tratamento medicamentoso apresentou melhora significativa na função visual e ligeira melhora dos limiares auditivos e da morfologia da onda $V$ do PEATE na orelha direita. Neste estudo concluíram que a NMO pode estar associada à perda auditiva do tipo retrococlear, e a mesma pode ser melhorada pelo tratamento com esteroides. 
Ohnari et al. (2016) realizaram um estudo com o objetivo de caracterizar os potenciais evocados motor, somatossensitivo, visual e auditivo (por meio do PEATE) em indivíduos com NMO e comparar aos resultados obtidos nos indivíduos com EM, analisando se os mesmos adicionam valores no diagnóstico diferencial entre as duas patologias. Compuseram a casuística 44 pacientes com diagnóstico de EM e 27 com diagnóstico de NMO. Nos achados do PEATE, encontraram anormalidade em $20,5 \%$ das orelhas nos indivíduos com EM (aumento do interpico I-III em 3 pacientes e aumento do interpico III-V em 7 pacientes) e não encontraram anormalidade em nenhum dos indivíduos com NMO. Concluíram, então, a necessidade de mais estudos a respeito dos potenciais evocados nas duas patologias, visando a sua real contribuição no diagnóstico diferencial. 
Metodologia 


\section{METODOLOGIA}

\subsection{Tipo de estudo e aspectos éticos}

Estudo prospectivo, realizado por meio da avaliação audiológica e eletrofisiológica da audição de indivíduos com diagnóstico de doença desmielinizante. A pesquisa foi desenvolvida no Departamento de Fisioterapia, Fonoaudiologia e Terapia Ocupacional da Universidade de São Paulo em conjunto com o Ambulatório de Neuroimunologia da Divisão de Neuropediatria do Instituto da Criança (HCFMUSP), sob responsabilidade do Dr. José Albino da Paz.

O estudo foi aprovado pelo Comitê de Ética para Análise dos Projetos de Pesquisa (CAPPesq) do HCFMUSP, sob o processo de número 1.784.316 (Anexo A), e os procedimentos foram realizados após assinatura de Termo de Consentimento Livre e Esclarecido (Anexo B) pelos pais/responsáveis dos pacientes e Termo de Assentimento (Anexo C) pelos pacientes menores de 18 anos de idade.

\subsection{Casuística}

A casuística foi composta por 40 indivíduos, de ambos os gêneros, na faixa etária entre 9 e 18 anos e 11 meses de idade, distribuídos em quatro grupos, a saber: Grupo Estudo 1 (GE1), composto por 11 indivíduos com diagnóstico de Esclerose Múltipla; Grupo Estudo 2 (GE2) composto por 9 indivíduos com diagnóstico de Neuromielite Óptica; Grupo Comparação 1 (GC1), composto por 11 indivíduos saudáveis pareados ao GE1 por idade e gênero; Grupo Comparação 2 (GC2), composto por 9 indivíduos saudáveis pareados ao GE2 por idade e gênero. 


\subsubsection{Grupo Estudo}

Os indivíduos que compuseram o grupo estudo (GE) foram selecionados pelo médico neurologista responsável pelo ambulatório de Neuroimunologia. Este grupo foi dividido em Grupo Estudo 1 (GE1), composto por 11 indivíduos com diagnóstico de Esclerose Múltipla; e Grupo Estudo 2 (GE2) composto por 9 indivíduos com diagnóstico de Neuromielite Óptica.

A composição da amostra do Grupo Estudo (GE) foi realizada adotando os seguintes critérios de inclusão:

Grupo Estudo 1 (GE1): indivíduos com diagnóstico de Esclerose Múltipla;

Grupo Estudo 2 (GE2): indivíduos com diagnóstico de Neuromielite Óptica.

Para os dois grupos supracitados, foram considerados como critérios de inclusão:

- Ter entre 9 a 18 anos e 11 meses de idade;

- Ausência de obstrução do meato acústico externo (MAE) em ambas as orelhas;

- Presença de timpanograma do tipo A;

- Presença de avaliação audiológica completa (audiometria tonal liminar, logoaudiometria e medidas de imitância acústica) dentro da normalidade.

Considerando tais critérios foram contatadas, no total, 23 famílias para compor o GE; destas, três não aceitaram participar. Dentre as 20 que aceitaram, todas compareceram em todas as avaliações e permitiram a realização de todos os procedimentos.

\subsubsection{Grupo Comparação}

Para cada grupo estudo (GE1 e GE2) foram selecionados indivíduos com desenvolvimento típico e sem queixas de alterações neurológicas e psiquiátricas, de forma a parear as características referentes à idade e gênero, compondo assim dois grupos: Grupo Comparação 1 (GC1), composto por 11 
indivíduos saudáveis pareados ao GE1 por idade e gênero; Grupo Comparação 2 (GC2), composto por 9 indivíduos saudáveis pareados ao GE2 por idade e gênero. Os indivíduos que participaram do GC1 e do GC2 foram voluntários, selecionados por amostra de conveniência, residentes nas cidades próximas ao local da coleta.

A composição da amostra do Grupo Comparação (GC) foi realizada adotando os seguintes critérios de inclusão:

- $\quad$ Ter entre 9 a 18 anos e 11 meses de idade;

- Ter apresentado desenvolvimento típico;

- $\quad$ Ausência de queixas neurológicas e psiquiátricas;

- Ausência de obstrução do meato acústico externo (MAE) em ambas as orelhas;

- Presença de timpanograma do tipo A;

- Presença de avaliação audiológica completa (audiometria tonal liminar, logoaudiometria e medidas de imitância acústica) dentro da normalidade.

\subsection{Materiais e equipamentos}

Os materiais do presente estudo constam da anamnese e resultados das avaliações audiológicas e eletrofisiológicas da audição, obtidos em indivíduos com diagnóstico de doenças desmielinizantes (GE1 e GE2) e em indivíduos com desenvolvimento típico e sem queixas neurológicas e/ou psiquiátricas (GC1 e GC2).

Os materiais e equipamentos utilizados para a realização das avaliações serão descritos a seguir:

- Protocolo de coleta da história clínica do paciente. Protocolo elaborado e utilizado pelo Ambulatório de Avaliação Eletrofisiológica da Audição do Instituto da Criança do Hospital das Clínicas da Faculdade de Medicina da USP (Anexo D);

- $\quad$ Otoscópio da marca Heine, para a realização da inspeção visual do meato acústico externo; 
- Analisadores de orelha média marca Interacoustics, modelo AT235 e modelo Zodiac 901, para realização das medidas de imitância acústica;

- Audiômetros modelos GSI 61 e AC33, marca Grason-Stadler e fones de ouvido supra-aurais modelo TDH-39 atendendo aos padrões ANSI S3.6-1989 e IEC-1988. Cabina acústica atendendo à norma ANSI S3.1-1991 de quantidade de ruído ambiental, para a realização da avaliação audiológica;

- Equipamento modelo Smart EP da marca Intelligent Hearing System para a realização da avaliação eletrofisiológica da audição por meio dos potenciais evocados auditivos. Este equipamento consiste em um computador portátil, um gerador de estímulos acústicos, um "mediador" (caixa na qual são conectados eletrodos), cinco eletrodos de superfície (cobre), e fones de ouvido de inserção modelo ER 3-A;

- Pastas abrasiva e eletrolítica;

- Esparadrapo do tipo microporoso.

\subsection{Procedimentos}

Inicialmente foi realizada uma parceria com a Divisão de Neuropediatria do Instituto da Criança do HCFMUSP que disponibilizou acesso aos prontuários médicos dos pacientes e seleção de acordo com os critérios de inclusão na amostra.

Os indivíduos que se enquadraram dentro dos critérios de inclusão foram convidados a participar da pesquisa por meio de contato pessoal e telefônico. Somente os indivíduos que apresentaram autorização por escrito, dos pais ou responsáveis, foram encaminhados para avaliação da audição.

Todos os indivíduos foram submetidos inicialmente a uma avaliação audiológica básica por meio de audiometria tonal liminar, logoaudiometria e medidas de imitância acústica, e a uma avaliação eletrofisiológica da audição por meio dos potenciais evocados auditivos (potencial evocado auditivo de tronco encefálico - PEATE e potenciais evocados auditivos de longa latência PEALL). 
Serão descritos, a seguir, os procedimentos na ordem em que foram executados:

\subsubsection{Informações sobre a pesquisa para os pais ou} responsáveis:

Os esclarecimentos sobre a pesquisa para os pais ou responsáveis dos indivíduos foram realizados no Ambulatório de Neuroimunologia do Instituto da Criança do HCFMUSP, anteriormente à realização das avaliações. Estes foram realizados verbalmente e por meio do Termo de Consentimento Livre e Esclarecido, aprovado pela Comissão de Ética desta Instituição, que foi assinado pelo responsável após a explicação e a leitura. Foi explicado aos pais e responsáveis dos participantes da pesquisa que as avaliações realizadas não apresentariam risco à saúde do indivíduo, e que os resultados desta avaliação seriam utilizados para pesquisa de mestrado.

\subsubsection{Coleta da história clínica dos indivíduos}

Inicialmente foi realizada a coleta da história clínica dos indivíduos com os pais ou responsáveis, utilizando-se do protocolo do Ambulatório de Avaliação Eletrofisiológica da Audição do Instituto da Criança do HCFMUSP para a obtenção de dados pessoais do indivíduo, assim como informações referentes à presença de fatores pré, peri e pós-natais considerados como de risco para deficiência auditiva; ocorrência de episódios de otite e/ou supuração; queixas dos pais sobre dificuldades auditivas, de fala, linguagem e/ou decorrentes da doença desmielinizante; desenvolvimento neuropsicomotor; presença de alterações neurológicas, psiquiátricas, comportamentais e uso de medicamentos. 


\subsubsection{Avaliação Audiológica}

Após a coleta da história clínica do indivíduo, foi realizada a inspeção visual do meato acústico externo, a fim de se verificar possíveis obstruções por presença de cerume ou corpo estranho que pudessem impedir a realização dos exames de audição.

Para a realização das avaliações foram fornecidas orientações aos indivíduos sobre as mesmas, sendo estas enfatizadas e repetidas durante as avaliações quando mostrou-se necessário. Descrição a seguir:

- Medidas de Imitância Acústica (timpanometria e pesquisa dos reflexos acústicos ipsi e contralaterais, nas frequências de 500, 1000, 2000, $4000 \mathrm{~Hz}$ e "Broadband" - BB). Cada indivíduo foi orientado a permanecer quieto;

- Audiometria Tonal Liminar, conforme os métodos descritos por Mangabeira - Albernaz et al. (1981), realizada nas frequências de 250, 500, $1000,2000,3000,4000,6000$ e $8000 \mathrm{~Hz}$. O indivíduo foi orientado a levantar a mão ou apertar o "botão" sempre que ouvia o estímulo acústico. O exame foi realizado com fones de ouvido supra-aurais modelo TDH-39 em cabina acústica;

- Logoaudiometria, sendo pesquisados o Limiar de Reconhecimento de Fala (LRF) e o Índice Percentual de Reconhecimento de Fala (IPRF) com as listas de vocábulos propostas por Santos e Russo (1991). $\mathrm{O}$ indivíduo foi orientado a repetir as palavras emitidas pelo avaliador da maneira que compreendia. Tais exames foram realizados com fones de ouvido supra-aurais em cabina acústica.

Os critérios adotados como normais na Audiometria Tonal Liminar, Logoaudiometria e Medidas de Imitância Acústica, para composição da casuística, foram: curva timpanométrica tipo A (Jerger, 1970); reflexo acústico desencadeado entre $70 \mathrm{~dB}$ e $90 \mathrm{~dB}$ acima do limiar de audibilidade do indivíduo (Linares, 2011); LRF igual ou até $10 \mathrm{~dB}$ acima da média dos limiares de audibilidade das frequências de 500, 1000 e $2000 \mathrm{~Hz}$ (média tritonal) da audiometria tonal (Santos e Russo, 1991); IPRF entre $88 \%$ e $100 \%$ na intensidade de $30 \mathrm{~dB}$ acima da média tritonal (Menegotto, 2013); limiar de 
audibilidade igual ou menor a $15 \mathrm{~dB}$ para todas as frequências testadas (Northern e Downs, 1984).

\subsubsection{Avaliação eletrofisiológica da audição}

Devido aos critérios de inclusão adotados, somente os indivíduos que apresentaram avaliação audiológica dentro da normalidade foram submetidos à avaliação eletrofisiológica da audição.

Os potenciais evocados auditivos de curta e longa latências foram obtidos com o indivíduo sentado em uma poltrona reclinável, dentro de uma sala tratada acústica e eletricamente. A superfície da pele (fronte, mastóides e couro cabeludo) foi limpa com pasta abrasiva, sendo em seguida fixados eletrodos por meio de pasta eletrolítica e esparadrapo microporoso, a fim de favorecer a condutividade elétrica.

Os eletrodos foram posicionados no vértex $(\mathrm{Cz})$, fronte $(\mathrm{Fpz}$ - eletrodo terra) e nas mastóides direita e esquerda (M2 e M1) de acordo com a norma International Electrode System IES 10-20 (Jasper, 1958). Os valores de impedância dos eletrodos foram verificados antes do início de cada exame, devendo encontrar-se abaixo de 5 kOhms. Os estímulos acústicos foram apresentados por meio de fones de inserção modelo ER 3-A.

A avaliação eletrofisiológica foi composta pelos seguintes exames:

Primeiramente foi realizado o Potencial Evocado Auditivo de Tronco Encefálico (PEATE) com o estímulo clique, apresentado a uma velocidade de apresentação de 19.1 estímulos por segundo, sendo promediados 2048 estímulos a 80 dBnNA (Jasper, 1958). A janela de gravação foi de 12 ms. Foram utilizados filtros passa-alto de $100 \mathrm{~Hz}$ e passa-baixo de $3000 \mathrm{~Hz}$ e ganho de $100.0 \mathrm{~K}$ nos dois canais. Uma segunda estimulação foi realizada a fim de verificar a reprodutibilidade do traçado e, consequentemente, a presença de resposta. Foram identificadas e analisadas as latências das ondas I, III e V e os interpicos I-III, III-V e I-V.

A seguir foram realizados os Potenciais Evocados Auditivos de Longa Latência (PEALL), sendo que para a captação dos mesmos foi utilizado o estímulo acústico tone burst na intensidade de $75 \mathrm{dBnNA}$, na frequência de 
$1000 \mathrm{~Hz}$ (estímulo frequente) e $2000 \mathrm{~Hz}$ (estímulo raro) (Jasper, 1958). Os estímulos acústicos tone burst foram apresentados em uma velocidade de apresentação de 1.1 estímulos por segundo, sendo empregado um total de 300 estímulos. A janela de análise foi de $500 \mathrm{~ms}$. Foram utilizados filtros passa-alto de $1 \mathrm{~Hz}$ e passa-baixo de $30.0 \mathrm{~Hz}$ e ganho de $150.0 \mathrm{~K}$ nos dois canais. Dos 300 estímulos que foram apresentados, 15\% corresponderam ao estímulo raro (Durrant e Ferraro, 2001; Musiek e Lee, 2001).

A criança foi orientada a prestar atenção no estímulo raro (tone burst $2000 \mathrm{~Hz}$ ) que apareceu, aleatoriamente, dentro de uma série de estímulos frequentes (tone burst $1000 \mathrm{~Hz}$ ), sendo solicitado que contasse, em voz alta, o número de vezes que o evento raro ocorria (Durrant e Ferraro, 2001; Musiek e Lee, 2001).

O traçado correspondente ao estímulo raro foi subtraído do traçado correspondente ao estímulo frequente, sendo no traçado final a onda P300 identificada e analisada em relação a sua latência e amplitude.

Os componentes P1, N1, P2, N2 e P300 foram identificados e analisados quanto à latência e amplitude no traçado correspondente ao estímulo frequente.

Os procedimentos de avaliação audiológica e eletrofisiológica foram realizados no mesmo dia, com duração de 2 horas, para que intercorrências como acúmulo de cerume, otites, disfunção tubária, perfuração de membrana timpânica não interferissem nos resultados. Todos os indivíduos apresentaram desempenho satisfatório durante a realização dos exames, sem queixas de dificuldade. Os resultados obtidos nos indivíduos com esclerose múltipla (GE1) e com neuromielite óptica (GE2) foram comparados com os dados obtidos nos indivíduos do grupo comparação (GC1 e GC2).

\subsection{Critérios de classificação dos resultados}

Os resultados das avaliações eletrofisiológicas da audição foram classificados como normais e alterados, para cada indivíduo. O indivíduo foi considerado alterado quando pelo menos uma das orelhas, ou um dos lados, 
apresentasse alteração. Posteriormente, foram descritos os tipos de alterações encontradas em cada exame.

Sendo assim, os resultados foram classificados como normal / alterado quando apresentaram:

I - PEATE: foram analisadas as latências absolutas das ondas I, III, e V, e dos interpicos I-III, III-V, e I-V.

Normal: latências absolutas das ondas I, III, e V, e interpicos I-III, III-V, e I-V, segundo os valores de normalidade propostos pelo Evoked Potential User Manual do equipamento BIO-LOGIC, para indivíduos acima de 24 meses, os quais encontram-se no Quadro 1.

Quadro 01: Padrão de normalidade das latências e interpicos do PEATE, para indivíduos acima de 24 meses, proposto pelo "Evoked Potential User Manual"

\begin{tabular}{|c|c|c|c|c|c|c|}
\hline & Onda I & Onda III & Onda V & $\begin{array}{c}\text { Interpico } \\
\text { I-III }\end{array}$ & $\begin{array}{c}\text { Interpico } \\
\text { III-V }\end{array}$ & $\begin{array}{c}\text { Interpico } \\
\text { I-V }\end{array}$ \\
\hline $\begin{array}{c}\text { Média } \\
\text { (ms) }\end{array}$ & 1,54 & 3,69 & 5,54 & 2,14 & 1,86 & 4,00 \\
\hline $\begin{array}{c}\text { Desvio } \\
\text { Padrão (ms) }\end{array}$ & 0,11 & 0,10 & 0,19 & 0,23 & 0,14 & 0,20 \\
\hline
\end{tabular}

Alterado: Os resultados que não preencheram os critérios descritos anteriormente no Quadro 1 foram considerados alterados. Os resultados alterados foram classificados de acordo com a localização da alteração (Matas, 2003):

- Tronco Encefálico Baixo (TEB): quando as latências das ondas III e V, e/ou dos interpicos I-III e I-V encontravam-se aumentadas, o resultado foi considerado como sugestivo de alteração na via auditiva em tronco encefálico baixo;

- Tronco Encefálico Alto (TEA): quando as latências da onda V e/ou dos interpicos I-V e III-V encontravam-se aumentadas na presença de latências absolutas normais para as ondas I e III, o resultado foi considerado como sugestivo de alteração na via auditiva em tronco encefálico alto; 
- Ambas: quando foram encontradas alterações do tipo TEB e TEA, concomitantemente, para o mesmo indivíduo.

II - PEALL: Foram analisadas as latências dos componentes P1, N1, P2, N2 e P300. Quanto as amplitudes P1-N1, P2-N2 e P300, estas foram analisadas apenas quantitativamente.

Normal: latências absolutas dos componentes P1, N1, P2, N2 e P300 segundo os valores de normalidade propostos por McPherson (1996), para as faixas etárias de 5 a 12 anos e acima de 12 anos, conforme o Quadro 2.

Quadro 02: Padrão de normalidade das latências dos componentes P1, N1, P2, N2 e P300 (em milissegundos -ms) do PEALL proposto por McPherson (1996), para as faixas etárias de 5 a 12 anos e acima de 12 anos.

\begin{tabular}{|c|c|c|}
\hline Componente & $\begin{array}{c}\text { Latência em ms } \\
\text { (5 a 12 anos) }\end{array}$ & $\begin{array}{c}\text { Latência em ms } \\
\text { (acima de 12 anos) }\end{array}$ \\
\hline P1 & 54 a $75 \mathrm{~ms}$ & 54 a $73 \mathrm{~ms}$ \\
\hline N1 & 83 a $135 \mathrm{~ms}$ & 83 a $135 \mathrm{~ms}$ \\
\hline P2 & 137 a $194 \mathrm{~ms}$ & 137 a $194 \mathrm{~ms}$ \\
\hline N2 & 200 a $280 \mathrm{~ms}$ & 188 a $231 \mathrm{~ms}$ \\
\hline P300 & 241 a $396 \mathrm{~ms}$ & 225 a $365 \mathrm{~ms}$ \\
\hline
\end{tabular}

Alterado: Os resultados que não preencheram os critérios descritos anteriormente no Quadro 2 foram considerados alterados, sendo os tipos de alterações classificados em:

- Atraso: quando a latência dos componentes encontrava-se aumentada, se comparada aos valores de normalidade adotados;

- Ausência: quando não foi encontrada presença do componente.

- Ambas: quando foram encontradas alterações do tipo atraso e ausente para o mesmo indivíduo. 
Foram comparados os resultados normais e alterados obtidos no PEALL por indivíduo, ou seja, o indivíduo foi considerado alterado quando pelo menos um componente (P1, N1, P2, N2 ou P300) de uma orelha apresentasse alteração.

\subsection{Método Estatístico}

Os resultados das avaliações eletrofisiológicas da audição foram analisados de forma quantitativa e qualitativa para os quatro grupos.

Para a análise dos dados quantitativos (contínuos), foram estabelecidos valores de média, mediana e desvio padrão dos resultados de cada avaliação realizada, para cada grupo. Além disso, foram comparados os valores de média obtidos entre GE1 e GC1, GE2 e GC2, GE1 e GE2, e verificados os níveis de significância para cada comparação realizada. Para a comparação de dados contínuos foi utilizado o teste ANOVA com um fator (one-way analysis of variance).

$\mathrm{Na}$ análise dos dados qualitativos (categóricos), os resultados foram descritos em proporção de alteração (normal e alterado) e em tipos de alterações, seguindo os critérios de avaliação apresentados no capítulo de Métodos. Para a comparação dos dados categóricos foi utilizado o Teste Exato de Fisher.

A partir destas comparações (normal e alterado), para cada procedimento realizado (PEATE e PEALL) e para cada grupo estudado (GE1 e GE2), foram calculadas as seguintes medidas e respectivos intervalos de confiança de 95\% (Rosner, 2010):

Sensibilidade - probabilidade de que o resultado do teste (PEATE e/ou PEALL) seja positivo (alterado) quando a doença (EM ou NMO) estiver presente (taxa de verdadeiro positivo)

Especificidade - probabilidade de que o resultado do teste (PEATE e/ou PEALL) seja negativo (normal) quando a doença (EM ou NMO) não estiver presente (taxa de verdadeiro negativo)

Acurácia - probabilidade geral de que um paciente seja classificado corretamente (ou seja, indivíduos que apresentaram o resultado alterado no 
PEATE e/ou PEALL tenham EM ou NMO, e que apresentaram o resultado normal no PEATE e/ou PEALL não tenham EM ou NMO) (Altman et al., 2000).

Os mesmos valores diagnósticos (sensibilidade, especificidade e acurácia) foram calculados considerando os resultados dos dois potenciais evocados (PEATE e PEALL) associados, ou seja, para ser classificado como alterado pelo menos um dos dois potenciais deveria apresentar-se com alteração.

Foi considerada uma probabilidade de erro do tipo I (a) de 0,05 em todas as análises inferenciais e os resultados que mostraram diferença estatisticamente significante $(p$-valor $<0,05)$ foram assinalados com asterisco $\left.{ }^{*}\right)$. 


\section{Resultados}




\section{Resultados}

Neste capítulo apresentaremos os resultados obtidos nas avaliações eletrofisiológicas da audição de 40 indivíduos, 20 dos Grupos Estudo (GE1 Esclerose Múltipla; GE2 - Neuromielite Óptica) e 20 dos Grupos Comparação (GC1 e GC2).

Foram realizadas análises qualitativas e quantitativas dos achados na avaliação eletrofisiológica por meio do PEATE e do PEALL. Para facilitar a visualização dos resultados, este capítulo foi dividido em três partes, a saber:

PARTE I - - Caracterização dos resultados do PEATE nos grupos estudo (GE1 e GE2) e comparação (GC1 e GC2).

PARTE II - Caracterização dos resultados do PEALL nos grupos estudo (GE1 e GE2) e comparação (GC1 e GC2).

PARTE III - Caracterização dos resultados da associação PEATE e PEALL nos grupos estudo (GE1 e GE2) e comparação (GC1 e GC2). 


\section{PARTE I - Caracterização dos resultados do PEATE nos grupos estudo (GE1 e GE2) e comparação (GC1 e GC2).}

Nesta parte serão apresentadas as análises dos dados qualitativos e quantitativos dos resultados obtidos no PEATE para os quatro grupos (GE1, GE2, GC1 e GC2).

Para a análise dos dados quantitativos, foram realizados testes estatísticos específicos para cada comparação. Além disso, foram verificados os níveis de significância, de cada resultado, para cada comparação. Cada teste estatístico utilizado será citado na apresentação dos resultados.

$\mathrm{Na}$ análise dos dados qualitativos, os resultados foram classificados em normais e alterados, e em tipos de alterações, seguindo os critérios apresentados no capítulo Métodos.

Para melhor visualização dos resultados, foi apresentado primeiro a análise dos dados quantitativos, e logo em seguida, a análise dos dados qualitativos.

\section{ANÁLISE DOS DADOS QUANTITATIVOS}

Inicialmente foram realizadas as análises dos dados quantitativos, na qual a primeira comparação realizada foi entre as orelhas direita e esquerda, para o PEATE, em cada grupo. Foram comparadas as latências absolutas das ondas I, III, e V e os interpicos I-III, III-V, e I-V, entre as orelhas no mesmo grupo. Utilizamos o teste ANOVA com amostras dependentes para esta comparação. 
Tabela 01: Comparação das latências das ondas I, III, e V e dos interpicos I-III, III-V e I-V entre as orelhas direita e esquerda no PEATE, para o GE1

\begin{tabular}{|c|c|c|c|c|c|}
\hline (GE1) PEATE & & Média & Mediana & Desvio Padrão & p-valor \\
\hline \multirow{2}{*}{ Onda I } & OD & 1,57 & 1,55 & 0,11 & \multirow{2}{*}{0,449} \\
\hline & $\mathrm{OE}$ & 1,54 & 1,53 & 0,08 & \\
\hline \multirow{2}{*}{ Onda III } & OD & 3,76 & 3,75 & 0,21 & \multirow{2}{*}{0,797} \\
\hline & $\mathrm{OE}$ & 3,74 & 3,75 & 0,19 & \\
\hline \multirow{2}{*}{ Onda V } & OD & 5,73 & 5,65 & 0,25 & \multirow{2}{*}{0,747} \\
\hline & $\mathrm{OE}$ & 5,70 & 5,58 & 0,27 & \\
\hline \multirow{2}{*}{ Interpico I-III } & OD & 2,19 & 2,20 & 0,17 & \multirow{2}{*}{0,922} \\
\hline & $\mathrm{OE}$ & 2,20 & 2,20 & 0,17 & \\
\hline \multirow{2}{*}{ Interpico III-V } & OD & 1,97 & 1,93 & 0,18 & \multirow{2}{*}{0,395} \\
\hline & $\mathrm{OE}$ & 1,91 & 1,90 & 0,18 & \\
\hline \multirow{2}{*}{ Interpico I-V } & OD & 4,16 & 4,10 & 0,18 & \multirow{2}{*}{0,334} \\
\hline & $\mathrm{OE}$ & 4,11 & 4,08 & 0,17 & \\
\hline
\end{tabular}


Tabela 02: Comparação das latências das ondas I, III, e V e dos interpicos I-III, III-V e I-V entre as orelhas direita e esquerda no PEATE, para o GC1

\begin{tabular}{|c|c|c|c|c|c|}
\hline (GC1) PEATE (ms) & & Média & Mediana & Desvio Padrão & p-valor \\
\hline \multirow{2}{*}{ Onda I } & OD & 1,60 & 1,60 & 0,05 & \multirow{2}{*}{0,546} \\
\hline & $\mathrm{OE}$ & 1,59 & 1,60 & 0,05 & \\
\hline \multirow{2}{*}{ Onda III } & OD & 3,78 & 3,80 & 0,11 & \multirow{2}{*}{0,082} \\
\hline & $\mathrm{OE}$ & 3,75 & 3,77 & 0,13 & \\
\hline \multirow{2}{*}{ Onda V } & OD & 5,61 & 5,58 & 0,14 & \multirow{2}{*}{0,783} \\
\hline & $\mathrm{OE}$ & 5,62 & 5,58 & 0,11 & \\
\hline \multirow{2}{*}{ Interpico I-III } & OD & 2,19 & 2,20 & 0,11 & \multirow{2}{*}{0,475} \\
\hline & $\mathrm{OE}$ & 2,17 & 2,20 & 0,11 & \\
\hline \multirow{2}{*}{ Interpico III-V } & OD & 1,82 & 1,80 & 0,08 & \multirow{2}{*}{0,178} \\
\hline & $\mathrm{OE}$ & 1,85 & 1,85 & 0,08 & \\
\hline \multirow{2}{*}{ Interpico I-V } & OD & 4,01 & 3,98 & 0,12 & \multirow{2}{*}{0,449} \\
\hline & $\mathrm{OE}$ & 4,03 & 4,00 & 0,08 & \\
\hline
\end{tabular}


Tabela 03: Comparação das latências das ondas I, III, e V e dos interpicos I-III, III-V e I-V entre as orelhas direita e esquerda no PEATE, para o GE2

\begin{tabular}{|c|c|c|c|c|c|}
\hline (GE2) PEATE (ms) & & Média & Mediana & Desvio Padrão & p-valor \\
\hline \multirow{2}{*}{ Onda I } & OD & 1,60 & 1,65 & 0,11 & \multirow{2}{*}{0,208} \\
\hline & $\mathrm{OE}$ & 1,57 & 1,55 & 0,14 & \\
\hline \multirow{2}{*}{ Onda III } & OD & 3,81 & 3,83 & 0,16 & \multirow{2}{*}{0,142} \\
\hline & $\mathrm{OE}$ & 3,87 & 3,85 & 0,21 & \\
\hline \multirow{2}{*}{ Onda V } & OD & 5,63 & 5,6 & 0,12 & \multirow{2}{*}{0,356} \\
\hline & $\mathrm{OE}$ & 5,68 & 5,65 & 0,20 & \\
\hline \multirow{2}{*}{ Interpico I-III } & OD & 2,22 & 2,20 & 0,11 & \multirow{2}{*}{0,104} \\
\hline & $\mathrm{OE}$ & 2,31 & 2,23 & 0,22 & \\
\hline \multirow{2}{*}{ Interpico III-V } & OD & 1,82 & 1,83 & 0,11 & \multirow{2}{*}{0,760} \\
\hline & $\mathrm{OE}$ & 1,80 & 1,83 & 0,12 & \\
\hline \multirow{2}{*}{ Interpico I-V } & OD & 4,04 & 4,05 & 0,06 & \multirow{2}{*}{0,236} \\
\hline & $\mathrm{OE}$ & 4,11 & 4,05 & 0,18 & \\
\hline
\end{tabular}


Tabela 04: Comparação das latências das ondas I, III, e V e dos interpicos I-III, III-V e I-V entre as orelhas direita e esquerda no PEATE, para o GC2

\begin{tabular}{|c|c|c|c|c|c|}
\hline (GC2) PEATE (ms) & & Média & Mediana & Desvio Padrão & p-valor \\
\hline \multirow{2}{*}{ Onda I } & OD & 1,58 & 1,57 & 0,10 & \multirow{2}{*}{0,923} \\
\hline & $\mathrm{OE}$ & 1,58 & 1,55 & 0,08 & \\
\hline \multirow{2}{*}{ Onda III } & OD & 3,76 & 3,77 & 0,09 & \multirow{2}{*}{0,347} \\
\hline & $\mathrm{OE}$ & 3,74 & 3,70 & 0,12 & \\
\hline \multirow{2}{*}{ Onda V } & OD & 5,55 & 5,50 & 0,15 & \multirow{2}{*}{0,891} \\
\hline & $\mathrm{OE}$ & 5,55 & 5,50 & 0,16 & \\
\hline \multirow{2}{*}{ Interpico I-III } & OD & 2,18 & 2,20 & 0,11 & \multirow{2}{*}{0,351} \\
\hline & $\mathrm{OE}$ & 2,16 & 2,15 & 0,15 & \\
\hline \multirow{2}{*}{ Interpico III-V } & OD & 1,78 & 1,75 & 0,12 & \multirow{2}{*}{0,550} \\
\hline & $\mathrm{OE}$ & 1,81 & 1,85 & 0,14 & \\
\hline \multirow{2}{*}{ Interpico I-V } & OD & 3,96 & 3,95 & 0,16 & \multirow{2}{*}{0,923} \\
\hline & $\mathrm{OE}$ & 3,97 & 3,92 & 0,16 & \\
\hline
\end{tabular}


Nas Tabelas 1, 2, 3 e 4 verificamos que, para nenhuma das latências absolutas das ondas I, III, e V, e interpicos I-III, III-V, e I-V, existiu diferença que possa ser considerada estatisticamente significante entre as orelhas direita e esquerda, respectivamente nos GE1, GC1, GE2 e GC2.

Visto que não foram encontradas diferenças estatisticamente significantes entre as orelhas em cada grupo estudado consideramos, para as próximas análises, as latências e interpicos de ambas as orelhas (agrupando as orelhas direita e esquerda).

Comparamos a seguir, as latências absolutas das ondas I, III, e V, e os interpicos I-III, III-V, e I-V entre GE1 e GC1, e entre GE2 e GC2. Desta forma, utilizamos o teste ANOVA com amostras independentes para esta análise.

Tabela 05: Comparação das latências absolutas das ondas I, III, e V e dos interpicos I-III, III-V e I-V do PEATE, nos GE1 e GC1.

\begin{tabular}{|c|c|c|c|c|c|}
\hline PEATE (ms) & & Média & Mediana & Desvio Padrão & p-valor \\
\hline \multirow{2}{*}{ Onda I } & GE1 & 1,55 & 1,54 & 0,09 & \multirow{2}{*}{0,090} \\
\hline & GC1 & 1,59 & 1,60 & 0,05 & \\
\hline \multirow{2}{*}{ Onda III } & GE1 & 3,75 & 3,75 & 0,20 & \multirow{2}{*}{0,793} \\
\hline & GC1 & 3,76 & 3,79 & 0,12 & \\
\hline \multirow{2}{*}{ Onda V } & GE1 & 5,71 & 5,62 & 0,25 & \multirow{2}{*}{0,101} \\
\hline & GC1 & 5,61 & 5,59 & 0,13 & \\
\hline \multirow{2}{*}{ Interpico I-III } & GE1 & 2,19 & 2,20 & 0,17 & \multirow{2}{*}{0,700} \\
\hline & GC1 & 2,18 & 2,20 & 0,11 & \\
\hline \multirow{2}{*}{ Interpico III-V } & GE1 & 1,94 & 1,92 & 0,18 & \multirow{2}{*}{$0,017^{*}$} \\
\hline & GC1 & 1,83 & 1,84 & 0,08 & \\
\hline \multirow{2}{*}{ Interpico I-V } & GE1 & 4,14 & 4,09 & 0,18 & \multirow{2}{*}{$0,010^{*}$} \\
\hline & $\mathrm{GC1}$ & 4,02 & 3,99 & 0,11 & \\
\hline
\end{tabular}

${ }^{*} \mathrm{p}$-valor considerado estatisticamente significante

$\mathrm{Na}$ Tabela 5, averiguamos que existiu diferença estatisticamente significante entre GE1 e GC1 para os interpicos III-V e I-V. Notamos que, em todas as análises nas quais observamos significância, a latência do GE1 foi sempre maior do que a do GC1. 
Tabela 06: Comparação das latências absolutas das ondas I, III, e V e dos interpicos I-III, III-V e I-V do PEATE, nos GE2 e GC2.

\begin{tabular}{|c|c|c|c|c|c|}
\hline PEATE (ms) & & Média & Mediana & Desvio Padrão & p-valor \\
\hline \multirow{2}{*}{ Onda I } & GE2 & 1,58 & 1,62 & 0,13 & \multirow{2}{*}{1,000} \\
\hline & GC2 & 1,58 & 1,56 & 0,09 & \\
\hline \multirow{2}{*}{ Onda III } & GE2 & 3,84 & 3,84 & 0,19 & \multirow{2}{*}{0,071} \\
\hline & GC2 & 3,75 & 3,77 & 0,10 & \\
\hline \multirow{2}{*}{ Onda V } & GE2 & 5,65 & 5,63 & 0,16 & \multirow{2}{*}{0,053} \\
\hline & GC2 & 5,55 & 5,55 & 0,15 & \\
\hline \multirow{2}{*}{ Interpico I-III } & GE2 & 2,26 & 2,23 & 0,17 & \multirow{2}{*}{0,079} \\
\hline & GC2 & 2,17 & 2,15 & 0,13 & \\
\hline \multirow{2}{*}{ Interpico III-V } & GE2 & 1,81 & 1,83 & 0,11 & \multirow{2}{*}{0,766} \\
\hline & GC2 & 1,80 & 1,82 & 0,13 & \\
\hline \multirow{2}{*}{ Interpico I-V } & GE2 & 4,07 & 4,05 & 0,14 & \multirow{2}{*}{$0,037^{*}$} \\
\hline & GC2 & 3,97 & 3,94 & 0,16 & \\
\hline
\end{tabular}

*p-valor considerado estatisticamente significante

Verificamos, na Tabela 6, diferença estatisticamente significante entre GE2 e GC2 para o interpico I-V, com resultado maior para o GE2.

Por fim, realizamos a comparação das latências absolutas das ondas I, III, e V, e dos interpicos I-III, III-V, e I-V entre GE1 e GE2, utilizando o teste ANOVA com amostras independentes para esta análise. 
Tabela 07: Comparação das latências absolutas das ondas I, III, e V e dos interpicos I-III, III-V e I-V do PEATE, nos GE1 e GE2

\begin{tabular}{|c|c|c|c|c|c|}
\hline PEATE (ms) & & Média & Mediana & Desvio Padrão & p-valor \\
\hline \multirow{2}{*}{ Onda I } & GE1 & 1,55 & 1,54 & 0,09 & \multirow{2}{*}{0,440} \\
\hline & GE2 & 1,58 & 1,62 & 0,13 & \\
\hline \multirow{2}{*}{ Onda III } & GE1 & 3,75 & 3,75 & 0,20 & \multirow{2}{*}{0,134} \\
\hline & GE2 & 3,84 & 3,84 & 0,19 & \\
\hline \multirow{2}{*}{ Onda V } & GE1 & 5,71 & 5,62 & 0,25 & \multirow{2}{*}{0,377} \\
\hline & GE2 & 5,65 & 5,63 & 0,16 & \\
\hline \multirow{2}{*}{ Interpico I-III } & GE1 & 2,19 & 2,20 & 0,17 & \multirow{2}{*}{0,224} \\
\hline & GE2 & 2,26 & 2,23 & 0,17 & \\
\hline \multirow{2}{*}{ Interpico III-V } & GE1 & 1,94 & 1,92 & 0,18 & \multirow{2}{*}{$0,012 *$} \\
\hline & GE2 & 1,81 & 1,83 & 0,11 & \\
\hline \multirow{2}{*}{ Interpico I-V } & GE1 & 4,14 & 4,09 & 0,18 & \multirow{2}{*}{0,219} \\
\hline & GE2 & 4,07 & 4,05 & 0,14 & \\
\hline
\end{tabular}

${ }^{*} \mathrm{p}$-valor considerado estatisticamente significante

Observamos, na Tabela 7, diferença estatisticamente significante entre GE1 e GE2 para o interpico III-V, com valores maiores no GE1. 


\section{ANÁLISE DOS DADOS QUALITATIVOS}

Para a análise dos dados qualitativos, foram comparados os resultados normais e alterados obtidos no PEATE por indivíduo, ou seja, o indivíduo foi considerado alterado quando pelo menos uma orelha apresentasse alteração. O Teste Exato de Fisher foi utilizado para as próximas análises. Sendo assim, foram estabelecidos os valores diagnósticos de sensibilidade, especificidade e acurácia para cada doença desmielinizante estudada.

Além disso, foram descritos os tipos de alterações encontradas no PEATE, sendo os resultados classificados em alterações de tronco encefálico baixo, tronco encefálico alto e ambas (conforme descrito no capítulo de Métodos).

Tabela 08: Distribuição da ocorrência de resultados normais e alterados no PEATE, nos GE1 e GC1

\begin{tabular}{cccccc}
\hline \multirow{2}{*}{ PEATE } & \multicolumn{3}{c}{ GE1 } & \multicolumn{3}{c}{ GC1 } & \multirow{2}{*}{ p-valor } \\
\cline { 2 - 5 } & $\mathrm{N}$ & $\%$ & $\mathrm{~N}$ & $\%$ & \\
\hline Alterado & 7 & 63,6 & 0 & 0 & \multirow{2}{*}{$0,004^{*}$} \\
\hline Normal & 4 & 36,4 & 11 & 100 & \\
\hline *p-valor considerado estatisticamente significante & &
\end{tabular}

${ }^{*} \mathrm{p}$-valor considerado estatisticamente significante

Ao compararmos GE1 e GC1, verificamos que existiu diferença estatisticamente significante entre os resultados normais e alterados, sendo que o GE1 apresentou maior ocorrência de alterações.

Em relação ao valor diagnóstico do PEATE para a doença desmielinizante Esclerose Múltipla (EM), obtivemos os seguintes resultados:

Sensibilidade $=63,64 \%$ (IC 95\% 30,79 - 89,07\%),

Especificidade $=100 \%($ IC 95\% 71,51 - 100\%)

Acurácia $=81,82 \%($ IC 95\% 59,72 - 94,81\%)

A seguir, encontram-se os tipos de alterações encontrados no PEATE entre os grupos. 
Tabela 09: Distribuição dos tipos de alterações encontrados no PEATE, nos GE1 e GC1

\begin{tabular}{ccccc}
\hline \multirow{2}{*}{ PEATE Tipos } & \multicolumn{2}{c}{ GE1 } & \multicolumn{2}{c}{ GC1 } \\
\cline { 2 - 5 } & $\mathrm{N}$ & $\%$ & $\mathrm{~N}$ & $\%$ \\
\hline Ambos & 2 & 28,6 & 0 & 0 \\
\hline Tronco Encefálico Alto & 4 & 57,1 & 0 & 0 \\
\hline Tronco Encefálico Baixo & 1 & 14,3 & & 0 \\
\hline
\end{tabular}

$\mathrm{Na}$ tabela 9 verificamos que o tipo de alteração que apresentou maior ocorrência foi o tronco encefálico alto para o GE1 $(57,1 \%)$.

Tabela 10: Distribuição da ocorrência de resultados normais e alterados no PEATE, nos GE2 e GC2

\begin{tabular}{cccccc}
\hline \multirow{2}{*}{ PEATE } & \multicolumn{3}{c}{ GE2 } & \multicolumn{3}{c}{ GC2 } & \multirow{2}{*}{ p-valor } \\
\cline { 2 - 5 } & $\mathrm{N}$ & $\%$ & $\mathrm{~N}$ & $\%$ & \\
\hline Alterado & 3 & 33,3 & 0 & 0 & \multirow{2}{*}{0,206} \\
\hline Normal & 6 & 66,7 & 9 & 100 & \\
\hline
\end{tabular}

Ao compararmos GE2 e GC2, apesar de não ter existido diferença estatisticamente significante entre os resultados normais e alterados, o GE2 apresentou maior ocorrência de alterações quando comparado com o GC2.

No que diz respeito ao valor diagnóstico do PEATE para a doença desmielinizante Neuromielite Óptica (NMO), obtivemos os seguintes resultados:

Sensibilidade $=33,34 \%$ (IC 95\% 7,49-70,07\%)

Especificidade $=100 \%($ IC 95\% 66,37 - 100\%)

Acurácia $=66,67 \%($ IC 95\% 40,99 - 86,66\%) 
Tabela 11: Distribuição dos tipos de alterações encontrados no PEATE, nos GE2 e GC2

\begin{tabular}{ccccc}
\hline \multirow{2}{*}{ PEATE Tipos } & \multicolumn{2}{c}{ GE2 } & GC2 \\
\cline { 2 - 5 } & $\mathrm{N}$ & $\%$ & 0 & $\%$ \\
\hline Ambos & 0 & 0 & 0 & 0 \\
\hline Tronco Encefálico Alto & 0 & 0 & 0 & 0
\end{tabular}

Na tabela 11 verificamos que o tipo de alteração que apresentou maior ocorrência foi o tronco encefálico baixo para o GE2 (100\%).

Por fim, realizamos a comparação dos resultados normais e alterados dos PEATE entre GE1 e GE2.

Tabela 12: Distribuição da ocorrência de resultados normais e alterados no PEATE, nos GE1 e GE2

\begin{tabular}{|c|c|c|c|c|c|}
\hline \multirow{2}{*}{ PEATE } & \multicolumn{2}{|c|}{ GE1 } & \multicolumn{2}{|c|}{ GE2 } & \multirow{2}{*}{ p-valor } \\
\hline & $\mathrm{N}$ & $\%$ & $\mathrm{~N}$ & $\%$ & \\
\hline Alterado & 7 & 63,6 & 3 & 33,3 & \multirow{2}{*}{0,370} \\
\hline Normal & 4 & 36,4 & 6 & 66,7 & \\
\hline
\end{tabular}

Ao compararmos GE1 e GE2, apesar de não ter existido diferença estatisticamente significante entre os resultados normais e alterados, o GE1 apresentou maior ocorrência de alterações quando comparado com o GE2.

Tabela 13: Distribuição dos tipos de alterações encontrados no PEATE, nos GE1 e GE2

\begin{tabular}{lcccc}
\hline \multirow{2}{*}{ PEATE Tipos } & \multicolumn{2}{c}{ GE1 } & \multicolumn{2}{c}{ GE2 } \\
\cline { 2 - 5 } & $\mathrm{N}$ & $\%$ & $\mathrm{~N}$ & $\%$ \\
\hline Ambos & 2 & 28,6 & 0 & 0 \\
\hline Tronco Encefálico Alto & 4 & 57,1 & 0 & 0 \\
\hline Tronco Encefálico Baixo & 1 & 14,3 & 3 & 100 \\
\hline
\end{tabular}


Na tabela 13 verificamos que o tipo de alteração que apresentou maior ocorrência foi o tronco encefálico baixo para o GE2 (100\%) e tronco encefálico alto para o GE1 $(57,1 \%)$.

\section{Parte II - Caracterização dos resultados do PEALL nos grupos estudo (GE1 e GE2) e comparação (GC1 e GC2).}

Nesta parte serão apresentadas as análises dos dados qualitativos e quantitativos dos resultados obtidos no PEALL para os quatro grupos (GE1, GE2, GC1 e GC2).

Para a análise dos dados quantitativos, foram realizados testes estatísticos específicos para cada comparação. Além disso, foram verificados os níveis de significância, de cada resultado, para cada comparação. Cada teste estatístico utilizado será citado na apresentação dos resultados.

$\mathrm{Na}$ análise dos dados qualitativos, os resultados foram classificados em normais e alterados, e em tipos de alterações, seguindo os critérios apresentados no capítulo Métodos.

Para melhor visualização dos resultados, foi apresentado primeiro a análise dos dados quantitativos, e logo em seguida, a análise dos dados qualitativos.

\section{ANÁLISE DOS DADOS QUANTITATIVOS}

Inicialmente foram realizadas as análises dos dados quantitativos, na qual a primeira comparação realizada foi entre as orelhas direita e esquerda, para as latências de P1, N1, P2, N2 e P300, e para as amplitudes P1-N1, P2N2 e P3, em cada grupo. Utilizamos o teste ANOVA com amostras dependentes para esta comparação. 
Tabela 14: Comparação das latências de P1, N1, P2, N2 e P300 e amplitudes P1-N1, P2-N2 e P3 entre as orelhas direita e esquerda no PEALL, para o GE1

\begin{tabular}{|c|c|c|c|c|c|}
\hline (GE1) PEALL (ms) & & Média & Mediana & Desvio Padrão & p-valor \\
\hline \multirow{2}{*}{ Latência P1 } & OD & 66,55 & 58 & 32,93 & \multirow{2}{*}{0,890} \\
\hline & $\mathrm{OE}$ & 64,91 & 67 & 19,53 & \\
\hline \multirow{2}{*}{ Latência N1 } & OD & 114,73 & 110 & 27,83 & \multirow{2}{*}{0,213} \\
\hline & $\mathrm{OE}$ & 101,18 & 103 & 19,67 & \\
\hline \multirow{2}{*}{ Latência P2 } & OD & 177,27 & 171 & 34,34 & \multirow{2}{*}{0,077} \\
\hline & $\mathrm{OE}$ & 160,27 & 160 & 14,41 & \\
\hline \multirow{2}{*}{ Latência N2 } & OD & 230,45 & 234 & 35,15 & \multirow{2}{*}{$0,048^{*}$} \\
\hline & $\mathrm{OE}$ & 211,82 & 206 & 21,56 & \\
\hline \multirow{2}{*}{ Latência P300 } & OD & 319,18 & 326 & 22,52 & \multirow{2}{*}{0,468} \\
\hline & $\mathrm{OE}$ & 313,45 & 315 & 22,83 & \\
\hline \multirow{2}{*}{ Amplitude P1 - N1 } & OD & 4,04 & 3,18 & 2,64 & \multirow{2}{*}{0,758} \\
\hline & $\mathrm{OE}$ & 3,78 & 4,57 & 2,79 & \\
\hline \multirow{2}{*}{ Amplitude P2 - N2 } & OD & 4,32 & 3,67 & 2,63 & \multirow{2}{*}{0,080} \\
\hline & $\mathrm{OE}$ & 3,19 & 2,79 & 2,49 & \\
\hline \multirow{2}{*}{ Amplitude P300 } & OD & 9,88 & 10,98 & 4,52 & \multirow{2}{*}{0,384} \\
\hline & $\mathrm{OE}$ & 8,65 & 8,38 & 4,78 & \\
\hline
\end{tabular}


Tabela 15: Comparação das latências de P1, N1, P2, N2 e P300 e amplitudes P1-N1, P2-N2 e P3 entre as orelhas direita e esquerda no PEALL, para o GC1

\begin{tabular}{|c|c|c|c|c|c|}
\hline (GC1) PEALL (ms) & & Média & Mediana & Desvio Padrão & p-valor \\
\hline \multirow{2}{*}{ Latência P1 } & OD & 55,73 & 55,00 & 13,73 & \multirow{2}{*}{0,475} \\
\hline & $\mathrm{OE}$ & 59,18 & 64 & 12,68 & \\
\hline \multirow{2}{*}{ Latência N1 } & OD & 99,82 & 108 & 19,10 & \multirow{2}{*}{0,770} \\
\hline & $\mathrm{OE}$ & 98,18 & 104 & 15,96 & \\
\hline \multirow{2}{*}{ Latência P2 } & OD & 167,18 & 169 & 10,09 & \multirow{2}{*}{0,075} \\
\hline & $\mathrm{OE}$ & 179,09 & 178 & 19,87 & \\
\hline \multirow{2}{*}{ Latência N2 } & OD & 230,64 & 233 & 19,28 & \multirow{2}{*}{0,866} \\
\hline & $\mathrm{OE}$ & 231,91 & 232 & 20,44 & \\
\hline \multirow{2}{*}{ Latência P300 } & OD & 321,64 & 325 & 33,29 & \multirow{2}{*}{0,758} \\
\hline & $\mathrm{OE}$ & 317,55 & 323 & 27,65 & \\
\hline \multirow{2}{*}{ Amplitude P1 - N1 } & OD & 4,59 & 4,36 & 1,47 & \multirow{2}{*}{1,000} \\
\hline & $\mathrm{OE}$ & 4,56 & 4,05 & 2,84 & \\
\hline \multirow{2}{*}{ Amplitude P2 - N2 } & OD & 6,58 & 6,16 & 3,89 & \multirow{2}{*}{0,122} \\
\hline & $\mathrm{OE}$ & 5,31 & 4,21 & 4,45 & \\
\hline \multirow{2}{*}{ Amplitude P300 } & OD & 9,00 & 8,02 & 5,31 & \multirow{2}{*}{0,315} \\
\hline & $\mathrm{OE}$ & 10,60 & 10,47 & 5,62 & \\
\hline
\end{tabular}


Tabela 16: Comparação das latências de P1, N1, P2, N2 e P300 e amplitudes P1-N1, P2-N2 e P3 entre as orelhas direita e esquerda no PEALL, para o GE2

\begin{tabular}{|c|c|c|c|c|c|}
\hline (GE2) PEALL (ms) & & Média & Mediana & Desvio Padrão & p-valor \\
\hline \multirow{2}{*}{ Latência P1 } & OD & 82,00 & 67 & 35,45 & \multirow{2}{*}{0,146} \\
\hline & $\mathrm{OE}$ & 68,22 & 61 & 19,77 & \\
\hline \multirow{2}{*}{ Latência N1 } & OD & 120,22 & 110 & 24,73 & \multirow{2}{*}{0,246} \\
\hline & $\mathrm{OE}$ & 109,44 & 110 & 16,72 & \\
\hline \multirow{2}{*}{ Latência P2 } & OD & 178,78 & 176 & 19,19 & \multirow{2}{*}{0,535} \\
\hline & $\mathrm{OE}$ & 172,22 & 182 & 17,09 & \\
\hline \multirow{2}{*}{ Latência N2 } & OD & 256,56 & 252 & 23,7 & \multirow{2}{*}{0,508} \\
\hline & $\mathrm{OE}$ & 247,33 & 253 & 27,54 & \\
\hline \multirow{2}{*}{ Latência P300 } & OD & 322,11 & 320 & 31,46 & \multirow{2}{*}{0,301} \\
\hline & $\mathrm{OE}$ & 333,44 & 330 & 41,12 & \\
\hline \multirow{2}{*}{ Amplitude P1 - N1 } & OD & 4,22 & 3,01 & 3,40 & \multirow{2}{*}{0,476} \\
\hline & $\mathrm{OE}$ & 4,64 & 2,80 & 4,80 & \\
\hline \multirow{2}{*}{ Amplitude P2 - N2 } & OD & 6,67 & 6,14 & 4,01 & \multirow{2}{*}{0,250} \\
\hline & $\mathrm{OE}$ & 5,91 & 6,73 & 3,66 & \\
\hline \multirow{2}{*}{ Amplitude P300 } & OD & 5,57 & 4,02 & 4,36 & \multirow{2}{*}{1,000} \\
\hline & $\mathrm{OE}$ & 5,43 & 4,03 & 4,06 & \\
\hline
\end{tabular}


Tabela 17: Comparação das latências de P1, N1, P2, N2 e P300 e amplitudes P1-N1, P2-N2 e P3 entre as orelhas direita e esquerda no PEALL, para o GC2

\begin{tabular}{|c|c|c|c|c|c|}
\hline (GC2) PEALL (ms) & & Média & Mediana & Desvio Padrão & p-valor \\
\hline \multirow{2}{*}{ Latência P1 } & OD & 56,22 & 45 & 25,73 & \multirow{2}{*}{0,813} \\
\hline & $\mathrm{OE}$ & 57,89 & 50 & 20,79 & \\
\hline \multirow{2}{*}{ Latência N1 } & OD & 101,22 & 97 & 23,36 & \multirow{2}{*}{0,464} \\
\hline & $\mathrm{OE}$ & 94,11 & 90 & 18,88 & \\
\hline \multirow{2}{*}{ Latência P2 } & OD & 164,89 & 160 & 18,84 & \multirow{2}{*}{0,760} \\
\hline & $\mathrm{OE}$ & 162,78 & 169 & 28,42 & \\
\hline \multirow{2}{*}{ Latência N2 } & OD & 223,11 & 221 & 18,84 & \multirow{2}{*}{0,587} \\
\hline & $\mathrm{OE}$ & 226,22 & 219 & 24,57 & \\
\hline \multirow{2}{*}{ Latência P300 } & OD & 328,22 & 335 & 38,45 & \multirow{2}{*}{0,651} \\
\hline & $\mathrm{OE}$ & 323,67 & 329 & 26,25 & \\
\hline \multirow{2}{*}{ Amplitude P1 - N1 } & OD & 6,35 & 5,56 & 4,43 & \multirow{2}{*}{0,593} \\
\hline & $\mathrm{OE}$ & 5,50 & 5,76 & 2,24 & \\
\hline \multirow{2}{*}{ Amplitude P2 - N2 } & OD & 5,28 & 5,25 & 2,74 & \multirow{2}{*}{0,256} \\
\hline & $\mathrm{OE}$ & 5,99 & 4,62 & 3,94 & \\
\hline \multirow{2}{*}{ Amplitude P300 } & OD & 11,23 & 11,19 & 3,52 & \multirow{2}{*}{0,631} \\
\hline & $\mathrm{OE}$ & 2,40 & 9,90 & 6,84 & \\
\hline
\end{tabular}


Nas Tabelas 14, 15, 16 e 17 não foram evidenciadas diferenças estatisticamente significantes nas latências de P1, N1, P2, N2 e P300 e amplitudes P1-N1, P2-N2 e P3 entre as orelhas direita e esquerda para os grupos GE1, GC1, GE2, GC2, exceto para o componente N2 no GE1, no qual a OD apresentou tempo de latência maior do que a OE.

Sendo assim, consideramos para as próximas análises, as latências e amplitudes de ambas as orelhas (agrupando as orelhas direita e esquerda) para cada grupo.

Comparamos, então, as latências de $\mathrm{P} 1, \mathrm{~N} 1, \mathrm{P} 2, \mathrm{~N} 2$ e $\mathrm{P} 3$ e as amplitudes P1-N1, P2-N2 e P3 do PEALL entre GE1 e GC1, e entre GE2 e GC2, sendo que para esta análise utilizamos o teste ANOVA com amostras independentes. 
Tabela 18: Comparação das latências de $\mathrm{P} 1, \mathrm{~N} 1, \mathrm{P} 2, \mathrm{~N} 2$ e $\mathrm{P} 300$ e das amplitudes P1-N1, P2-N2 e P3 do PEALL, entre GE1 e GC1.

\begin{tabular}{|c|c|c|c|c|c|c|c|c|c|c|}
\hline \multirow{2}{*}{ Latência em ms } & \multicolumn{2}{|c|}{ P1 } & \multicolumn{2}{|c|}{ N1 } & \multicolumn{2}{|c|}{$\mathbf{P 2}$} & \multicolumn{2}{|c|}{ N2 } & \multicolumn{2}{|c|}{ P300 } \\
\hline & GE1 & GC1 & GE1 & GC1 & GE1 & GC1 & GE1 & GC1 & GE1 & GC1 \\
\hline Média & 65,73 & 57,45 & 107,95 & 99,00 & 168,77 & 173,14 & 221,14 & 231,27 & 316,32 & 319,59 \\
\hline Mediana & 63,50 & 59,00 & 104,50 & 105,00 & 160,50 & 174,00 & 216,50 & 232,50 & 318,50 & 324,50 \\
\hline Desvio Padrão & 26,43 & 13,02 & 24,52 & 17,20 & 27,13 & 16,54 & 30,01 & 19,40 & 22,32 & 29,94 \\
\hline p-valor & \multicolumn{2}{|c|}{0,196} & \multicolumn{2}{|c|}{0,168} & \multicolumn{2}{|c|}{0,525} & \multicolumn{2}{|c|}{0,191} & \multicolumn{2}{|c|}{0,682} \\
\hline \multirow{2}{*}{\multicolumn{3}{|c|}{ Amplitude em microvolts }} & \multicolumn{2}{|c|}{ P1 - N1 } & & \multicolumn{2}{|l|}{ P2-N2 } & \multicolumn{3}{|c|}{ P300 } \\
\hline & & & GE1 & GC1 & & E1 & GC1 & & $E 1$ & GC1 \\
\hline \multicolumn{3}{|l|}{ Média } & 3,91 & 4,57 & & ,76 & 5,95 & \multicolumn{2}{|c|}{9,26} & 9,80 \\
\hline \multicolumn{3}{|c|}{ Mediana } & 3,35 & 4,10 & & 12 & 4,65 & \multicolumn{2}{|c|}{9,86} & 10,29 \\
\hline \multicolumn{3}{|c|}{ Desvio Padrão } & 2,66 & 2,21 & & ,57 & 4,13 & \multicolumn{2}{|c|}{4,59} & 5,40 \\
\hline \multicolumn{3}{|l|}{ p-valor } & \multicolumn{2}{|c|}{0,367} & \multicolumn{3}{|c|}{$0,040^{*}$} & \multicolumn{3}{|c|}{0,720} \\
\hline
\end{tabular}

${ }^{*} \mathrm{p}$-valor considerado estatisticamente significante

$\mathrm{Na}$ Tabela 18 pudemos verificar que não ocorreu diferença estatisticamente significante entre GE1 e GC1, para a latência de P1, N1, P2, N2 e P300, porém o GE1 apresentou maior latência do que o GC1 para os componentes P1 e N1. Observou-se diferença estatisticamente significante para a amplitude P2-N2, onde o GC1 apresentou maior valor de amplitude em comparação ao GE1. 
Tabela 19: Comparação das latências de $\mathrm{P} 1, \mathrm{~N} 1, \mathrm{P} 2, \mathrm{~N} 2$ e $\mathrm{P} 300$ e das amplitudes P1-N1, P2-N2 e P3 do PEALL, entre GE2 e GC2.

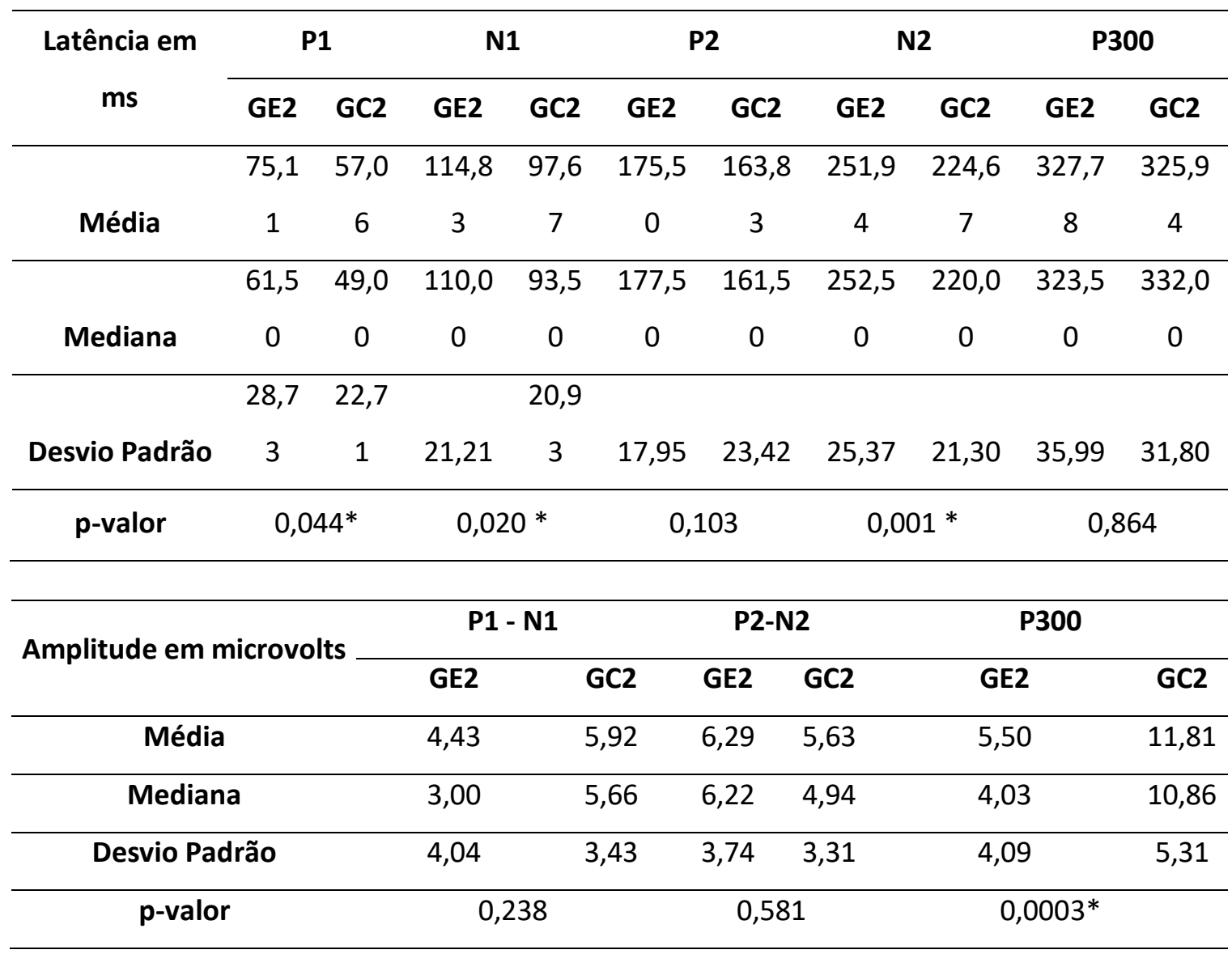

${ }^{*} \mathrm{p}$-valor considerado estatisticamente significante

Verificamos, na Tabela 19, diferença estatisticamente significante entre GE2 e GC2 para as latências de P1, N1 e N2, sendo que em todas as análises nas quais observamos significância, a latência do GE2 foi sempre maior do que a do GC2. Evidenciamos, também, diferença estatisticamente significante para a amplitude P3, com menor valor para o GE2.

Por fim, comparamos das latências de P1, N1, P2, N2 e P3 e as amplitudes P1-N1, P2-N2 e P3 entre GE1 e GE2, utilizando o teste ANOVA com amostras independentes para esta análise. 
Tabela 20: Comparação das latências de P1, N1, P2, N2 e P300 e das amplitudes P1-N1, P2-N2 e P3 do PEALL, entre GE1 e GE2.

\begin{tabular}{|c|c|c|c|c|c|c|c|c|c|c|}
\hline \multirow{2}{*}{$\begin{array}{l}\text { Latência em } \\
\text { ms }\end{array}$} & \multicolumn{2}{|c|}{ P1 } & \multicolumn{2}{|c|}{ N1 } & \multicolumn{2}{|c|}{$\mathbf{P 2}$} & \multicolumn{2}{|c|}{ N2 } & \multicolumn{2}{|c|}{ P300 } \\
\hline & GE1 & GE2 & GE1 & GE2 & GE1 & GE2 & GE1 & GE2 & GE1 & GE2 \\
\hline & 65,7 & 75,1 & 107,9 & 114,8 & 168,7 & 175,5 & 221,1 & 251,9 & 316,3 & 327,7 \\
\hline \multirow[t]{2}{*}{ Média } & 3 & 1 & 5 & 3 & 7 & 0 & 4 & 4 & 2 & 8 \\
\hline & 63,5 & 61,5 & 104,5 & 110,0 & 160,5 & 177,5 & 216,5 & 252,5 & 318,5 & 323,5 \\
\hline \multirow[t]{2}{*}{ Mediana } & 0 & 0 & 0 & 0 & 0 & 0 & 0 & 0 & 0 & 0 \\
\hline & 26,4 & 28,7 & & & & & & & & \\
\hline Desvio Padrão & 3 & 3 & 24,52 & 21,21 & 27,13 & 17,95 & 30,01 & 25,37 & 22,32 & 35,99 \\
\hline p-valor & \multicolumn{2}{|c|}{0,290} & \multicolumn{2}{|c|}{0,354} & \multicolumn{2}{|c|}{0,374} & \multicolumn{2}{|c|}{$0,001^{*}$} & \multicolumn{2}{|c|}{0,225} \\
\hline \multirow{2}{*}{\multicolumn{3}{|c|}{$\begin{array}{c}\text { Amplitude em } \\
\text { microvolts }\end{array}$}} & \multicolumn{2}{|c|}{ P1 - N1 } & \multicolumn{3}{|c|}{ P2-N2 } & \multicolumn{3}{|c|}{ P300 } \\
\hline & & & GE1 & GE2 & \multicolumn{2}{|c|}{ GE1 } & GE2 & GE1 & & GE2 \\
\hline \multicolumn{3}{|l|}{ Média } & 3,91 & 4,43 & \multicolumn{2}{|c|}{3,76} & 6,29 & 9,26 & & 5,50 \\
\hline \multicolumn{3}{|c|}{ Mediana } & 3,35 & 3,00 & \multicolumn{2}{|c|}{3,12} & 6,22 & 9,86 & & 4,03 \\
\hline \multicolumn{3}{|c|}{ Desvio Padrão } & 2,66 & 4,04 & \multicolumn{2}{|c|}{2,57} & 3,74 & 4,59 & & 4,09 \\
\hline \multicolumn{3}{|l|}{ p-valor } & \multicolumn{2}{|c|}{0,627} & \multicolumn{3}{|c|}{$0,015^{*}$} & \multicolumn{3}{|c|}{$0,010^{*}$} \\
\hline
\end{tabular}

Verificamos, na Tabela 20, diferença estatisticamente significante entre GE1 e GE2 para a latência de N2, sendo que a latência do GE2 foi maior do que a do GE1. Verificamos, também, diferença estatisticamente significante entre GE1 e GE2 para as amplitudes P2-N2 onde a do GE2 foi maior, e para a amplitude P300, onde o GE1 apresentou maior valor. 


\section{ANÁLISE DOS DADOS QUALITATIVOS}

A seguir, analisamos os resultados dos dados qualitativos do PEALL para os quatro grupos estudados e entre os grupos. Foram comparados os resultados normais e alterados obtidos no PEALL por indivíduo, ou seja, o indivíduo foi considerado alterado quando pelo menos um componente (P1, N1, P2, N2 ou P3) de uma orelha apresentasse alteração. O Teste Exato de Fisher foi utilizado para as próximas análises. Desta forma, foram estabelecidos os valores diagnósticos de sensibilidade, especificidade e acurácia para cada doença desmielinizante estudada.

Além disso, foram descritos os tipos de alterações encontradas no PEALL, sendo os resultados classificados em atraso, ausência ou ambas (conforme descrito no capítulo de Métodos).

Tabela 21: Distribuição da ocorrência de resultados normais e alterados no PEALL, nos GE1 e GC1

\begin{tabular}{|c|c|c|c|c|c|}
\hline \multirow[b]{2}{*}{ PEALL } & \multicolumn{2}{|c|}{ GE1 } & \multicolumn{2}{|c|}{ GC1 } & \multirow{2}{*}{ p-valor } \\
\hline & $\mathrm{N}$ & $\%$ & $\mathrm{~N}$ & $\%$ & \\
\hline Normal & 7 & 63,6 & 10 & 90,9 & \multirow{2}{*}{0,311} \\
\hline Alterado & 4 & 36,4 & 1 & 9,1 & \\
\hline
\end{tabular}

Ao compararmos GE1 e GC1, apesar de não ter existido diferença estatisticamente significante entre os resultados normais e alterados, o GE1 apresentou maior ocorrência de alterações quando comparado com o GC1.

Em relação ao valor diagnóstico do PEALL para a doença desmielinizante Esclerose Múltipla (EM), obtivemos os seguintes resultados:

Sensibilidade $=36,36 \%($ IC 95\% 10,93 - 69,21\%)

Especificidade $=90,91 \%$ (IC 95\% 58,72 - 99,77\%)

Acurácia $=63,64 \%($ IC 95\% 40,66 - 82,80\%)

A seguir, encontram-se os tipos de alterações encontrados no PEALL entre os grupos. 
Tabela 22: Distribuição dos tipos de alterações encontrados no PEALL, nos GE1 e GC1

\begin{tabular}{lcccccc}
\hline \multirow{2}{*}{ Tipo de Alteração } & \multicolumn{2}{c}{ Atraso de latência } & \multicolumn{2}{c}{ Ausência de resposta } & \multicolumn{2}{c}{ Ambas } \\
\cline { 2 - 7 } & $\mathrm{N}$ & $\%$ & $\mathrm{~N}$ & $\%$ & $\mathrm{~N}$ & $\%$ \\
\hline GE1 & 4 & 100 & 0 & 0 & 0 & 0 \\
\hline GC1 & 1 & 100 & 0 & 0 & 0 & 0 \\
\hline
\end{tabular}

$\mathrm{Na}$ Tabela 22 verificamos que o tipo de alteração que apresentou maior ocorrência foi o atraso de latência, tanto para o GE1 (100\%) como para o GC1 (100\%).

Tabela 23: Distribuição da ocorrência de resultados normais e alterados no PEALL, nos GE2 e GC2

\begin{tabular}{|c|c|c|c|c|c|}
\hline \multirow{2}{*}{ PEALL } & \multicolumn{2}{|c|}{ GE2 } & \multicolumn{2}{|c|}{ GC2 } & \multirow{2}{*}{ p-valor } \\
\hline & $\mathrm{N}$ & $\%$ & $\mathrm{~N}$ & $\%$ & \\
\hline Normal & 3 & 33,3 & 8 & 88,9 & \multirow{2}{*}{$0,050^{*}$} \\
\hline Alterado & 6 & 66,7 & 1 & 11,1 & \\
\hline
\end{tabular}

Ao compararmos GE2 e GC2, verificamos que existiu diferença estatisticamente significante entre os resultados normais e alterados, sendo que o GE2 apresentou maior ocorrência de alterações quando comparado com o GC2.

No que diz respeito ao valor diagnóstico do PEALL para a doença desmielinizante Neuromielite Óptica (NMO), obtivemos os seguintes resultados:

Sensibilidade $=66,67 \%($ IC 95\% 29,93 - 92,51\%)

Especificidade $=88,89 \%($ IC 95\% 51,75 - 99,72\%)

Acurácia $=77,78 \%($ IC 95\% 52,36 - 93,59\%) 
Tabela 24: Distribuição dos tipos de alterações encontrados no PEALL, nos GE2 e GC2

\begin{tabular}{lcccccc}
\hline \multirow{2}{*}{ Tipo de Alteração } & \multicolumn{2}{c}{ Atraso de latência } & \multicolumn{2}{c}{ Ausência de resposta } & \multicolumn{2}{c}{ Ambas } \\
\cline { 2 - 7 } & $\mathrm{N}$ & $\%$ & $\mathrm{~N}$ & $\%$ & $\mathrm{~N}$ & $\%$ \\
\hline GE2 & 6 & 100 & 0 & 0 & 0 & 0 \\
\hline GC2 & 1 & 100 & 0 & 0 & 0 & 0
\end{tabular}

$\mathrm{Na}$ Tabela 24 verificamos que o tipo de alteração que apresentou maior ocorrência foi o atraso de latência, tanto para o GE2 (100\%) como para o GC2 (100\%).

Por fim, realizamos a comparação dos resultados normais e alterados dos PEALL entre GE1 e GE2.

Tabela 25: Distribuição da ocorrência de resultados normais e alterados no PEALL, nos GE1 e GE2

\begin{tabular}{|c|c|c|c|c|c|}
\hline \multirow[b]{2}{*}{ PEALL } & \multicolumn{2}{|c|}{ GE1 } & \multicolumn{2}{|c|}{ GE2 } & \multirow{2}{*}{ p-valo } \\
\hline & $\mathrm{N}$ & $\%$ & $\mathrm{~N}$ & $\%$ & \\
\hline Normal & 7 & 63,6 & 3 & 33,3 & \multirow{2}{*}{0,370} \\
\hline Alterado & 4 & 36,4 & 6 & 66,7 & \\
\hline
\end{tabular}

Ao compararmos GE1 e GE2, apesar de não ter existido diferença estatisticamente significante entre os resultados normais e alterados, o GE2 apresentou maior ocorrência de alterações quando comparado com o GE1.

Tabela 26: Distribuição dos tipos de alterações encontrados no PEALL, nos GE1 e GE2

\begin{tabular}{ccccccc}
\hline \multirow{2}{*}{ Tipo de Alteração } & \multicolumn{2}{c}{ Atraso de Latência } & \multicolumn{2}{c}{ Ausência de resposta } & \multicolumn{2}{c}{ Ambas } \\
\cline { 2 - 7 } & $\mathrm{N}$ & $\%$ & $\mathrm{~N}$ & $\%$ & $\mathrm{~N}$ & $\%$ \\
\hline GE1 & 4 & 100 & 0 & 0 & 0 & 0 \\
\hline GE2 & 6 & 100 & 0 & 0 & 0 & 0 \\
\hline
\end{tabular}


$\mathrm{Na}$ Tabela 26 verificamos que o tipo de alteração que apresentou maior ocorrência foi o atraso de latência tanto para o GE1 (100\%) como para o GE2 (100\%).

\section{PARTE III - Caracterização dos resultados da associação PEATE e PEALL nos grupos estudo (GE1 e GE2) e comparação (GC1 e GC2).}

Considerando os dois potenciais conjuntamente (PEATE e PEALL), comparamos os resultados normais e alterados obtidos na associação destes potenciais por indivíduo, ou seja, o indivíduo foi considerado alterado quando pelo menos um potencial apresentasse alteração. O Teste Exato de Fisher foi utilizado para as próximas análises. Foram estabelecidos, também, os valores diagnósticos de sensibilidade, especificidade e acurácia para cada doença desmielinizante estudada.

Tabela 27: Distribuição da ocorrência de resultados normais e alterados na associação PEATE e PEALL, nos GE1 e GC1

\begin{tabular}{|c|c|c|c|c|c|}
\hline \multirow[b]{2}{*}{ PEATE + PEALL } & \multicolumn{2}{|c|}{ GE1 } & \multicolumn{2}{|c|}{ GC1 } & \multirow[b]{2}{*}{ p-valor } \\
\hline & $\mathrm{N}$ & $\%$ & $\mathrm{~N}$ & $\%$ & \\
\hline Normal & 3 & 27,3 & 10 & 90,9 & ค คno* \\
\hline Alterado & 8 & 72,7 & 1 & 9,1 &, 000 \\
\hline
\end{tabular}

Ao compararmos GE1 e GC1, verificamos diferença estatisticamente significante entre os resultados normais e alterados para a associação PEATE e PEALL, sendo que o GE1 apresentou maior ocorrência de alterações quando comparado com o GC1.

No que diz respeito ao valor diagnóstico da associação PEATE e PEALL para a doença desmielinizante Esclerose Múltipla (EM), obtivemos os seguintes resultados:

Sensibilidade $=72,73 \%($ IC 95\% 39,03 - 93,98\%)

Especificidade $=90,91 \%$ (IC 95\% 58,72 - 99,77\%)

Acurácia $=81,82 \%($ IC 95\% 59,72 - 94,81\%) 
Tabela 28: Distribuição da ocorrência de resultados normais e alterados na associação PEATE e PEALL, nos GE2 e GC2

\begin{tabular}{|c|c|c|c|c|c|}
\hline \multirow[b]{2}{*}{ PEATE + PEALL } & \multicolumn{2}{|c|}{ GE2 } & \multicolumn{2}{|c|}{ GC2 } & \multirow[b]{2}{*}{ p-valor } \\
\hline & $\mathrm{N}$ & $\%$ & $\mathrm{~N}$ & $\%$ & \\
\hline Normal & 2 & 22,2 & 8 & 88,9 & \\
\hline Alterado & 7 & 77,8 & 1 & 11,1 & $0,015^{*}$ \\
\hline
\end{tabular}

${ }^{*} \mathrm{p}$-valor considerado estatisticamente significante

Ao compararmos GE2 e GC2, observamos diferença estatisticamente significante entre os resultados normais e alterados para a associação PEATE e PEALL, sendo que o GE2 apresentou maior ocorrência de alterações quando comparado com o GC2.

Em relação ao valor diagnóstico da associação PEATE e PEALL para a doença desmielinizante Neuromielite Óptica (NMO), obtivemos os seguintes resultados:

Sensibilidade $=77,78 \%($ IC 95\% 39,99 - 97,19\%)

Especificidade $=88,89 \%$ (IC 95\% 51,75 - 99,72\%)

Acurácia $=83,33 \%($ IC 95\% 58,58 - 96,42\%)

Tabela 29: Distribuição da ocorrência de resultados normais e alterados na associação PEATE e PEALL, nos GE1 e GE2

\begin{tabular}{|c|c|c|c|c|c|}
\hline \multirow[b]{2}{*}{ PEATE + PEALL } & \multicolumn{2}{|c|}{ GE1 } & \multicolumn{2}{|c|}{ GE2 } & \multirow[b]{2}{*}{ p-valor } \\
\hline & $\mathrm{N}$ & $\%$ & $\mathrm{~N}$ & $\%$ & \\
\hline Normal & 3 & 27,3 & 2 & 22,2 & \\
\hline Alterado & 8 & 72,7 & 7 & 77,8 & $>0.999$ \\
\hline
\end{tabular}

Ao compararmos GE1 e GE2, apesar de não ter existido diferença estatisticamente significante entre os resultados normais e alterados, o GE2 apresentou maior ocorrência de alterações quando comparado com o GE1 para a associação PEATE e PEALL. 


\section{DISCUSSÃO}

O diagnóstico de EM em crianças e adolescentes está se tornando cada vez mais comum (Chitnis et al., 2011). No entanto, informações sobre o tema não tem sido desenvolvidas na mesma velocidade, pois faltam estudos caracterizando o perfil dos casos de EM na infância e na adolescência (Waldman, 2011).

O diagnóstico diferencial da EM numa idade precoce é diferente daquele para indivíduos mais velhos (Polman et al., 2010).

Estudo realizado por Fragoso et al. (2012), na cidade de Santos (São Paulo), verificou que apenas $7,1 \%$ dos 182 pacientes com EM do Centro de Referência de EM para a região litorânea, receberam o diagnóstico até os 16 anos de idade.

Estudo realizado por Ferreira et al. (2008), descreveu as características epidemiológicas e clínicas de 31 casos de EM de início precoce, diagnosticados no Centro Estadual de Referência para Atenção a Pacientes Portadores de Doenças Desmielinizantes do Hospital da Restauração de Recife (Pernambuco). Dos 31 pacientes analisados, os sintomas precoces atribuídos à EM foram identificados em 9,7\% dos pacientes na primeira infância (entre zero e cinco anos de idade); em 29\% dos pacientes na infância (entre seis e 10 anos de idade); e em 61,3\% na adolescência (de 11 a 17 anos de idade).

A idade média de acometimento é ao redor da quarta década de vida (mais tardia do que o acometimento na Esclerose Múltipla, mais freqüente em torno da terceira década), porém a NMO também pode acometer crianças e idosos (Adams \& Victor, 2009; Wingerchuk \& Weinshenker, 2008).

Embora haja poucos estudos na população infantil, estudo realizado por Neri et al. (2010), relatou o caso de uma paciente brasileira, com 10 anos de idade, a qual apresentou início precoce de múltiplos surtos característicos de NMO.

Neste capítulo realizaremos a análise crítica dos resultados desta pesquisa, confrontando-os com a literatura específica consultada. 
Conforme ressaltado anteriormente, existe uma escassez na literatura nacional e internacional sobre o tema "doença desmielinizante em crianças e adolescentes", além do fato de serem raros os casos destas doenças na população de menor faixa etária, quando comparado com a população adulta. Sendo assim, por vezes nossos resultados foram comparados com os obtidos em outros trabalhos que utilizaram a população adulta como casuística.

Para facilitar a discussão dos resultados obtidos, manteremos a mesma divisão do capítulo de resultados, a saber:

PARTE I - Discussão sobre a caracterização dos resultados do PEATE nos grupos estudo (GE1 e GE2) e comparação (GC1 e GC2).

PARTE II - Discussão sobre a caracterização dos resultados do PEALL nos grupos estudo (GE1 e GE2) e comparação (GC1 e GC2).

PARTE III - Discussão sobre a caracterização dos resultados da associação PEATE e PEALL nos grupos estudo (GE1 e GE2) e comparação (GC1 e GC2).

PARTE I - Discussão sobre a caracterização dos resultados do PEATE nos grupos estudo (GE1 e GE2) e comparação (GC1 e GC2).

Nesta parte serão apresentadas as discussões das análises dos dados qualitativos e quantitativos dos resultados obtidos no PEATE para os quatro grupos (GE1, GE2, GC1 e GC2), comparando com os dados encontrados na literatura consultada.

Analisando as tabelas 1, 2, 3 e 4, observamos que não houve diferença estatisticamente significante para nenhuma das latências absolutas das ondas I, III, e V, e interpicos I-III, III-V, e I-V, entre as orelhas direita e esquerda, respectivamente nos GE1, GC1, GE2 e GC2 (na comparação intragrupo). Portanto as análises foram realizadas agrupando as orelhas direita e esquerda.

Em nosso estudo chegamos à conclusão que não houve diferença na condução do impulso nervoso, até o tronco encefálico, entre as orelhas direita e esquerda, tanto para os grupos de indivíduos com desenvolvimento típico como para os grupos com doença desmielinizante. Porém, encontramos na 
literatura um estudo realizado por Ohnari et al. (2016), no qual realizaram a comparação entre as orelhas e verificaram que os pacientes com EM apresentaram achados anormais em 9 (20,5\%) orelhas, enquanto nenhum dos pacientes com NMO apresentou anormalidades no PEATE.

Ao compararmos as latências e interpicos dos indivíduos do GE1 com as dos indivíduos do GC1 (Tabela 5), observamos diferença estatisticamente significante para os interpicos III-V e I-V, onde o GE1 sempre apresentou maior latência. Estes resultados indicaram que indivíduos com EM apresentam um atraso na condução do impulso nervoso nas regiões do tronco encefálico alto (entre o núcleo coclear e lemnisco lateral), sugerindo uma disfunção em tronco encefálico nestes indivíduos (conforme classificação de Matas, 2003).

Este dado corrobora o estudo realizado por Nuwer (1997), no qual foi descrito que as anormalidades encontradas em pacientes com EM podem incluir desde o prolongamento das latências das ondas e dos intervalos interpicos, até desaparecimento da onda V.

Verificamos, na Tabela 6, diferença estatisticamente significante entre os indivíduos do GE2 e do GC2 para o interpico I-V, com resultado maior para - GE2. Existem poucos estudos na literatura sobre alterações auditivas em pacientes com NMO. Estudo realizado em 2014 (Takanashi et al.) analisou o caso de uma paciente de 40 anos, com diagnóstico de NMO, que apresentava queixas visuais e auditivas. Foi realizada uma bateria de exames audiológicos, antes e após tratamento medicamentoso. Dentre os achados antes do tratamento, verificou-se emissões otoacústicas normais bilateralmente, evidenciando integridade coclear; pesquisa de reflexos acústicos ipsi e contralaterais ausentes (sugerindo alteração retrococlear) e diminuição da amplitude das ondas no PEATE, com pior resultado em orelha direita. Após o tratamento medicamentoso apresentou melhora significativa na função visual, bem como verificou-se ligeira melhora dos limiares auditivos e na morfologia da onda $V$ do PEATE na orelha direita.

Observamos, na Tabela 7, diferença estatisticamente significante entre os indivíduos do GE1 e do GE2 para o interpico III-V, com valores maiores nos indivíduos do GE1. Este dado corrobora o estudo de Ohnari et al. (2016), que 
verificou que os indivíduos com EM tem maior probabilidade de apresentar alterações no PEATE quando comparados aos indivíduos com NMO.

Para a análise dos dados qualitativos, foram comparados os resultados normais e alterados obtidos no PEATE por indivíduo, ou seja, o indivíduo foi considerado alterado quando pelo menos uma orelha apresentasse alteração.

Ao compararmos os indivíduos do GE1 com os do GC1 e os indivíduos do GE2 com os do GC2 (Tabelas 8 e 10), verificamos que existiu diferença estatisticamente significante entre os resultados normais e alterados apenas na comparação entre GE1 e GC1, porém os indivíduos dos grupos estudo GE1 e do GE2 apresentaram maior ocorrência de alterações no PEATE.

Este dado enfatiza a importância da pesquisa do PEATE em indivíduos com doenças desmielinizantes para a avaliação do envolvimento do SNAC (Chiappa, 1997; Lima et al., 2009).

Em relação ao valor diagnóstico do PEATE para a EM, obtivemos a sensibilidade de $63,64 \%$, especificidade de $100 \%$ e acurácia de $81,82 \%$. Estes valores indicam, respectivamente, a probabilidade de que o resultado do teste seja alterado quando a EM estiver presente (taxa de verdadeiro positivo); a probabilidade de que o resultado do teste seja normal quando a EM não estiver presente (taxa de verdadeiro negativo); e a probabilidade geral de que um paciente seja classificado corretamente (Altman et al., 2000). Este dado indica que, neste estudo, o PEATE apresentou valor diagnóstico moderado para a EM, podendo ser grande aliado no diagnóstico diferencial da doença.

Ao compararmos GE1 e GE2 (Tabela 12), apesar de não ter existido diferença estatisticamente significante entre os resultados normais e alterados, os indivíduos com EM apresentaram maior ocorrência de alterações quando comparado aos indivíduos com NMO, semelhante ao verificado por Ohnari et al. (2016).

Ainda analisando a Tabela 12, verificamos que dos 11 indivíduos com EM, 63,6\% apresentaram alteração no PEATE. Portanto, o presente estudo demonstrou maior índice de alterações quando comparado ao estudo de Lima et al. (2009), no qual verificou-se alterações de tronco encefálico em $36 \%$ dos 25 indivíduos com EM. No entanto, em estudo realizado por Jerger 
(1986), foram encontradas alterações no PEATE em 52\% dos indivíduos com EM, em uma ou ambas as orelhas.

No que diz respeito ao valor diagnóstico do PEATE para a NMO, obtivemos a sensibilidade de 33,34\%, especificidade de 100\% e uma acurácia de $66,67 \%$. Este dado indica que, neste estudo, a realização do PEATE na NMO apresenta um valor diagnóstico mais baixo quando comparado aos valores verificados para a EM.

Nas tabelas 9, 11 e 13 verificamos que os grupos GC1 e GC2 não apresentaram nenhum tipo de alteração, e que o GE1 apresentou maior ocorrência de alteração do tipo tronco encefálico alto $(57,1 \%)$ e o GE2 apresentou maior ocorrência de alteração do tipo tronco encefálico baixo (100\%). Não encontramos nenhum estudo na literatura onde fosse comparado o tipo de alteração do PEATE mais frequente entre EM e NMO. Porém, estudo realizado em 2003 (Santos et al.) encontrou alteração do PEATE em 58,62\% dos 29 indivíduos com EM que compuseram sua casuística. Outro estudo, realizado por Robinson e Rudge (1975), encontrou alteração do PEATE em $73 \%$ dos 30 indivíduos com diagnóstico de EM. Para enfatizar ainda mais a importância de verificar a contribuição deste exame na avaliação do acometimento do tronco encefálico, em 1977, Rudge e Robinson encontraram alteração no PEATE de $51 \%$ dos seus indivíduos com EM.

Os dados do presente estudo corroboram o estudo realizado por Matas et al. (2010), no qual verificou-se que os indivíduos com EM apresentaram anormalidades no PEATE sugerindo a possibilidade de mudanças estruturais e / ou funcionais na transmissão do estímulo acústico ao longo da via auditiva em tronco encefálico.

Verificamos grande dificuldade para encontrar estudos do potencial evocado auditivo em indivíduos com NMO. No entanto, encontramos um estudo realizado por Ohnari et al. (2016), que realizou a investigação dos potenciais evocados auditivos em indivíduos com diagnóstico de NMO e verificou que nenhum deles apresentou anormalidades auditivas em tronco encefálico. Em nosso estudo encontramos alteração de tronco encefálico nos indivíduos com NMO, porém em menor número quando comparado ao número de alterações encontradas nos indivíduos com EM. 
Diante dos achados, verifica-se a grande necessidade de maior investimento em pesquisas a respeito da avaliação eletrofisiológica da via auditiva em tronco encefálico por meio do PEATE nos indivíduos com NMO, visto que a maioria dos estudos ainda encontra-se com atenção dirigida aos indivíduos com EM.

\section{PARTE II - Discussão sobre a caracterização dos resultados do PEALL nos grupos estudo (GE1 e GE2) e comparação (GC1 e GC2).}

Nesta parte serão apresentadas as discussões das análises dos dados qualitativos e quantitativos dos resultados obtidos no PEALL para os quatro grupos (GE1, GE2, GC1 e GC2), comparando com os dados encontrados na literatura consultada.

Inicialmente foram realizadas as análises dos dados quantitativos, na qual a primeira comparação realizada foi entre as orelhas direita e esquerda, para as latências de P1, N1, P2, N2 e P300, e para as amplitudes P1-N1, P2N2 e P3, em cada grupo.

Nas Tabelas 14, 15, 16 e 17 verificamos que não foram evidenciadas diferenças estatisticamente significantes nas latências de P1, N1, P2, N2 e P300 e amplitudes P1-N1, P2-N2 e P300 entre as orelhas direita e esquerda para os indivíduos dos grupos GE1, GC1, GE2, GC2, exceto para o componente N2 nos indivíduos do GE1. Entretanto foi visualizada uma tendência à diferença estatisticamente significante entre as orelhas direita e esquerda para o componente N2, no grupo GE1, na qual a OD apresentou tempo de latência maior do que a OE.

Sendo assim, consideramos para as próximas análises, as latências e amplitudes de ambas as orelhas (agrupando as orelhas direita e esquerda) para cada grupo.

$\mathrm{Na}$ Tabela 18 verificamos que não ocorreu diferença estatisticamente significante entre GE1 e GC1, para a latência de P1, N1, P2, N2 e P300. Porém os indivíduos com EM apresentaram maior latência do que os indivíduos com desenvolvimento típico para os componentes $\mathrm{P} 1$ e N1. Observou-se diferença estatisticamente significante para a amplitude P2-N2, onde os indivíduos com 
EM apresentaram menor valor de amplitude em comparação aos indivíduos com desenvolvimento típico.

Verificamos, na Tabela 19, diferença estatisticamente significante entre GE2 e GC2 para as latências de P1, N1 e N2, sendo que em todas as análises nas quais observamos significância, a latência dos indivíduos com NMO foi sempre maior do que as latências dos indivíduos com desenvolvimento típico.

Observamos, ainda, diferença estatisticamente significante entre GE1 e GE2 para a latência de N2 (Tabela 20), sendo que os indivíduos com NMO apresentaram maior valor do que os indivíduos com EM. Houve, também, diferença estatisticamente significante entre GE1 e GE2 para as amplitudes P2$\mathrm{N} 2$, sendo que a do grupo com EM foi menor, e para a amplitude P300, onde o grupo com NMO apresentou menor valor.

A seguir, analisamos os resultados dos dados qualitativos do PEALL para os quatro grupos estudados e entre os grupos. Foram comparados os resultados normais e alterados obtidos no PEALL por indivíduo, ou seja, o indivíduo foi considerado alterado quando pelo menos um componente (P1, N1, P2, N2 ou P3) de uma orelha apresentasse alteração.

Ao compararmos GE1 e GC1, apesar de não ter existido diferença estatisticamente significante entre os resultados normais e alterados, o GE1 apresentou maior ocorrência de alterações quando comparado com o GC1 (Tabela 21), sendo todas estas do tipo atraso de latência (Tabela 22). Portanto, os indivíduos com EM apresentaram maior ocorrência de alterações do que os indivíduos com desenvolvimento típico.

Em relação ao valor diagnóstico do PEALL para a EM, obtivemos a sensibilidade de $36,36 \%$, especificidade de $90,91 \%$ e acurácia de $63,64 \%$. Este dado indica que para a EM, neste estudo, o PEALL apresentou menor valor diagnóstico quando comparado ao PEATE.

Estudo realizado por Matas et al. (2010) verificou que, além das alterações na transmissão do estímulo acústico ao longo da via auditiva em tronco encefálico, indivíduos com EM também podem apresentar anormalidades no Potencial Cognitivo (P300) sugerindo comprometimento de regiões corticais do sistema auditivo e déficits no processamento cognitivo, de atenção, memória e discriminação auditiva. 
Existem evidências de que as alterações cognitivas podem acometer pacientes com EM. Estudos neuropsicológicos (Rao et al., 1991; Fischer, 2001) indicaram disfunções cognitivas em 54 a $65 \%$ destes pacientes, sendo que os mesmos podem apresentar alterações na memória, atenção, fluência verbal, execução de tarefas e percepção visual.

Ao compararmos GE2 e GC2, verificamos que existiu diferença estatisticamente significante entre os resultados normais e alterados, sendo que o GE2 apresentou maior ocorrência de alterações quando comparado com o GC2 (Tabela 23).

No que diz respeito ao valor diagnóstico do PEALL para a NMO, obtivemos a sensibilidade de $66,67 \%$, especificidade de $88,89 \%$ e acurácia de $77,78 \%$. Portanto, podemos observar que o valor diagnóstico do PEALL é maior na NMO quando comparado a EM.

$\mathrm{Na}$ Tabela 24 verificamos que o tipo de alteração que apresentou maior ocorrência foi o atraso, tanto para o GE2 (100\%) como para o GC2 (100\%).

A partir destes achados, podemos verificar que os indivíduos com diagnóstico de doença desmielinizante (EM e NMO) deste estudo, apresentaram maior ocorrência de alterações quando comparados aos indivíduos que apresentaram desenvolvimento típico e sem queixas de alterações neurológicas. Portanto, tais achados enfatizam a importância da investigação do comprometimento das vias auditivas no SNC (Matas et al., 2010) nestas populações.

Em nossa casuística, nenhum dos indivíduos com EM apresentava queixa auditiva. Porém Musiek et al. (1989) encontraram que $18 \%$ de seus sujeitos com diagnóstico de EM apresentaram perda auditiva significativa, embora mais de $40 \%$ dos avaliados com audição periférica normal, apresentassem queixa auditiva. Verificaram, também, que $80 \%$ de indivíduos avaliados apresentou uma anormalidade em pelo menos um teste quando foram administrados testes que avaliam a via auditiva central e periférica.

Estudo realizado por Gil et al. (1993) utilizou o potencial auditivo P300 em um grupo de pacientes com EM submetidos a uma bateria de testes psicométricos, visando confrontar os dados do P300 com o comprometimento 
cognitivo e o curso da doença. O mesmo estudo verificou que as latências dos componentes P300 e N200 tornaram-se mais longas conforme a deficiência cognitiva foi se acentuando (evidenciado por meio dos testes psicométricos). Este dado enfatiza a necessidade da avaliação por meio dos PEALL ao longo do curso da doença, verificando se haverá então piora dos resultados conforme a piora dos surtos.

Schochat et al. (2006) verificaram em estudo de caso de um paciente com EM, que o mesmo apresentou anormalidade no PEATE (ausência da onda III e aumento de 2 ms na latência da onda $V$ na orelha direita), porém com normalidade em nível mais central (Potencial Evocado Auditivo de Média Latência - PEAML e PEALL).

Por sua vez, o estudo realizado por Celebisoy et al. (1996) realizou o PEATE e o PEAML em 30 pacientes com EM e encontraram anormalidades no PEATE em 18 dos pacientes e anormalidades no PEAML em 22 pacientes.

Estudo enfatizou que a realização do P300 é um diferencial clínico em pacientes com EM, e que este potencial tem se mostrado extremamente eficaz na detecção de disfunções cognitivas (Magnano et al., 2006).

O Multiple Sclerosis Health Center (2007) enfatizou que, para o diagnóstico de EM, é muito importante também a realização dos PEATE e PEALL, devido a comprovação do acometimento da via auditiva do nervo ao tronco encefálico nestes casos, podendo levar a uma perda auditiva ou alteração nas latências das ondas do PEATE. O PEALL deve ser realizado por se tratar de um exame específico de mensuração das habilidades cognitivas, sendo comum encontrar pacientes com EM com queixas de déficit de atenção, memória e processamento auditivo.

Estudo realizado no Japão (Kurokawa et al, 2003) ressaltou a importância dos exames eletrofisiológicos da audição no diagnóstico e acompanhamento dos indivíduos com EM. Verificaram $34,3 \%$ de anormalidades no PEATE de 73 indivíduos de sua casuística e enfatizaram a importância da inclusão do P300 na bateria de exames necessários para o diagnóstico e acompanhamento da evolução da EM.

Por fim, realizamos a comparação dos resultados normais e alterados dos PEALL entre GE1 e GE2. 
Ao compararmos GE1 e GE2 (Tabela 25), apesar de não ter existido diferença estatisticamente significante entre os resultados normais e alterados, o GE2 apresentou maior ocorrência de alterações quando comparado com o GE1 e o tipo de alteração que apresentou maior ocorrência foi o atraso, tanto para o GE1 (100\%) como para o GE2 (100\%) (Tabela 26).

Analisando a Tabela 25, podemos verificar que no presente estudo houve alteração do PEALL em $66,7 \%$ dos indivíduos com NMO e alteração em apenas $36,4 \%$ dos indivíduos com EM, achado este que corrobora o estudo realizado por Japaridze et al. (2002), no qual verificou-se que apenas $30 \%$ dos seus indivíduos com EM apresentaram anormalidades nos PEALL, mas por outro lado $65 \%$ apresentaram anormalidade no PEATE.

Conforme já mencionado anteriormente, verificou-se escassez de estudos na literatura nacional e internacional sobre potenciais evocados auditivos em NMO. Nota-se grande atenção à EM neste aspecto, enfatizando a necessidade também de mais pesquisas envolvendo a NMO.

No presente estudo, comparando o GE1 e o GE2, verificou-se que houve maior ocorrência de alterações do PEATE nos indivíduos com EM e maior ocorrência de alterações do PEALL nos indivíduos com NMO. Estes achados sugerem que indivíduos com EM apresentam maior probabilidade de alterações funcionais e estruturais da via auditiva ao longo do tronco encefálico; e que os indivíduos com NMO apresentam maior probabilidade a alterações funcionais e estruturais da via auditiva a nível mais central, em regiões corticais do sistema auditivo.

As lesões cerebrais na NMO podem ser identificadas na ressonância magnética como extensas e confluentes, seja nas regiões subcorticais, seja nas regiões profundas da substância branca. Lesões periependimárias no assoalho do IV ventrículo (tronco encefálico e cerebelo) são bastante características. O acometimento difuso do corpo caloso com acentuado edema, lesões periependimárias diencefálicas (no hipotálamo e no tálamo) com impregnação pelo gadolínio e as lesões do trato corticoespinhais, uni ou bilateralmente, bem como o envolvimento da cápsula interna e dos pedúnculos cerebrais, são bastante sugestivos de NMO. 
Apesar dos sítios geradores dos PEALL ainda não terem sido completamente estabelecidos, sabe-se que o componente $\mathrm{N} 1$ parece ser originado na região do córtex auditivo primário e córtex auditivo de associação, o P2 parece apresentar-se na região do lobo temporal e do sistema límbico, o N2 no córtex auditivo supratemporal e o P300 tem sua possível geração na região do hipocampo, córtex auditivo, córtex auditivo centro-parietal e córtex auditivo frontal (McPherson, 1996).

Portanto, de acordo com o exposto acima, indivíduos com NMO apresentam maior incidência de alterações centrais quando comparados aos indivíduos com EM. Tal aspecto explicaria a maior ocorrência de alterações nos PEALL em indivíduos com NMO, devido ao fato dos sítios geradores deste potencial evocado auditivo estarem localizados também em vias auditivas mais centrais.

PARTE III - Discussão sobre a caracterização dos resultados da associação PEATE e PEALL nos grupos estudo (GE1 e GE2) e comparação (GC1 e GC2).

Comparamos os resultados (normais e alterados) obtidos na associação dos dois potenciais (PEATE e PEALL) por indivíduo, ou seja, o indivíduo foi considerado alterado quando pelo menos um potencial apresentasse alteração. Estabelecemos, também, os valores diagnósticos de sensibilidade, especificidade e acurácia para cada doença desmielinizante estudada (EM e NMO.

Comparando o GE1 e o GC1 na Tabela 27, verificamos diferença estatisticamente significante entre os resultados normais e alterados para a associação PEATE e PEALL, sendo que o GE1 apresentou maior ocorrência de alterações quando comparado com o GC1. No que diz respeito ao valor diagnóstico da associação PEATE e PEALL para a EM, obtivemos a sensibilidade de $72,73 \%$, especificidade de $90,91 \%$ e acurácia $81,82 \%$ (ou seja, $90,91 \%$ de probabilidade que desse normal quando a EM não estivesse presente). 
Na Tabela 28, ao compararmos o GE2 e o GC2, observamos diferença estatisticamente significante entre os resultados normais e alterados para a associação PEATE e PEALL, sendo que o GE2 apresentou maior ocorrência de alterações quando comparado com o GC2. Em relação ao valor diagnóstico da associação PEATE e PEALL para a NMO, obtivemos sensibilidade de $77,78 \%$, especificidade de $88,89 \%$ e acurácia de $83,33 \%$ (ou seja, $88,89 \%$ de probabilidade que desse normal quando a NMO não estivesse presente).

Por fim, ao compararmos o GE1 e o GE2 (Tabela 29), apesar de não ter existido diferença estatisticamente significante entre os resultados normais e alterados, o GE2 apresentou maior ocorrência de alterações quando comparado com o GE1 para a associação PEATE e PEALL. Este dado sugere, portanto, que quando associamos os dois exames, ocorreu maior probabilidade de alterações no grupo de indivíduos com NMO.

Comparando os valores diagnósticos dos dois exames eletrofisiológicos da audição, verificamos que o PEATE apresentou maior acurácia para a EM e o PEALL maior acurácia para a NMO. Porém a associação dos dois testes (PEATE e PEALL) apresentou grande acurácia para as duas patologias estudadas. 


\section{Conclusões}




\section{CONCLUSÕES}

Frente aos resultados obtidos no presente estudo pôde-se concluir que:

1. Indivíduos com doença desmielinizante (EM e NMO) apresentam maior ocorrência de alterações na avaliação eletrofisiológica da audição por meio do PEATE e do PEALL, quando comparados aos indivíduos com desenvolvimento típico e sem queixas neurológicas (GC1 e GC2);

2. Indivíduos com EM apresentam maior ocorrência de alterações no PEATE quando comparados aos indivíduos com NMO, sendo predominante o comprometimento em tronco encefálico alto na EM e o comprometimento em tronco encefálico baixo na NMO;

3. Indivíduos com NMO apresentam maior ocorrência de alterações no PEALL quando comparados aos indivíduos com EM, sendo predominante a alteração do tipo atraso de latência tanto na NMO como na EM;

4. Indivíduos com EM apresentaram valores de sensibilidade, especificidade e acurácia para o PEATE de $63,64 \%, 100 \%$ e $81,82 \%$, e de $36 \%, 90,91 \%$ e $63,64 \%$ respectivamente para o PEALL; indivíduos com NMO apresentaram valores de sensibilidade, especificidade e acurácia para o PEATE de $33,34,100 \%$ e $66,67 \%$, e de $66,67 \%, 88,89 \%$ e $77,78 \%$ respectivamente para o PEALL. Sendo assim, o exame eletrofisiológico da audição com maior acurácia para indivíduos com EM foi o PEATE e para indivíduos com NMO foi o PEALL. 
Anexos 
8. ANEXOS

ANEXO A

HOSPITAL DAS CLÍNICAS DA
FACULDADE DE MEDICINA DA Platoforma
USP - HCFMUSP

PARECER CONSUBSTANCIADO DO CEP

\section{DADOS DO PROJETO DE PESQUISA}

Título da Pesquisa: POTENCIAIS EVOCAdos AUdITIVOS EM DOENÇAS DESMIELINIZANTES NA INFÂNCIA

Pesquisador: CARLA GENTILE MATAS

Área Temática:

Versão: 1

CAAE: 60477316.4 .0000 .0068

Instituição Proponente: HOSPITAL DAS CLINICAS DA FACULDADE DE MEDICINA DA U S P

Patrocinador Principal: Financiamento Próprio

DADOS DO PARECER

Número do Parecer: 1.784.316

\section{Apresentação do Projeto:}

Trata-se de um estudo clínico, de corte transversal e prospectivo, em crianças e adolescentes com doenças desmielinizantes, na faixa etária de 7 a 20 anos incompletos, atendidas no Ambulatório de Neuropsiquiatria do Instituto da Criança do Hospital das Clínicas da Faculdade de Medicina da Universidade de São Paulo. Participarão desta pesquisa 34 crianças e adolescentes, sendo 17 no grupo estudo e 17 no grupo controle. Todos os indivíduos serão submetidos inicialmente a uma avaliação audiológica básica por meio de audiometria tonal liminar e medidas de imitância acústica, e a uma avaliação eletrofisiológica da audição por meio dos potenciais evocados auditivos (potencial evocado auditivo de tronco encefálico - PEATE e potenciais evocados auditivos de longa latência - PEALL).

Os critérios de inclusão são:

- ter entre 7 e 18 anos;

- apresentar diagnóstico de esclerose múltipla para inclusão no GE1;

- apresentar diagnóstico de neuromielite óptica para inclusão no GE2;

- ausência de obstrução do meato acústico externo (MAE) em ambas as orelhas;

- ausência de alteração de orelha média evidenciada pela imitânciometria;

- possuir avaliação audiológica completa (audiometria tonal liminar, logoaudiometria e medidas de

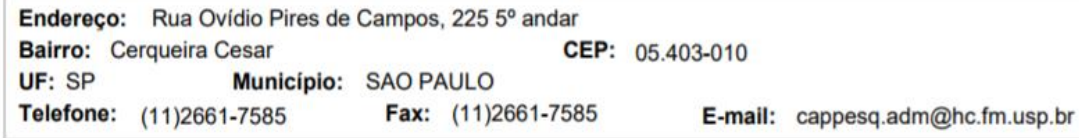




\section{$\mathrm{r}^{\prime}$ \\ HOSPITAL DAS CLÍNICAS DA \\ FACULDADE DE MEDICINA DA USP - HCFMUSP}

Continuaçäo do Parecer: 1.784.316

imitância acústica) dentro da normalidade.

Os resultados obtidos nas avaliações eletrofisiológicas da audição serão analisados por um profissional da área de estatística por meio das seguintes comparações:

1. Comparação dos resultados dos potenciais evocados auditivos de curta e longa latência obtidos nos indivíduos com esclerose múltipla (GE1) com aqueles obtidos no GC1.

2. Comparação dos resultados dos potenciais evocados auditivos de curta e longa latência obtidos nos indivíduos com neuromielite óptica (GE2) com aqueles obtidos no GC2.

\section{Objetivo da Pesquisa:}

Caracterizar os potenciais evocados auditivos de curta e longa latência em crianças com doenças desmielinizantes, acompanhadas no ambulatório de Neuroimunologia da Divisão de Neuropediatria do Instituto da Criança do Hospital das Clínicas da FMUSP.

Avaliação dos Riscos e Benefícios:

Riscos:

Os riscos ou desconfortos nos procedimentos que serão aplicados são mínimos.

Benefícios:

- identificação precoce de alteração auditiva em crianças e adolescentes com doenças desmielinizantes. Isto possibilita uma intervenção precoce.

\section{Comentários e Considerações sobre a Pesquisa:}

Estudo transversal e prospectivo para avaliar a audição de crianças e adolescentes com doenças desmielinizantes. Será de muita utilidade no acompanhamento do participante e também pode fornecer informações valiosas na escolha do melhor teste laboratorial para detectar a deficiência auditiva nesta população de crianças e adolescentes. Os métodos estão corretos.

\section{Considerações sobre os Termos de apresentação obrigatória:}

O pesquisador postou na Plataforma Brasil:

1. Folha de rosto devidamente preenchida e assinada;

2. Protocolo completo da pesquisa, com o detalhamento de todos os procedimentos que serão realizados;

3. Anuência do responsável pelos participantes no Setor de Neuropediatria do Instituto da Criança;

4. Cronograma;

5. Termos de assentimento muito bem elaborados com explicações simples e ilustrações para os

Endereço: Rua Ovídio Pires de Campos, $2255^{\circ}$ andar

Bairro: Cerqueira Cesar

CEP: $05.403-010$

UF: SP Município: SAO PAULO

Telefone: (11)2661-7585 Fax: (11)2661-7585 E-mail: cappesq.adm@hc.fm.usp.br 


\section{HOSPITAL DAS CLÍNICAS DA FACULDADE DE MEDICINA DA USP - HCFMUSP}

Continuação do Parecer: 1.784 .316

participantes do grupo estudo e do grupo controle;

6. Termo de consentimento livre e esclarecido para pais/responsáveis e para participantes com mais de 18 anos.

\section{Recomendações:}

Não há.

\section{Conclusões ou Pendências e Lista de Inadequações:}

Estudo transversal e prospectivo para avaliar a audição de crianças e adolescentes com doenças desmielinizantes. Será de muita utilidade no acompanhamento do participante e também pode fornecer informações valiosas na escolha do melhor teste laboratorial para detectar a deficiência auditiva nesta população de crianças e adolescentes. Os métodos estão corretos. Serão 34 participantes: 17 no grupo estudo e 17 no grupo controle. O estudo atende as normas de ética em pesquisa vigentes no país e não há impedimentos para a sua aprovação.

\section{Considerações Finais a critério do CEP:}

Em conformidade com a Resolução CNS n 466/12 - cabe ao pesquisador: a) desenvolver o projeto conforme delineado; b) elaborar e apresentar relatórios parciais e final; c)apresentar dados solicitados pelo CEP, a qualquer momento; d) manter em arquivo sob sua guarda, por 5 anos da pesquisa, contendo fichas individuais e todos os demais documentos recomendados pelo CEP; e) encaminhar os resultados para publicação, com os devidos créditos aos pesquisadores associados e ao pessoal técnico participante do projeto; f) justificar perante ao CEP interrupção do projeto ou a não publicação dos resultados.

Este parecer foi elaborado baseado nos documentos abaixo relacionados:

\begin{tabular}{|l|l|c|l|c|}
\hline \multicolumn{1}{|c|}{ Tipo Documento } & \multicolumn{1}{|c|}{ Arquivo } & Postagem & Autor & Situação \\
\hline Informações Básicas & PB_INFORMAÇŌES_BASICAS_DO_P & $27 / 09 / 2016$ & & Aceito \\
do Projeto & ROJETO 780027.pdf & $13: 56: 09$ & & \\
\hline Outros & cadastro_protocolo_de_pesquisa.pdf & $27 / 09 / 2016$ & CARLA GENTILE & Aceito \\
& & $13: 55: 04$ & MATAS & \\
\hline Folha de Rosto & folha_de_rosto.pdf & $27 / 09 / 2016$ & CARLA GENTILE & Aceito \\
& & $13: 51: 54$ & MATAS & \\
\hline TCLE / Termos de & TCLE_responsavel_GE.pdf & $14: 27: 23$ & MATAS & Aceito \\
Assentimento / & & & & \\
Justificativa de & & & & \\
Ausência & & & & \\
\hline
\end{tabular}

Endereço: Rua Ovídio Pires de Campos, $2255^{\circ}$ andar

Bairro: Cerqueira Cesar CEP: $05.403-010$

UF: SP Município: SAOPAULO

Telefone: (11)2661-7585 Fax: (11)2661-7585 E-mail: cappesq.adm@hc.fm.usp.br 
HOSPITAL DAS CLÍNICAS DA

FACULDADE DE MEDICINA DA USP - HCFMUSP

Continuação do Parecer: 1.784.316

\begin{tabular}{|c|c|c|c|c|}
\hline $\begin{array}{l}\text { TCLE / Termos de } \\
\text { Assentimento / } \\
\text { Justificativa de } \\
\text { Ausência }\end{array}$ & TCLE_responsavel_GC.pdf & $\begin{array}{c}06 / 09 / 2016 \\
14: 27: 16\end{array}$ & $\begin{array}{l}\text { CARLA GENTILE } \\
\text { MATAS }\end{array}$ & Aceito \\
\hline $\begin{array}{l}\text { TCLE / Termos de } \\
\text { Assentimento / } \\
\text { Justificativa de } \\
\text { Ausência }\end{array}$ & TCLE_18_anos_GE.pdf & $\begin{array}{c}06 / 09 / 2016 \\
14: 27: 08\end{array}$ & $\begin{array}{l}\text { CARLA GENTILE } \\
\text { MATAS }\end{array}$ & Aceito \\
\hline $\begin{array}{l}\text { TCLE / Termos de } \\
\text { Assentimento / } \\
\text { Justificativa de } \\
\text { Ausência }\end{array}$ & TCLE_18_anos_GC.pdf & $\begin{array}{c}06 / 09 / 2016 \\
14: 27: 00\end{array}$ & $\begin{array}{l}\text { CARLA GENTILE } \\
\text { MATAS }\end{array}$ & Aceito \\
\hline $\begin{array}{l}\text { TCLE / Termos de } \\
\text { Assentimento / } \\
\text { Justificativa de } \\
\text { Ausência }\end{array}$ & TCLE_7_17_anos_GE.pdf & $\begin{array}{c}06 / 09 / 2016 \\
14: 26: 51\end{array}$ & $\begin{array}{l}\text { CARLA GENTILE } \\
\text { MATAS }\end{array}$ & Aceito \\
\hline $\begin{array}{l}\text { TCLE / Termos de } \\
\text { Assentimento / } \\
\text { Justificativa de } \\
\text { Ausência }\end{array}$ & TCLE_7_17_anos_GC.pdf & $\begin{array}{c}06 / 09 / 2016 \\
14: 26: 41\end{array}$ & $\begin{array}{l}\text { CARLA GENTILE } \\
\text { MATAS }\end{array}$ & Aceito \\
\hline $\begin{array}{l}\text { Projeto Detalhado / } \\
\text { Brochura } \\
\text { Investigador }\end{array}$ & $\begin{array}{l}\text { Projeto_de_mestrado_DAYANE_FINAL. } \\
\text { pdf }\end{array}$ & $\begin{array}{c}24 / 08 / 2016 \\
15: 18: 36\end{array}$ & $\begin{array}{l}\text { CARLA GENTILE } \\
\text { MATAS }\end{array}$ & Aceito \\
\hline Outros & carta_anuencia.jpg & $\begin{array}{c}24 / 08 / 2016 \\
15: 17: 12\end{array}$ & $\begin{array}{l}\text { CARLA GENTILE } \\
\text { MATAS }\end{array}$ & Aceito \\
\hline Cronograma & CRONOGRAMA.pdf & $\begin{array}{c}24 / 08 / 2016 \\
15: 14: 31\end{array}$ & $\begin{array}{l}\text { CARLA GENTILE } \\
\text { MATAS }\end{array}$ & Aceito \\
\hline
\end{tabular}

Situação do Parecer:

Aprovado

Necessita Apreciação da CONEP:

Não

SAO PAULO, 20 de Outubro de 2016

Assinado por:

ALFREDO JOSE MANSUR

(Coordenador)

Endereço: Rua Ovídio Pires de Campos, $2255^{\circ}$ andar

Bairro: Cerqueira Cesar

CEP: $\quad 05.403-010$

UF: SP Município: SAOPAULO

Telefone: (11)2661-7585 Fax: (11)2661-7585 E-mail: cappesq.adm@hc.fm.usp.br 


\section{ANEXO B}

HOSPITAL DAS CLÍNICAS DA FACULDADE DE MEDICINA DA UNIVERSIDADE DE SÃO PAULO

TERMO DE CONSENTIMENTO LIVRE E ESCLARECIDO Indivíduos - 18 anos de idade

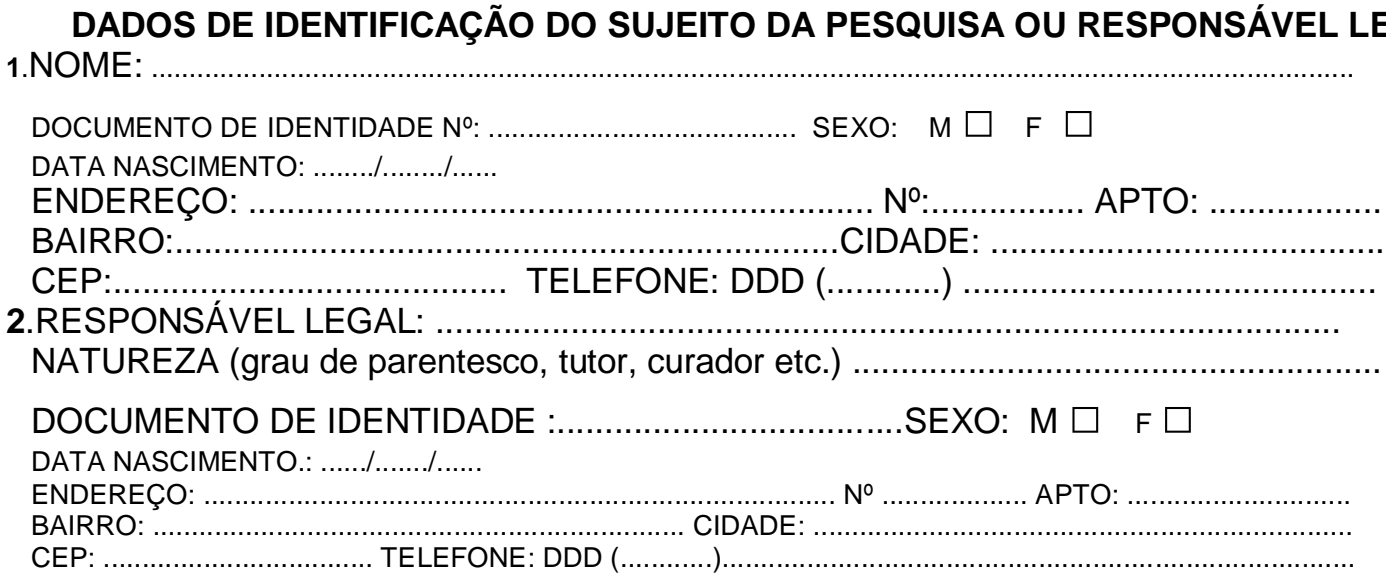

\section{DADOS SOBRE A PESQUISA}

1. TÍTULO DA PESQUISA: Potenciais Evocados Auditivos em Doenças Desmielinizantes na Infância

2. PESQUISADOR RESPONSÁVEL: Carla Gentile Matas CARGO/FUNCCÃO: DOCOnTE INSCRIÇÃO CONSELHO REGIONAL n: :04927-7

3. PESQUISADOR EXECUTANTE: Dayane Aparecida Nascimento de Andrade CARGO/FUNÇÃO: Fonoaudióloga INSCRIÇÃO CONSELHO REGIONAL no: 2 18715 UNIDADE DO HCFMUSP: Instituto da Criança

DEPARTAMENTO/INSTITUIÇÃO: Departamento de Fisioterapia, Fonoaudiologia e Terapia Ocupacional da Universidade de São Paulo. 


\section{FACULDADE DE MEDICINA DA UNIVERSIDADE DE SÃO PAULO}

As seguintes informações serão apresentadas para a sua participação voluntária. Esta pesquisa será realizada com o objetivo de investigar se doenças desmielinizantes ocasionam alteração no sistema auditivo central e para isso será necessário a realização de exames que avaliam a sua audição.

Você ficará com a pesquisadora por aproximadamente 2 horas realizando exames auditivos. Os exames serão realizados de modo não invasivo e não te deixarão em situação desconfortável.

Serão realizados os seguintes exames para avaliar a via auditiva:

- Meatoscopia: com um otoscópio irei verificar se não há obstrução do seu meato acústico externo.

- Medidas de Imitância Acústica: sentado em uma poltrona, você deve permanecer quieto e irá escutar alguns apitos por meio de um fone de ouvido.

- Audiometria Tonal e Vocal: você entrará em uma cabina e escutará alguns apitos por meio de fone de ouvido e terá que levantar a mão toda vez que escutar o apito. Posteriormente escutará algumas palavras, também por meio de um fone de ouvido, e terá que repetí-las da forma que entender.

- Potenciais Evocados Auditivos: serão fixados na pele, com esparadrapo, alguns eletrodos que irão captar as ondas cerebrais relacionadas à audição.

O benefício desse estudo é dar informações sobre a sua audição, verificando se ocorreu alguma alteração auditiva.

Os resultados obtidos serão analisados em conjunto com os de outros indivíduos e a sua identidade e dados pessoais serão preservados. Os dados analisados serão armazenados sem a sua identificação e serão utilizados apenas para análises das respostas obtidas.

Esta pesquisa irá nos ajudar a entender melhor como é a audição de indivíduos com doenças desmielinizantes, contribuindo para diagnóstico e intervenção precoces.

A sua participação neste estudo é de caráter voluntário, não oferece riscos à sua saúde ou à sua integridade física e psíquica e não haverá despesas para a sua participação no estudo. Você terá esclarecimento de eventuais dúvidas em qualquer momento da realização do estudo, e está garantido o direito de deixar de participar da pesquisa a qualquer momento.

Não há despesas pessoais em qualquer fase do estudo, incluindo exames e consultas. Também não há compensação financeira relacionada à sua participação, porém você tem direito a indenização por danos decorrentes da presente pesquisa.

Em qualquer etapa do estudo, você terá acesso aos profissionais responsáveis pela pesquisa para esclarecimento de dúvidas. O principal investigador é a Dra Carla Gentile Matas que pode ser encontrado no endereço pode ser encontrada na Rua Cipotânea, 51 - telefone: 3091- 8411, e-mail: cgmatas@usp.br. Se você tiver alguma consideração ou dúvida sobre a ética da pesquisa, entre em contato com o Comitê de Ética em Pesquisa (CEP) - Rua Ovídio Pires de Campos, 225 - 5o andar - tel: (11) 2661-7585, (11) 2661-1548, (11) 2661-1549; email: cappesq.adm@hc.fm.usp.br.

Fui suficientemente informado a respeito do estudo "Potenciais Evocados Auditivos em Doenças Desmielinizantes na Infância".

Eu discuti as informações acima com o Pesquisador Responsável, Carla Gentile Matas ou pessoa (s) por ele delegada (s), Dayane Aparecida Nascimento de Andrade, sobre a minha decisão em participar nesse estudo. Ficaram claros para mim os objetivos, os procedimentos, os potenciais desconfortos e riscos e as garantias. Concordo voluntariamente em participar deste estudo, assino este termo de consentimento e recebo uma via rubricada pelo pesquisador.

Assinatura do participante /representante legal

Assinatura do responsável pelo estudo
Data

Data 
ANEXO C

HOSPITAL DAS CLÍNICAS DA FACULDADE DE MEDICINA DA UNIVERSIDADE DE SÃO PAULO

TERMO DE ASSENTIMENTO

Crianças entre 7 e 17 anos de idade

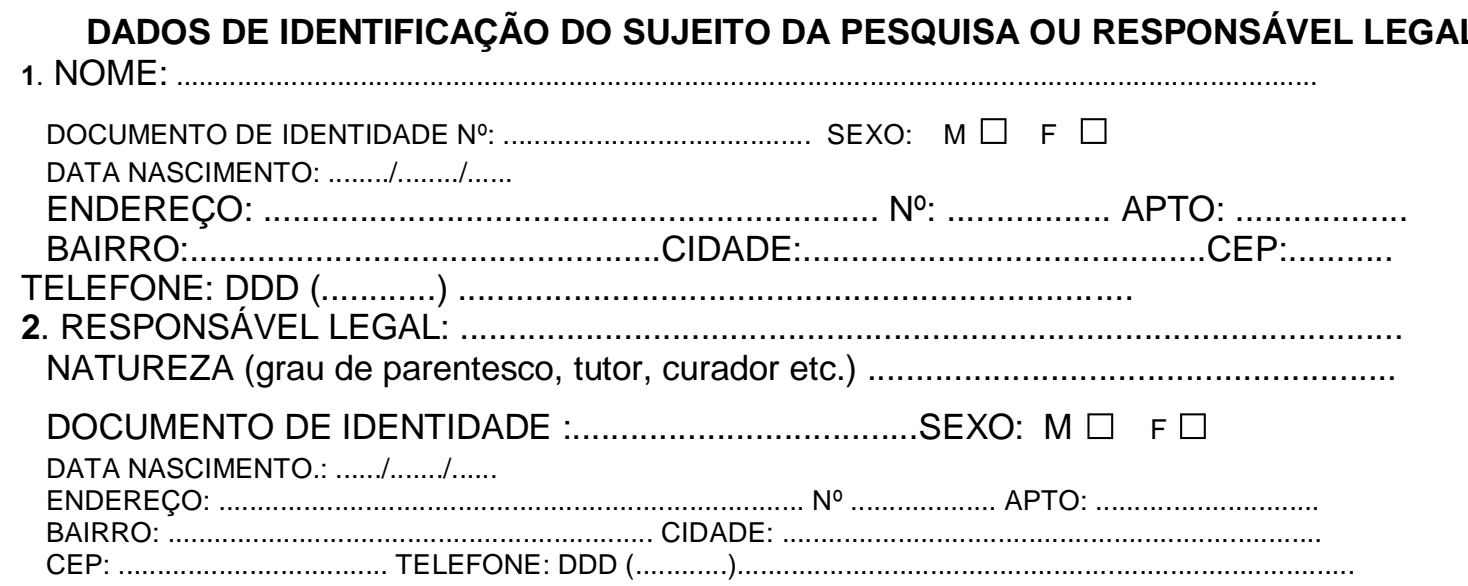

\section{DADOS SOBRE A PESQUISA}

1. TÍTULO DA PESQUISA: Potenciais Evocados Auditivos em Doenças Desmielinizantes na Infância

2. PESQUISADOR RESPONSÁVEL: Carla Gentile Matas CARGO/FUNÇÃO: Docente

INSCRIÇÃO CONSELHO REGIONAL nº: 04927-7

3. PESQUISADOR EXECUTANTE: Dayane Aparecida Nascimento de Andrade CARGO/FUNÇÃO: Fonoaudióloga INSCRIÇÃO CONSELHO REGIONAL n: : 218715

UNIDADE DO HCFMUSP: Instituto da Criança

DEPARTAMENTO/INSTITUIÇÃO: Departamento de Fisioterapia, Fonoaudiologia e Terapia Ocupacional da Universidade de São Paulo. 


\section{HOSPITAL DAS CLÍNICAS DA FACULDADE DE MEDICINA DA UNIVERSIDADE DE SÃO} PAULO

Essas informações estão sendo fornecidas para sua participação voluntária. O presente estudo pretende avaliar como está a sua audição e para isso serão realizados os seguintes testes:

- Meatoscopia: com uma luz irei ver se está tudo bem dentro da sua orelha.

- Medidas de Imitância Acústica: sentado em uma poltrona, você deve permanecer quieto e irá escutar alguns apitos por meio de um fone de ouvido.

- Audiometria Tonal e Vocal: você entrará em uma cabina e escutará alguns apitos por meio de fone de ouvido e terá que levantar a mão toda vez que escutar o apito. Posteriormente escutará algumas palavras, também por meio de um fone de ouvido, e terá que repetí-las da forma que entender.

- Potenciais Evocados Auditivos: serão fixados na pele, com esparadrapo, alguns fios que irão captar as respostas cerebrais relacionadas à audição.

Os testes realizados não oferecem nenhum risco ou desconforto.

O benefício desse estudo é dar informações sobre a sua audição, verificando se ocorreu alguma alteração auditiva.

A sua participação neste estudo é de caráter voluntário, não oferece riscos à sua saúde ou à sua integridade física e psíquica e não haverá despesas para a sua participação no estudo. Você terá esclarecimento de eventuais dúvidas em qualquer momento da realização do estudo, e está garantido o direito de deixar de participar da pesquisa a qualquer momento.

Não há despesas pessoais em qualquer fase do estudo, incluindo exames e consultas. Também não há compensação financeira relacionada à sua participação, porém você tem direito a indenização por danos decorrentes da presente pesquisa.

Em qualquer etapa do estudo, você terá acesso aos profissionais responsáveis pela pesquisa para esclarecimento de dúvidas. O principal investigador é a Dra Carla Gentile Matas que pode ser encontrado no endereço pode ser encontrada na Rua Cipotânea, 51 - telefone: 3091- 8411, e-mail: cgmatas@usp.br. Se você tiver alguma consideração ou dúvida sobre a ética da pesquisa, entre em contato com o Comitê de Ética em Pesquisa (CEP) - Rua Ovídio Pires de Campos, 225 - 5o andar - tel: (11) 2661-7585, (11) 2661-1548, (11) 2661-1549; email: cappesq.adm@hc.fm.usp.br.

Fui suficientemente informado a respeito do estudo "Potenciais Evocados Auditivos em Doenças Desmielinizantes na Infância".

Eu discuti as informações acima com o Pesquisador Responsável, Carla Gentile Matas ou pessoa (s) por ele delegada (s), Dayane Aparecida Nascimento de Andrade, sobre a minha 
decisão em participar nesse estudo. Ficaram claros para mim os objetivos, os procedimentos, os potenciais desconfortos e riscos e as garantias. Concordo voluntariamente em participar deste estudo, assino este termo de consentimento e recebo uma via rubricada pelo pesquisador.

Assinatura do participante /representante legal

Data

$1 /$

Assinatura do responsável pelo estudo

Data / / 


\section{ANEXO D}

\section{Instituto da Criança \\ Hospital das Clínicas - FMUSP}

\section{Ambulatório de Avaliação Eletrofisiológica da Audição}

ANAMNESE AUDIOLÓGICA INFANTIL

Data do exame:

Encaminhado por:

Motivo:

HDs:

Escolaridade:

Queixas:

Responsável:

\section{Dados da Gestação:}

Doenças/intercorrências:
( )drogas
( )álcool
( )cigarro
( ) medicamentos:

Dados do Parto/Nascimento:
( ) normal
IG:
$\lg C:$
( ) cesariana
Peso ao nascimento:
( ) fórceps
Tempo de internação:
Peso atual:
( ) incubadora

Apgar: ______

Desenvolvimento geral:

\begin{tabular}{|c|c|}
\hline \multicolumn{2}{|c|}{ MOTOR GERAL / LINGUAGEM } \\
\hline Habilidade & Idade \\
\hline Fixação de cabeça & \\
\hline Sentou & \\
\hline Andou & \\
\hline Primeiras palavras & \\
\hline
\end{tabular}

\begin{tabular}{|l|l|}
\hline \multicolumn{2}{|c|}{ AUDIÇÃo } \\
\hline Reage a sons? & ( ) sim ( ) não \\
\hline Procura a fonte sonora? & ( ) sim ( ) não \\
\hline Mantém a atenção? & ( ) sim ( ) não \\
\hline Compreende ordens? & ( ) sim ( ) não \\
\hline
\end{tabular}

\section{Saúde auditiva/Comportamento auditivo:}

$\begin{array}{lllll}\text { ( )dor de ouvido } & \text { ( )otites } & \text { ( )perda auditiva } & \text { ( )coceira } & \text { ( )pede para repetir o que foi } \\ \text { falado } & & & \\ \text { ( )supuração } & \text { ( )fala alto } & \text { ( )trocas na fala } & \text { ( )cirurgia } & \text { ( ) uso de AASI: }\end{array}$

Indicadores de risco para perda auditiva: $(\mathrm{JCH}, 2007$; Azevedo, 2009)
( )DA na família ( )RNPT <31sem ( )PN (<1000g)
( ) Asfixia perinatal [apgar até 6 no $10 \% \mathrm{~min}$ ]
( ) Síndromes
( )Meningite $\mathrm{V} / \mathrm{B}$
( )Encefalopatias, hidrocefalia, HIC, TCE
( )Distúrbios neurodegenerativos
( )Hiperbilirrubinemia com transfusão
( )Consanguinidade
( )Ototóxicos $>5$ dias
( )Crises convulsivas
( )Anomalias craniofacias
( )UTI/VM >5 dias

( )DBP, Hipertensão pulmonar, Hérnia diafragmática

( )Inf. Congênitas [rubéola, sífilis, CMV, herpes, toxoplasmose, HIV] 
Referências 


\section{REFERÊNCIAS}

Absoud M, Lim MJ, Appleton R, Jacob A, Kitley J, Leite MI, et al. Paediatric neuromyelitis optica: clinical, MRI of the brain and prognostic features. J. Neurol. Neurosurg, Psychiatry 2014;86:470-2.

Adams RD, Victor M. Multiple sclerosis and allied demyelinative diseases. In: Principles of Neurology. $4 \mathrm{a}$ ed. New York, McGraw-Hill international editions, 1989. p. $755-74$.

Adams RD, Victor M. Adams and Victor's Principles of Neurology. 9a ed, 2009.

Altman DG, Machin D, Bryant TN, Gardner MJ. Statistics with confidence, 2nd ed. (2000): BMJ Books.

Andrade EP, Sacai PY, Berezovsky A, Salomão SR. Alterações encontradas no potencial visual evocado por padrão reverso em pacientes com esclerose múltipla definida. Arq Bras Oftalmol. 2007;70:943-8.

Anias CR, Lima MAMT, Kós AOA. Avaliação da influência da idade no potencial evocado auditivo de tronco encefálico. Rev Bras Otorrinolaringol. 2004;70:84-9.

Asgari N, Lillevang ST, Skejoe HPB, Falah M, Stenager E, Kyvik KO. A population-based study of neuromyelitis optica in Caucasians. Neurology $2011 ; 76: 1589-95$.

Asselman P, Chadwick DW, Marsden CD. Visual evoked responses in the diagnosis and management of patients suspected of multiple sclerosis. Brain. 1975;98:261-82.

Associação Brasileira de Esclerose Múltipla (ABEM). Disponível em: http://abem.org.br/\#o-que-e-esclerose-multipla. Acesso em: 06 jul. 2017. 
Banwell B, Ghezzi A, Bar-Or A, Mikaeloff Y, Tardieu M. Multiple sclerosis in children: clinical diagnosis, therapeutic strategies, and future directions. Lancet Neurol. 2007;6:887-902.

Banwell B, Kennedy J, Sadovick D, Arnold DI, Magalhaes S, Wambera K, et al. Incidence of adquired demyelination of the CNS in Canadian children. Neurology 2009;72:232-9.

Beck RW. The optic neuritis treatment trial. Arch Ophthalmol. 1988;106:1051-3.

Bizzoco E, Lolli F, Repice AM, Hakiki B, Falcini M, Barilaro A, et al. Prevalence of neuromyelitis optica spectrum disorder and phenotype distribution. Journal of neurology 2009;256:1891-8.

Brilot F, Dale RC, Seiter RC, Grummel V, Kalluri SR, Aslam M, et al. Antibodies to native myelin oligodendrocyte glycoprotein in children with inflammatory demyelinating central nervous system disease. Ann. Neurol. 2009;66:842-8.

Brusa A, Jones SJ, Plant GT. Long-term remyelination after optic neuritis: A 2year visual evoked potential and psychophysical serial study. Brain. 2001;124:468-79.

Cardoso FAG. Atuação fisioterapêutica na esclerose múltipla forma recorrenteremitente. Revista Movimenta; 2010; vol 3.

Celebisoy N, Aydogdu I, Ekmekci O, Akurekli O. Middle latency auditory evoked potentials (MLAEPs) in MS. Acta Neurol Scand 1996; 93:318-21.

Chanson J-B, Paolini I, Collongues N, Alcaro MC, Blanc F, Barbetti F, et al. Evaluation of new immunological targets in neuromyelitis optica. Journal of peptide science: an official publication of the European Peptide Society 2013;19:25-32. 
Chiappa KH. Evoked potentials in clinical medicine. 3rd ed. Philadelphia: Lippincott-Raven; 1997;1-3.

Chitnis T, Krupp L, Yeh A, Rubin J, Kuntz N, Strober JB et al. Pediatric multiple sclerosis. Neurol Clin 2011;29:481-505

Cuypers MH, Dickson K, Pinckers AJ, Thijssen JM, Hommes OR. Discriminative power of visual evoked potential characteristics in multiple sclerosis. Doc Ophthalmol. 1995;90:247-57.

Dantas AM, Spielmann A, Lalanne M, Corbe C. Neuro-oftalmologia. Rio de Janeiro: Cultura Médica 1999;316.

Dantas AM, Zangalli AL, editores. Neuro-oftalmologia. Rio de Janeiro: Cultura Médica; 1999:1:65.

Datasus, ago, 2014. Disponível em: http://datasus.saude.gov.br/. Acesso em: 04 jul. 2017.

Duarte JL, Alvarenga KF, Costa OA. Potencial cognitivo P300 realizado em campo livre: aplicabilidade do teste. Rev Bras Otorrinolaringol. 2004;70:781-6.

Durrant JD, Ferraro JA. Potenciais auditivos evocados de curta latência: eletrococleografia e audiometria de tronco encefálico. In: Musiek FE, Rintelmann WF, org. Perspectivas atuais em avaliação auditiva. São Paulo: Manole; 2001. p.193-238.

Duwaer AL, Spekreijse H. Latency of luminance and contrast evoked potentials in multiple sclerosis patients. Electroencephalogr Clin Neurophysiol. 1978;45:244-58. 
Esteves MCBN, Dell'Aringa AHB, Arruda GV, Dell'Aringa AR, Nardi JC. Estudo das latências das ondas dos potenciais auditivos de tronco encefálico em indivíduos normo-ouvintes. Braz J Otorhinolaryngol. 2009;75:420-5.

Fazekas F, Offenbacher H, Fuchs S, Schmidt R, Niederkorn K, Horner S, et al. Criteria for an increased specificity of MRI interpretation in elderly subjects with suspected multiple sclerosis. Neurology, 1988;38:1822-5.

Ferreira MLB, Machado MIM, Dantas MJG, Moreira AJP, Souza AMMH. Analysis of clinical and epidemiological aspects according to National MS Society Consensus 2007. Arq Neuropsiquiatr 2008;66(3-B).

Ferreira MLB, Machado MIM, Vilela ML, Guedes MJ, Ataíde L, Jr. Santos S, et al. Epidemiologia de 118 casos de esclerose múltipla com follow-up de 15 anos no Centro de Referência do Hospital da Restauração de Pernambuco. Archives of Neuro-Psichiatry 2004;62:1027-32.

Fragoso YD, Brooks JBB, Leal TMS. Perfil descritivo de esclerose múltipla com início até os 16 anos nos pacientes de um centro de referência do estado de São Paulo. Rev Paul Pediatr 2012;30(4):617-20.

Fuhr P, Borggrefe-Chappuis A, Schindler C, Kappos L. Visual and motor evoked potentials in the course of multiple sclerosis. Brain. 2001;124:2162-8.

Galligo IGG, Orue OA. Unilateral neurosensory hearing loss as a manifestation of multiple sclerosis. Acta Otorrinolaringol Esp. 1999;50:147-9.

Gil R, Zai L, Neau JP, Jonveaux T, Agbo C, Rosolacci T, Burbaud P, Ingrand P. Event-related auditory evoked potentials and multiple sclerosis. Electroencephalography and clinical Neurophysiology, 1993;88:182-7. 
Goldacre MJ, Wotton CJ, Seagroatt V, Yeates D. Multiple sclerosis after infectious mononucleosis: Record linkage study. Journal of Epidemiology \& Community Health 2004;58:1032-5.

Halliday AM, McDonald WI, Mushin J. Delayed visual evoked response in optic neuritis. Lancet. 1972;1:982-5.

Hartung HP, Michels M, Reiners K, Seeldrayers P, Archelos JJ, Toyka KV. Soluble ICAM-1 serum levels in multiple sclerosis and viral encephalitis. Neurology, 1993;43:2331-5.

Herndon RM. Cognitive deficits and emotional dysfunction in mul- tiple sclerosis. Arch. Neurol., 1990,47:18.

Hinson SR, Roemer SF, Lucchinetti CF, Fryer JP, Kryzer TJ, Chamberlain JL, et al. Aquaporin-4-binding autoantibodies in patients with neuromyelitis optica impair glutamate transport by down-regulating EAAT2. The Journal of experimental medicine 2008;205:2473-81.

Hinson SR, Romero MF, Popescu BFG, Lucchinetti CF, Fryer JP, Wolburg H, et al. Molecular outcomes of neuromyelitis optica (NMO)-IgG binding to aquaporin4 in astrocytes. Proceedings of the National Academy of Sciences of the United States of America 2012;109:1245-50.

Hood L. Clinical applications of the auditory brain response. San Diego: Singular Publishing Group. 1998;67-91.

Jarius S, Wildemann B. The history of neuromyelitis optica. Journal of neuroinflammation 2013;10:8. 
Jacob A, McKeon A, Nakashima I, Sato DK, Elsone L, Fujihara K, et al. Current concept of neuromyelitis optica (NMO) and NMO spectrum disorders. Journal of neurology, neurosurgery, and psychiatry 2013;84:922-30.

Japaridze G, Shakarishvili R, Kevanishvili Z. Auditory brainstem, middlelatency, and slow cortical responses in multiple sclerosis. Acta Neurol Scand. 2002;106(1):47-53.

Jasper HA. The ten-twenty system of the International Federation. Electroencephalogr Clin Neurophysiol.1958;10: 371-75.

Jerger J. Clinical experience with impedance audiometry. Arch Otolaryngol. 1970;92:311-24.

Jerger J, Oliver TA, Chmiel RA, Rivera VM. Patterns of auditory abnormality in multiple sclerosis. Audiology. 1986;25:193-209.

Jewett DL, Romano MN, Williston JS. Human-auditory evoked potential: Possible brain stem components detected on the scalp. Science 1970;167:1517-8.

Johnson KP, Brooks BR, Cohen JA, Ford CC, Goldstein J, Lisak RP, et al. Extended use of glatiramer acetate (Copaxone) is well tolerated and maintain its clinical effect on multiple sclerosis relapse rate and degree of disability. Copolimer 1 Multiple Sclerosis Study Group. Neurology, 1998;50:701-8.

Junqueira CAO, Frizzo ACF. Potenciais evocados auditivos e curta, média e longa latência. In: Aquino AMCM, org. Processamento auditivo - Eletrofisiologia e Psicoacústica. São Paulo: Lovise; 2011;63-85.

Kraus N, McGee T. Potenciais evocados auditivos de longa latência. In: Katz, J. Tratado de Audiologia Clínica. São Paulo: Manole; 1999; 403-20. 
Kurokawa T, Kira J, Tobimatsu S. Electrophysiological diagnosis for multiple sclerosis. Nippon Rinsho. 2003 Aug; 61(8):1347-54.

Kurtzke JF, Beebe GW, Dagler B, Auth TL, Kurland LT, Defzger MD. Studies on the natural history of multiple sclerosis: clinical and laboratorial findings at first diagnoses. Acta Neurol Scand. 1972;48:19-46.

Kurtzke JF. Epidemiologic contributions to multiple sclerosis: an overview. Neurology, 1980;30:61-79.

Lennon VA, Kryzer TJ, Pittock SJ, Verkman AS, Hinson SR. IgG marker of optic-spinal multiple sclerosis binds to the aquaporin-4 water channel. The Journal of experimental medicine 2005;202:473-7.

Lennon VA, Wingerchuk DM, Kryzer TJ, Pittock SJ, Lucchinetti CF, Fujihara K, et al. A serum autoantibody marker of neuromyelitis optica: distinction from multiple sclerosis. Lancet 2004;364:2106-12.

Leocani L, Rovaris M, Boneschi FM, Medaglini S, Rossi P, Martinelli V, et al. Multimodel evoked potential to assess the evolution of multiple sclerosis: a longitudinal study. J. Neurol. Neurosurg. Psychiatry 77 (2006) 1030-5.

Lima TMA, Crato AN, Mancini PC, Simões LC, Gonçalves DU. Alterações dos potenciais evocados auditivos do tronco encefálico em pacientes com esclerose múltipla. Braz J Otorhinolaryngol. 2009;75:177-81.

Linares AE. Reflexo acústico. In: Bevilacqua MC et al. (Org.). Tratado de Audiologia. São Paulo: Santos; 2011. p.135-44.

Lublin FD, Reingold SC, Cohen JA, et al. Defining the clinical course of multiple sclerosis. The 2013 revisions. Neurology. 2014;15;83(3):278-86. 
Lublin FD, Reingold SC. Defining the clinical course of multiple sclerosis: results of an international survey. Neurology, 1996; 46:907-11.

Lucchinetti CF, Mandler RN, McGavern D, Bruck W, Gleich G, Ransohoff RM, et al. A role for humoral mechanisms in the pathogenesis of Devic's neuromyelitis optica. Brain : a journal of neurology 2002;125:1450-61.

Mader S, Gredler V, Schanda K, Rostasy K, Dujmovic I, Pfaller K, et al. Complement activating antibodies to myelin oligodendrocyte glycoprotein in neuromyelitis optica and related disorders. J. Neuroinflammation. 2011;8:184.

Magnano I, Aiello I, Piras MR. Cognitive impairment and neurophysiological correlates in MS. Jounal of the Neurological Sciences. 2006;245:117-22.

Marignier R, Nicolle A, Watrin C, Touret M, Cavagna S, Varrin-Doyer M, et al. Oligodendrocytes are damaged by neuromyelitis optica immunoglobulin $\mathrm{G}$ via astrocyte injury. Brain : a journal of neurology 2010;133:2578-91.

Matas CG, Matas SLA, Oliveira CRS, Gonçalves IC. Auditory evoked potentials and multiple sclerosis. Arq Neuropsiquiatr. 2010;68:528-34.

Matas CG. Medidas Eletrofisiológicas da Audição. Audiometria de Tronco Cerebral. In: Carvallo RMM. Fonoaudiologia Informação para Formação. Procedimentos em Audiologia. Rio de Janeiro: Guanabara Koogan; 2003. p.4357.

Matà S, Lolli F. Neuromyelitis optica: an update. Journal of the neurological sciences 2011;303:13-21.

Maudonnet O, Maudonnet E. Causas centrais da vertigem. In Campos CAH, Costa HOO, (EDS). Tratado de otorrinolaringologia. São Paulo: Roca; 2002. v.2 
McPherson D. Late Potentials of the auditory system. San Diego: Singular Publishing Group; 1996.

Menegotto IH. Logoaudiometria Básica. In: Bevilacqua MC et al. (Org.). Tratado de Audiologia. São Paulo: Santos; 2013. p. 81-100.

Medaer R. Does the history of multiple sclerosis go back as faz as the 14 th century? Acta Neurol Scand, 1979;60:189-92.

Miller NR, Newman NJ. The essentials: Wash and Hoyt's clinical neuroophthalmology. 5th ed. Baltimore: Williams \& Wilkins; 1998. p.198.

Musiek FE, Gollegly KM, Kibbe KS, Reeves AG. Electrophysiologic and behavioral auditory findings in multiple sclerosis. Am J Otol 1989;10:343-50.

Musiek FE, Lee WW. Potenciais auditivos de média e longa latência. In: Musiek FE, Lee WW. Perspectivas atuais em avaliação auditiva. São Paulo: Manole; 2001. p.239-67.

Nakashima I, Fujihara K, Okita N, Takase S, Itoyama Y. Clinical and MRI study of brain stem and cerebellar involvement in Japanese patients with multiple sclerosis. J Neurol Neurosurg Psychiatry 1999;67:153-7.

Neri VC, Mendonça TVD, Papais Alvarenga RM. Neuromielite Óptica (Doença de Devic): Relato de Caso e Revisão dos Critérios Diagnósticos. Revista Científica da FMC. Vol. 5, o 1, 2010.

Neto SP, Alvarenga RM, Vasconcelos CC, Alvarenga MP, Pinto LC, Pinto VL, et al.. Evaluation of pattern-reversal visual evoked potential in patients with neuromyelitis optica. Mult. Scler. 2013;19:173-8.

Northern JL, Downs MP. Hearing in Children. 3rd ed. Baltimore: Williams \& Wilkins; 1984. p.89. 
Nuwer MR. Evoked potencial in multiple sclerosis. In: Raine CS, McFarland HF, Tourtellotte WW. Multiple Sclerosis: clinical and pathogenetic basis. London: Chapman e Hall; 1997. p.43-55.

Ohnari K, Okada K, Takahashi T, Mafune K, Adachi H. Evoked potentials are useful for diagnosis of neuromyelitis óptica spectrum disorder. Journal of the Neurological Sciences 2016;364: 97-101.

Oliveira EML, Souza NA. Esclerose Múltipla. Rev. Neurociências 1998;6(3): 114-8.

O'Riordan JI, Gallagher HL, Thompson AJ, Howard RS, Kingsley DP, Thompson EJ, et al. Clinical, CSF, and MRI findings in Devic's neuromyelitis optica. Journal of neurology, neurosurgery, and psychiatry 1996;60:382-7.

Papais-Alvarenga RM, Alvarenga H. Esclerose múltipla: manifestações clínicas, aspectos epidemiológicos e critérios diagnósticos. Rev Bras Neurol. 1995;31:61-70.

Paty DW, Oger JJF, Kastrukoff LF, Hashimoto SA, Hooge JP, Eisen AA, et al. MRI in the diagnosis of MS: a prospective study with comparison of clinical evaluation, evoked potentials, oligoclonal banding and CT. Neurology, 1988;38: 180-185.

Peyser JM, Edwards KR, Poser CM, Filskov SB. Cognitive function in patients with multiple sclerosis. Arch. Neurol., 1980, 37: 577-9.

Pires CE, Silva CM, Lopes FC, et al. Brain MRI abnormalities in Brazilian patients with neuromyelitis optica. J Clin Neurosci. 2012;19:969-74. 
Polman $\mathrm{CH}$, Reingold SC, Banwell B, Clanet M, Cohen JA, Filippi M et al. Diagnostic criteria for multiple sclerosis: 2010 revisions to the McDonald criteria. Ann Neurol 2011;69:292-302.

Poser C. Multiple sclerosis: diagnosis and treatment. Med Principles Pract 93:116, 1992.

Poser C. The epidemiology of Multiple Sclerosis: a general overview. Ann Neurol, 1994;36:S180-93.

Poser S, Poser W. Multiple sclerosis and gestation. Neurology, 1983;33:1422-7. Probstel AK, Dornmair K, Bittner R, Sperl P, Jenne D, Magalhaes S, et al. Antibodies to MOG are transient in childhood acute disseminated encephalomyelitis. Neurology 2011;77:580-8.

Rao SM, Leo GJ, Bernardin L, Unverzagt F. Cognitive dysfunction in multiple sclerosis. Neurology 1991;34:694-702.

Ratelade J, Verkman AS. Neuromyelitis optica: aquaporin-4 based pathogenesis mechanisms and new therapies. The international journal of biochemistry \& cell biology 2012;44:1519-30.

Reinhardt K, Weiss S, Rosenbauer J, Gartner J, von Kries R. Multiple sclerosis in children and adolescentes: incidence and clinical Picture - new insights from the Nationwide German surveillance (2009 - 2011). Eur. J. Neurol. 2014;21:654-9.

Robinson K, Rudge P. Auditory evoked responses in multiple sclerosis. Lancet 1975;24:1164-6.

Rose NR, Bona C. Defining criteria for autoimmune diseases (Witebsky's postulates revisited). Immunology Today. 1993;14:426-30. 
Rosner B. Fundamentals of Biostatistics. 7th Edition. Brooks/Cole Cengage Learning; 2010.

Rudge P, Robinson K. Abnormaties of the auditory evoked potentials in patients with multiple sclerosis. Brain 1977;100:19-40.

Santos MAR, Peixoto MAL, Munhoz MSL, Almeida AV. Avaliação dos potenciais evocados auditivos do tronco encefálico na esclerose múltipla. Arq. NeuroPsiquiatr. vol.61 no.2B São Paulo Jun, 2003.

Santos TMM, Russo ICP. A prática da audiologia clínica. 3a ed. São Paulo: Cortez; 1991.

Schochat E, Matas CG, Sanches SGG, Carvalho RMM, Matas S. Central auditory evaluation in multiple sclerosis: case report. Arq Neuropsiquiatr 2006;64(3-B).

Sellner J, Schirmer L, Mühlau M. The radiologically isolated syndrome: take action when the unexpected is uncovered. J Neurol. 2010;257:1602-11.

Soares AJC, Sanches SGG, Neves-Lobo IF, Carvallo RMM, Matas CG, Cárnio MS. Potenciais evocados auditivos de longa latência e processamento auditivo central em crianças com alterações de leitura e escrita: dados preliminares. Arq. Int. Otorrinolaringol. / Intl. Arch. Otorhinolaryngol. 2011;15:486-91.

Shibasaki H, McDonald WI, Kuroiwa Y. Racial modification of clinical picture of multiple sclerosis: comparison between British and Japanese patients. J. Neurol SCI, 1981;49:253-71.

Schumacher GA, Beebe G, Kibler RF, Kurland LT, Kurtzke JF, McDowell F, et al. Problems of experimental trials of therapy in multiple sclerosis: report by the 
panel on evaluation of experimental trials of therapy in multiple sclerosis. Ann NY Acad Sci, 1965;122:552-68.

Takanashi T, Misu T, Oda K, Miyazaki H, Yahata I, Hidaka H, et al. Audiological evidence of therapeutic effect of steroid treatment in neuromyelitis optica with hearing loss. Case Reports/Journal of Clinical Neuroscience 2014;21:2249-51.

The IFNB Multiple Sclerosis Study Group \& University of British Columbia MS/MRI Analysis Group. Interferon beta- $1 \mathrm{~b}$ in the treatment of multiple sclerosis: final outcome of the randomized controlled trial. Neurology, 1995;45:1277-85.

Tumas V, Sakamoto AC. Anormalidades do potencial visual por padrão reverso em pacientes com esclerose múltipla definida. Arq Neuropsiquiatr. 1995;53:743-8.

Waldman AT, Gorman MP, Rensel MR, Austin TE, Hertz DP, Kuntz NL. Management of pediatric central nervous system demyelinating disorders: consensus of United States neurologists. J Child Neurol 2011;26:675-82.

Watanabe A, Matsushita $T$, Doi $H$, Matsuoka $T$, Shigeto $H$, Isobe $N$, et al. Multimodality-evoked potential study of anti-aquaporin-4 antibody-positive and negative multiple sclerosis patients. J. Neurol. Sci. 2009;281:34-40.

Wingerchuk DM, Hogancamp WF, O'Brien PC, Weinshenker BG. The clinical course of neuromyelitis optica (Devic's syndrome). Neurology 1999;53:110714.

Wingerchuk DM, Lennon VA, Lucchinetti CF, Pittock SJ, Weinshenker BG. The spectrum of neuromyelitis optica. Lancet neurology 2007;6:805-15. 
Wingerchuk DM, Lennon VA, Pittock SJ, Lucchinetti CF, Weinshenker BG. Revised diagnostic criteria for neuromyelitis optica. Neurology 2006;66:1485-9.

Wingerchuk DM, Weinshenker BG. Unusual presentations and variants of central nervous system idiopathic demyelinating diseases. In: RAINE, C.S.; MCFARLAND H.F.; HOHLFELD R. Multiple Sclerosis. A comprehensive text. Saunders: Elsevier; 2008. p. 24-42.

Yeh EA, Chitnis T, Krupp L, Ness J, Chabas D, Kuntz N, Waubant E. Pediatric multiple sclerosis. Nat Rev Neurol. 2009;5:621-31. 